Utah State University

DigitalCommons@USU

\title{
$5-2018$
}

\section{Accuracy of Residential Water Meters in Response to Short, Intermittent Flows}

John R. Chadwick

Utah State University

Follow this and additional works at: https://digitalcommons.usu.edu/etd

Part of the Civil and Environmental Engineering Commons

\section{Recommended Citation}

Chadwick, John R., "Accuracy of Residential Water Meters in Response to Short, Intermittent Flows" (2018). All Graduate Theses and Dissertations. 7034.

https://digitalcommons.usu.edu/etd/7034

This Thesis is brought to you for free and open access by the Graduate Studies at DigitalCommons@USU. It has been accepted for inclusion in All Graduate Theses and Dissertations by an authorized administrator of DigitalCommons@USU. For more information, please contact digitalcommons@usu.edu.

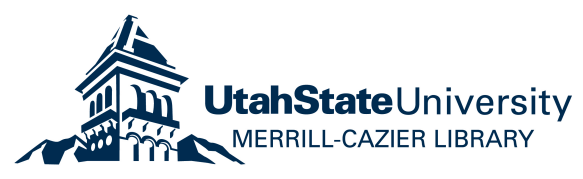


ACCURACY OF RESIDENTIAL WATER METERS IN RESPONSE TO SHORT, INTERMITTENT FLOWS

\author{
by \\ John R. Chadwick \\ A thesis submitted in partial fulfillment \\ of the requirements for the degree \\ of \\ MASTER OF SCIENCE \\ in \\ Civil and Environmental Engineering
}

Approved:

Steven L. Barfuss

Michael C. Johnson

Major Professor

Committee Member

Paul J. Barr

Mark R. McLellan, Ph.D.

Committee Member

Vice President for Research and

Dean of the School of Graduate Studies

UTAH STATE UNIVERSITY

Logan, Utah 
Copyright @ John R. Chadwick 2018

All Rights Reserved 


\author{
ABSTRACT \\ Accuracy of Residential Water Meters in Response to Short, \\ Intermittent Flows \\ by \\ John R. Chadwick, Master of Science \\ Utah State University, 2018
}

Major Professor: Steven L. Barfuss

Department: Civil and Environmental Engineering

Residential water meters increase in accuracy as standards and technology improve, bringing a fairer balance to utility and customer. The ability to make improvements to a meter is possible as its limits under different circumstances become known. One potential limitation of residential water meters previously unknown was researched for this thesis, offering insights to further meter improvement.

The purpose of this thesis was to measure the accuracy of residential water meters in response to burst flows. Burst flows are intermittent flows that can occur for a variety of reasons. Burst flows have short durations (a few seconds or less), and occur at flow rates typical of household appliances.

The data for this thesis was collected at the Utah Water Research Laboratory. A gravimetric test bench was used as a standard. Forty-two meters of seven different models were tested (six meters for each model). Positive displacement (oscillating piston and nutating disc) and electronic (electromagnetic and ultrasonic) meters were included. 
To allow repeated bursts to pass through the test setup over a reasonable time, a programmable solenoid valve was fixed at the end of the test setup. Multiple time combinations (the time the solenoid was open and closed, constituting a complete cycle) were used. Accuracies of water meters were found at three different flow rates: 4 gallons per minute, 2 gallons per minute, and 0.25 gallons per minute. A thermal expansion tank and cross-linked polyethylene tubing, which are typical residential components within a common small water system in the United States, were included in some tests.

The electromagnetic meters were generally unaffected by burst flows. Burst flows caused one of the ultrasonic meter models to have decreased accuracies, while the other model remained mostly unaffected. Nutating disc and oscillating piston meters were generally affected by burst flows only at the lowest flow rate. 
PUBLIC ABSTRACT

\author{
Accuracy of Residential Water Meters in Response to Short, \\ Intermittent Flows \\ John R. Chadwick
}

In this study, water meter accuracy in response to short, intermittent flows was tested. Burst flows have short durations (a few seconds or less), and occur at a variety of flow rates. For some types of meters, it is difficult to accurately measure short, intermittent flow rates. Depending on the meter type, an intermittent flow can result in either under-registering or over-registering of the actual throughput.

During the testing for this research, water was passed through meters for various time combinations, test setups, and flows. It should be understood that realistically, a household setting will not see burst flows occurring in a repeated manner. For the purposes of laboratory testing, however, time-on and condensed time-off combinations were used. The reduced time off allowed for a controlled test procedure and efficient data collection.

Ultrasonic, electromagnetic, nutating disc, and oscillating piston meters were tested. The meter types were found to perform differently under the varying test setups, time combinations, and flow rates. The electromagnetic meters were generally unaffected by burst flows. Burst flows caused one of the ultrasonic meter models to have decreased accuracies, while the other model remained mostly unaffected. Nutating disc and oscillating piston meters were generally affected by burst flows only at the lowest flow. 


\section{ACKNOWLEDGMENTS}

I give thanks to Steve Barfuss for providing me an opportunity to work with him at the Utah Water Research Laboratory. I appreciate his advice and insights in relation to my research. I thank Ryan Weller and Kade Beck for their help with my research and for their friendship. I also thank Mike Johnson and Paul Barr for serving on my committee.

Special thanks is given to my father, George Chadwick, for his mentoring throughout my college career. Also, I am grateful to my grandfather, Duane Chadwick, for directing me to a job at the UWRL. I appreciate Dan Dyer for providing guidance toward the field of civil engineering.

I am thankful to my Heavenly Father for the direction and guidance He has given me, and I thank my family for their support.

John R. Chadwick 
ABSTRACT iii

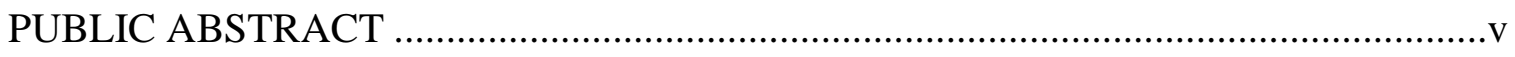

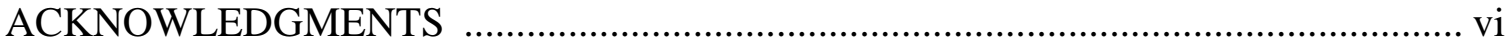

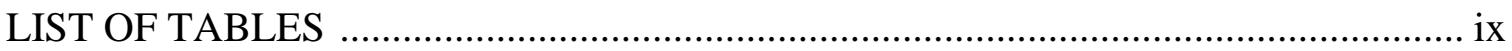

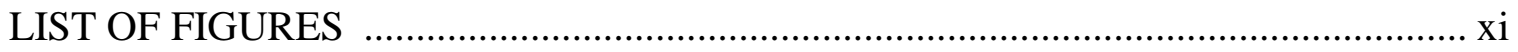

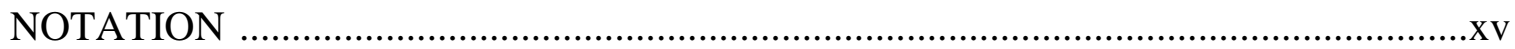

\section{CHAPTER}

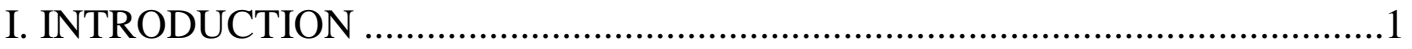

II. LITERATURE REVIEW ...........................................................................4

III. EXPERIMENTAL SETUP AND TEST PROCEDURE ............................. 6

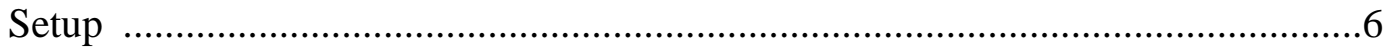

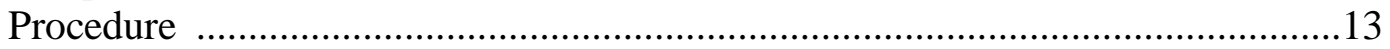

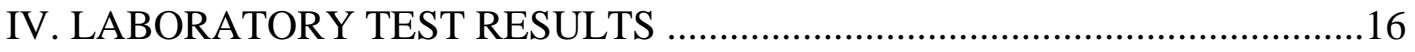

Accuracy by meter model for continuous flow tests ........................................16

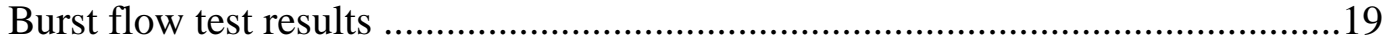

Accuracy by flow and meter model .................................................................20

Accuracy by test setup and meter model ..........................................................23

Accuracy by time combination and meter model ...........................................24

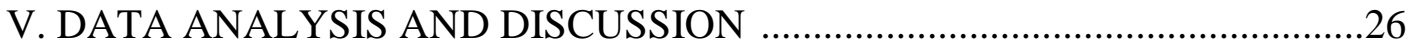

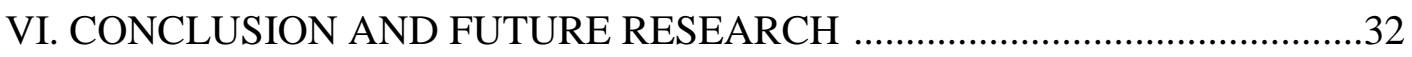

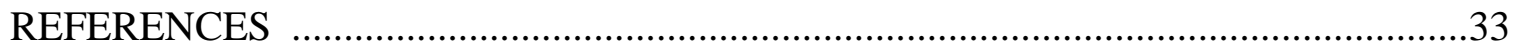

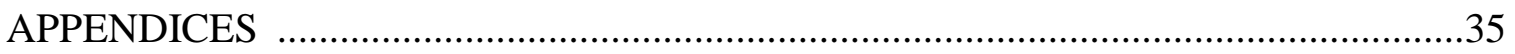

APPENDIX A: Comparison of Continuous and Burst Flows ...............................36

Accuracy of meters as a function of flow and test setup ..............................37

Accuracy of meters as a function of flow and burst time combination ..........43 
Accuracy of meters as a function of flow and meter type ...........................51

APPENDIX B: Individual Meter Results for Burst Flows ...................................57

APPENDIX C: Individual Meter Results for Continuous Flows...........................65 


\section{LIST OF TABLES}

$1 \quad$ Placement of meters in test setup based on type ..................................... 7

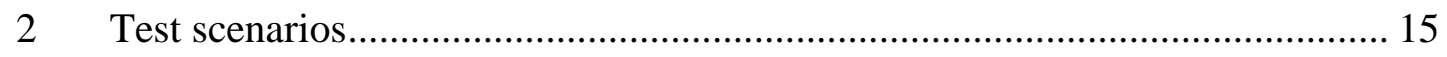

3 Accuracy by flow and meter model for continuous flow tests ....................... 19

4 Average length of burst flow tests and average number of cycles required

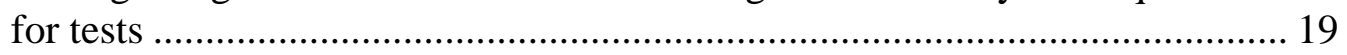

5 Accuracy by flow and meter model for burst flow tests............................. 20

$6 \quad$ Accuracy by test setup and meter model ................................................ 23

$7 \quad$ Accuracy by time combination and meter model ..................................... 24

8 Accuracies of ultrasonic Manufacturer 1 meters in the burst flow condition... 58

9 Accuracies of ultrasonic Manufacturer 2 meters in the burst flow condition... 59

10 Accuracies of electromagnetic Manufacturer 1 meters in the burst flow

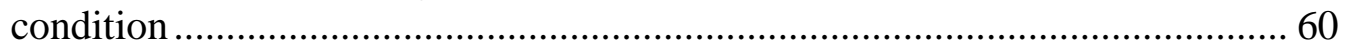

11 Accuracies of nutating disc Manufacturer 1 meters in the burst flow condition

12 Accuracies of nutating disc Manufacturer 2 meters in the burst flow condition

13 Accuracies of oscillating piston Manufacturer 1 meters in the burst flow condition

14 Accuracies of oscillating piston Manufacturer 2 meters in the burst flow condition

15 Accuracies of ultrasonic Manufacturer 1 meters in the continuous flow condition

16 Accuracies of ultrasonic Manufacturer 2 meters in the continuous flow condition

17 Accuracies of electromagnetic Manufacturer 1 meters in the continuous flow condition. 
18 Accuracies of nutating disc Manufacturer 1 meters in the continuous flow

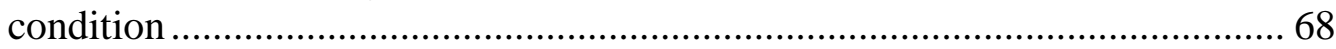

19 Accuracies of nutating disc Manufacturer 2 meters in the continuous flow

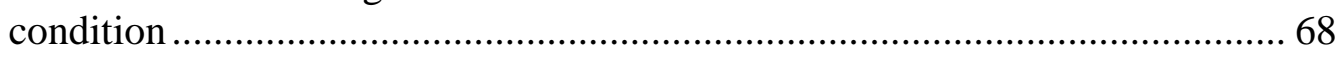

20 Accuracies of oscillating piston Manufacturer 1 meters in the continuous flow condition..

21 Accuracies of oscillating piston Manufacturer 2 meters in the continuous flow condition... 


\section{LIST OF FIGURES}

1 Pressure reducing valve placed upstream of test meters in laboratory setup ..... 6

2 Thermal expansion tank included in test setup downstream of meters ............. 8

3 PEX tubing included in test setup downstream of thermal expansion tank ..... 10

4 Example of flow change for solenoid valve over a short time ....................... 11

5 Average accuracy of ultrasonic meters for continuous flow tests (log scale

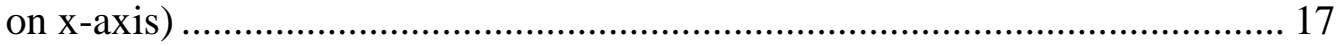

6 Average accuracy of electromagnetic meters for continuous flow tests (log scale on $\mathrm{x}$-axis).

7 Average accuracy of nutating disc meters for continuous flow tests (log scale on $\mathrm{x}$-axis).

8 Average accuracy of oscillating piston meters for continuous flow tests (log scale on $\mathrm{X}$-axis).

9 Comparison of continuous and burst accuracies of ultrasonic meters (log scale on $\mathrm{x}$-axis)

10 Comparison of continuous and burst accuracies of electromagnetic meters (log scale on $\mathrm{x}$-axis)

11 Comparison of continuous and burst accuracies of nutating disc meters (log scale on $\mathrm{x}$-axis)

12 Comparison of continuous and burst accuracies of oscillating piston meters

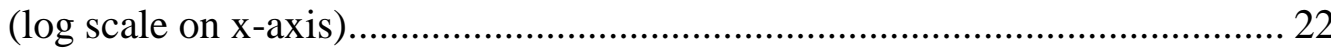

13 Burst flow results categorized by test setup ............................................. 24

14 Burst flow results categorized by burst time combination ............................. 25

15 Average accuracy of ultrasonic meters in continuous and burst (PEX tubing) conditions

16 Average accuracy of oscillating piston meters in continuous and burst (1/2 second on, 3 seconds off) conditions.

17 Average accuracy of ultrasonic meters in continuous and burst (1 second 
18 Average accuracy of ultrasonic meters in continuous and burst (thermal expansion tank) conditions

19 Average accuracy of ultrasonic meters in continuous and burst (1/2 second on, 3 seconds off) conditions.

20 Average accuracy of electromagnetic meters in continuous and burst (1/2 second on, 3 seconds off) conditions.

21 Average accuracy of nutating disc meters in continuous and burst (1/2 second on, 3 seconds off) conditions.

22 Average accuracy of oscillating piston meters in continuous and burst (1/2 second on, 3 seconds off) conditions.

23 Average accuracy of ultrasonic meters in continuous and burst (1 second on, 4 seconds off) conditions

24 Average accuracy of electromagnetic meters in continuous and burst (1 second on, 4 seconds off) conditions

25 Average accuracy of nutating disc meters in continuous and burst (1 second on, 4 seconds off) conditions.....

26 Average accuracy of oscillating piston meters in continuous and burst (1 second on, 4 seconds off) conditions.

27 Average accuracy of ultrasonic meters in continuous and burst (1 second on, 3 seconds off) conditions

28 Average accuracy of electromagnetic meters in continuous and burst (1 second on, 3 seconds off) conditions

29 Average accuracy of nutating disc meters in continuous and burst ( 1 second on, 3 seconds off) conditions

30 Average accuracy of oscillating piston meters in continuous and burst (1 second on, 3 seconds off) conditions.....

31 Average accuracy of ultrasonic meters in continuous and burst (neither thermal expansion tank nor PEX tubing) conditions

32 Average accuracy of electromagnetic meters in continuous and burst (neither thermal expansion tank nor PEX tubing) conditions

33 Average accuracy of nutating disc meters in continuous and burst (neither 
thermal expansion tank nor PEX tubing) xiii

thermal expansion tank nor PEX tubing) conditions

34 Average accuracy of oscillating piston meters in continuous and burst (neither thermal expansion tank nor PEX tubing) conditions

35 Average accuracy of ultrasonic meters in continuous and burst (thermal expansion tank) conditions

36 Average accuracy of electromagnetic meters in continuous and burst (thermal expansion tank) conditions

37 Average accuracy of nutating disc meters in continuous and burst (thermal expansion tank) conditions

38 Average accuracy of oscillating piston meters in continuous and burst (thermal expansion tank) conditions

39 Average accuracy of ultrasonic meters in continuous and burst (PEX tubing) conditions

40 Average accuracy of electromagnetic meters in continuous and burst (PEX tubing) conditions

41 Average accuracy of nutating disc meters in continuous and burst (PEX tubing) conditions

42 Average accuracy of oscillating piston meters in continuous and burst (PEX tubing) conditions 48

43 Average accuracy of ultrasonic meters in continuous and burst (both thermal expansion tank and PEX tubing) conditions

44 Average accuracy of electromagnetic meters in continuous and burst (both thermal expansion tank and PEX tubing) conditions

45 Average accuracy of nutating disc meters in continuous and burst (both thermal expansion tank and PEX tubing) conditions

46 Average accuracy of oscillating piston meters in continuous and burst (both thermal expansion tank and PEX tubing) conditions

47 Average accuracy of meters in continuous and burst (neither thermal expansion tank nor PEX tubing with time combination of 1/2 second on, 3 seconds off) conditions

48 Average accuracy of meters in continuous and burst (neither thermal expansion tank nor PEX tubing with time combination of 1 second on, 4 
49 Average accuracy of meters in continuous and burst (neither thermal expansion tank nor PEX tubing with time combination of 1 second on, 3 seconds off) conditions

50 Average accuracy of meters in continuous and burst (thermal expansion tank with time combination of $1 / 2$ second on, 3 seconds off) conditions

51 Average accuracy of meters in continuous and burst (thermal expansion tank with time combination of 1 second on, 4 seconds off) conditions

52 Average accuracy of meters in continuous and burst (thermal expansion tank with time combination of 1 second on, 3 seconds off) conditions

53 Average accuracy of meters in continuous and burst (PEX tubing with time combination of $1 / 2$ second on, 3 seconds off) conditions

54 Average accuracy of meters in continuous and burst (PEX tubing with time combination of 1 second on, 4 seconds off) conditions

55 Average accuracy of meters in continuous and burst (PEX tubing with time combination of 1 second on, 3 seconds off) conditions

56 Average accuracy of meters in continuous and burst (both thermal expansion tank and PEX tubing with time combination of $1 / 2$ second on, 3 seconds off) conditions

57 Average accuracy of meters in continuous and burst (both thermal expansion tank and PEX tubing with time combination of 1 second on, 4 seconds off) conditions

58 Average accuracy of meters in continuous and burst (both thermal expansion tank and PEX tubing with time combination of 1 second on, 3 seconds off) conditions 


\section{NOTATION}

$\begin{array}{ll}\text { AWWA } & \text { American Water Works Association } \\ \text { EM } & \text { Electromagnetic } \\ \text { gpm } & \text { Gallons per minute } \\ \text { ND } & \text { Nutating Disc } \\ \text { OP } & \text { Oscillating Piston } \\ \text { PEX } & \text { Cross-linked polyethylene } \\ \text { PRV } & \text { Pressure-reducing valve } \\ \text { psi } & \text { Pounds per square inch } \\ \text { PVC } & \text { Polyvinyl chloride } \\ \text { US } & \text { Ultrasonic }\end{array}$




\section{CHAPTER I}

\section{INTRODUCTION}

Accuracies of residential flow meters have been studied over a wide range of circumstances. Household water use has been studied and documented for at least the past half-century (Anderson and Watson, 1967; Larson and Hudson, 1951). One water usage parameter that had not been previously researched was the occurrence of short, or "burst," flows that occur intermittently. Intermittent flows can have durations as small as one or two seconds. While the size of intermittent flows can vary, for this study typical flows for household appliances, usually a few gallons per minute, have been considered.

Some examples of possible intermittent flows occurring in a residential setting are:

- Wetting a toothbrush

- Rinsing off a razor

- Rinsing off a utensil or a dish

- Wetting a cloth or paper towel

- Intermittent leaking from a toilet flapper

- Spraying plants or washing cars with garden hoses equipped with nozzles

- Filling up a small glass of water

- Using a motion-activated faucet in a public bathroom Although an individual burst has a small volume, multiple bursts add up over time. If they are not measured accurately, burst flows result in lost revenue for utilities and more water consumed than customers are aware of. 
Janković-Nišić et al. (2004) explained that water usage is an "intermittent stochastic function rather than a standard deterministic continuous function." A faucet, or other appliance, is not used once daily to deliver all the anticipated water for a given residence. Rather, water is delivered in the precise moment at the appliance where it is needed. For example, the Residential End Uses of Water 2016 study found there were 5.0 toilet flushes, 0.69 showers, 20 faucet uses, 0.3 clothes washer loads, 43.3 leak events, 0.07 baths, and 0.10 dishwasher loads per capita per day. (The leaks lost an average of 0.15 gallons of water per event.) (DeOreo et al. 2016.) The durations and flows of water uses in a household setting are constantly fluctuating. Fine measuring resolutions are necessary to accurately record water usage. Cole and Stewart (2013) sometimes used one-second intervals when logging water meter data. "The capability of the automated reading system" made this precision possible. Al-Hoqani and Yang (2015) also used a one-second sampling interval in measuring flows. Further, Creaco et al. (2015) stressed that when modeling water demand pulses, a resolution as small as one second was necessary. These researchers understood that without logging the meter data in short intervals, many of the common household flows would be missed.

An example of how much water can add up nationwide over time is the amount of water Americans use to simply wet their toothbrushes before brushing. Typical modern bathroom faucets have a maximum flow of 1.2 gallons per minute (gpm). Assuming that 170 million people in the United States brush their teeth twice per day, commonly wetting their toothbrushes by turning on the faucet for one second each time. Over the course of one year, almost 2.5 billion gallons of water are used. This is the equivalent of filling a football field over a mile deep with water, or filling over 3,700 Olympic-sized 
swimming pools (assuming dimensions of 50 meters long, 25 meters wide, and 2 meters deep). While this amount of water is miniscule in the grand scheme of water usage in the United States, it is important to recognize that the aggregate accumulation of all possible intermittent or burst flows occurring from the sources listed above is significant.

The largest occurrence of burst flows may occur in leaks. DeOreo (2011) stated that intermittent leaks, which are "very common," can come from appliances such as “dripping faucets, evaporative cooling, or valves that flow at a low rate." Toilet flappers are a possible cause of leaks also cited in the study.

Britton et al. (2008) observed that leaks from appliances like dripping faucets and toilet cisterns can be hidden among regular household usage. "When considered individually leaks may seem insignificant; however, taken collectively over a long period they result in a major loss of water." While most leaks are constant in nature, some of the leaks mentioned can be classified as burst flows, and the amount of water that can accumulate from these intermittent leaks over time is significant.

The purpose of this study was to determine the accuracy of different types and models of residential flow meters in response to burst flows. 
CHAPTER II

\section{LITERATURE REVIEW}

The purpose of the literature review is to highlight the occurrence of burst flows in residential settings. Burst flows are found in many household settings, as explained in Chapter I. For example, faucet use can occur randomly and at irregular intervals, resulting in short durations and low volumes of throughput (DeOreo et al. 2011). Intermittent flows have been attributed to leaks occurring from dripping faucets and toilet flappers (DeOreo et al. 2011).

Roberts (2005) found almost 30\% of regular tap use events have a duration of less than five seconds. Because data were only collected in five-second intervals, the makeup of this percentage at a finer resolution was not known (zero to one second, one to two seconds, etc.). Because such a large portion of the total water usage was in this fivesecond range, it would be beneficial to know water usage at a more precise time interval-even as low as one second.

Gan and Redhead (2013) found leaks were often arbitrary and happened in short intervals. They concluded, "the largest volume of water was lost by leaks lasting less than 5 seconds."

Studies have found that flows smaller than 4 gpm accounted for $79.5 \%$ of all residential water use (Hudson, 1978) and flows less than $1 \mathrm{gpm}$ accounted for $16 \%$ of all residential water use (Noss, Newman, and Male, 1987).

Burst flows may become more common as technology improves, because water use will become more efficient as flows and event durations decrease. As it becomes simpler to turn faucets on and off with touchless (and other) technology, less water will 
be used for events like shaving, brushing teeth, and washing dishes (DeOreo et al. 2011). Devices that turn water on and off quickly will allow for usage in "short bursts rather than continuous flows" (Aquacraft, 2005). 
CHAPTER III

\section{EXPERIMENTAL SETUP AND TEST PROCEDURE}

Testing for this study occurred at the Utah Water Research Laboratory in Logan, Utah. The water for this study came from a city line, providing the cleanest water available.

\section{Setup}

The setup included a PRV to control the pressure in the system. Because water pressures in residences are generally between 20 to 80 psi, the PRV was set so the system pressure was $50 \mathrm{psi}( \pm 5 \mathrm{psi})$ for all tests. The PRV that was used is shown in Figure 1 .

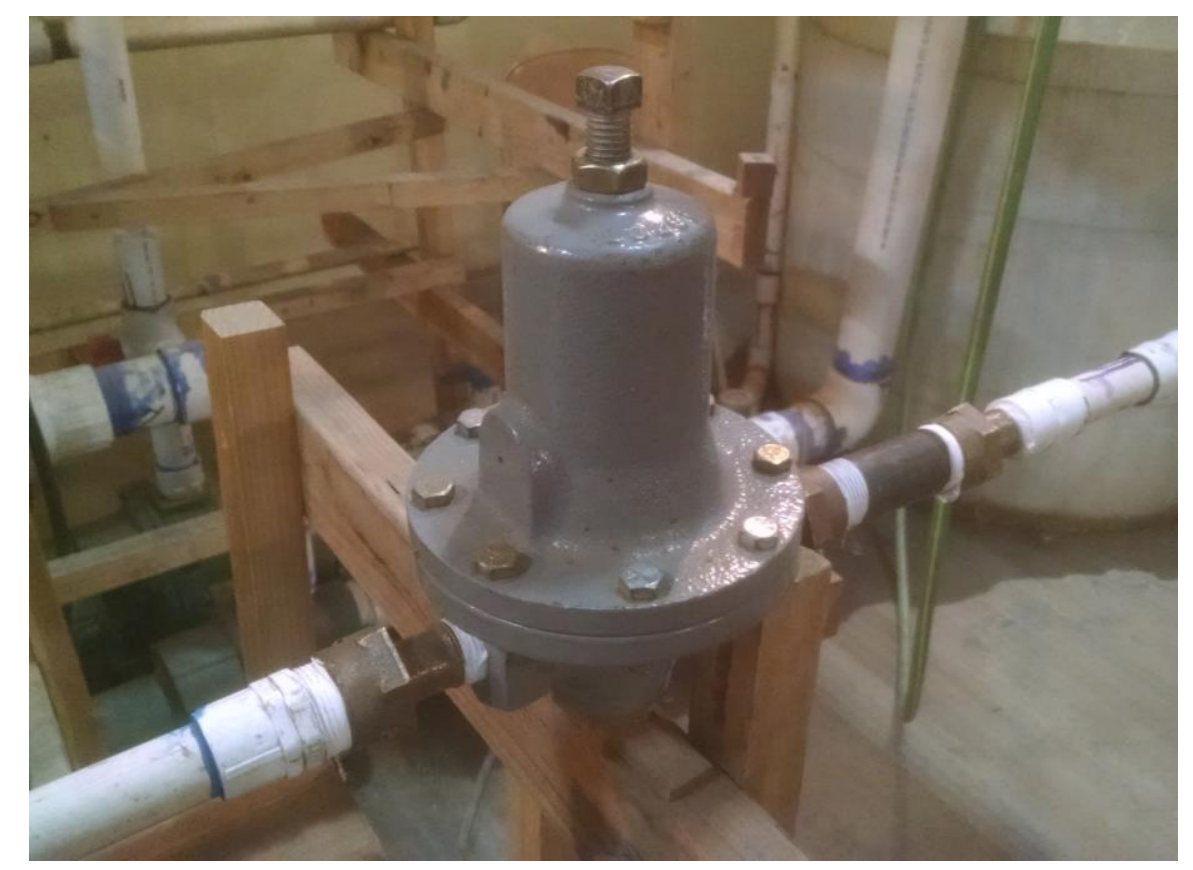

Figure 1. Pressure reducing valve placed upstream of test meters in laboratory setup.

Four different meter types were used in this study. These included ultrasonic, electromagnetic, nutating disc, and oscillating piston meters. Among these were seven 
different meter models with each model having six identical meters (42 meters total). Included in the test meters were two models of ultrasonic meters (US), one model of electromagnetic (EM) meters, two models of nutating disc (ND) meters, and two models of oscillating piston (OP) meters. To prevent excessive head loss, the meters were separated into two sets of 21 meters, with each set being identical in terms of meter quantity (three meters of each model were placed in each set) and order.

The meters for each test group were placed in the order shown in Table 1, beginning at the upstream end.

Table 1. Placement of meters in test setup based on type.

\begin{tabular}{cccc}
$\begin{array}{c}\text { Meter } \\
\text { placement }\end{array}$ & $\begin{array}{c}\text { Meter model } \\
\text { and set }\end{array}$ & $\begin{array}{c}\text { Meter } \\
\text { placement }\end{array}$ & $\begin{array}{c}\text { Meter model } \\
\text { and set }\end{array}$ \\
\hline 1 & US1 & 12 & US2 \\
2 & ND1 & 13 & ND2 \\
3 & OP1 & 14 & OP2 \\
4 & EM1 & 15 & US1 \\
5 & US2 & 16 & ND1 \\
6 & ND2 & 17 & OP1 \\
7 & OP2 & 18 & EM1 \\
8 & US1 & 19 & US2 \\
9 & ND1 & 20 & ND2 \\
10 & OP1 & 21 & OP2 \\
11 & EM1 & &
\end{tabular}

For some of the tests, the system setup included a 2.1-gallon thermal expansion tank downstream of the meters, simulating residences that have thermal expansion tanks. Figure 2 shows the thermal expansion tank used for the system setup.

Thermal expansion tanks are commonly included in newer homes when backflow prevention valves have been installed. Water in homes without backflow prevention valves is able to expand backward toward the water main. Backflow prevention valves 


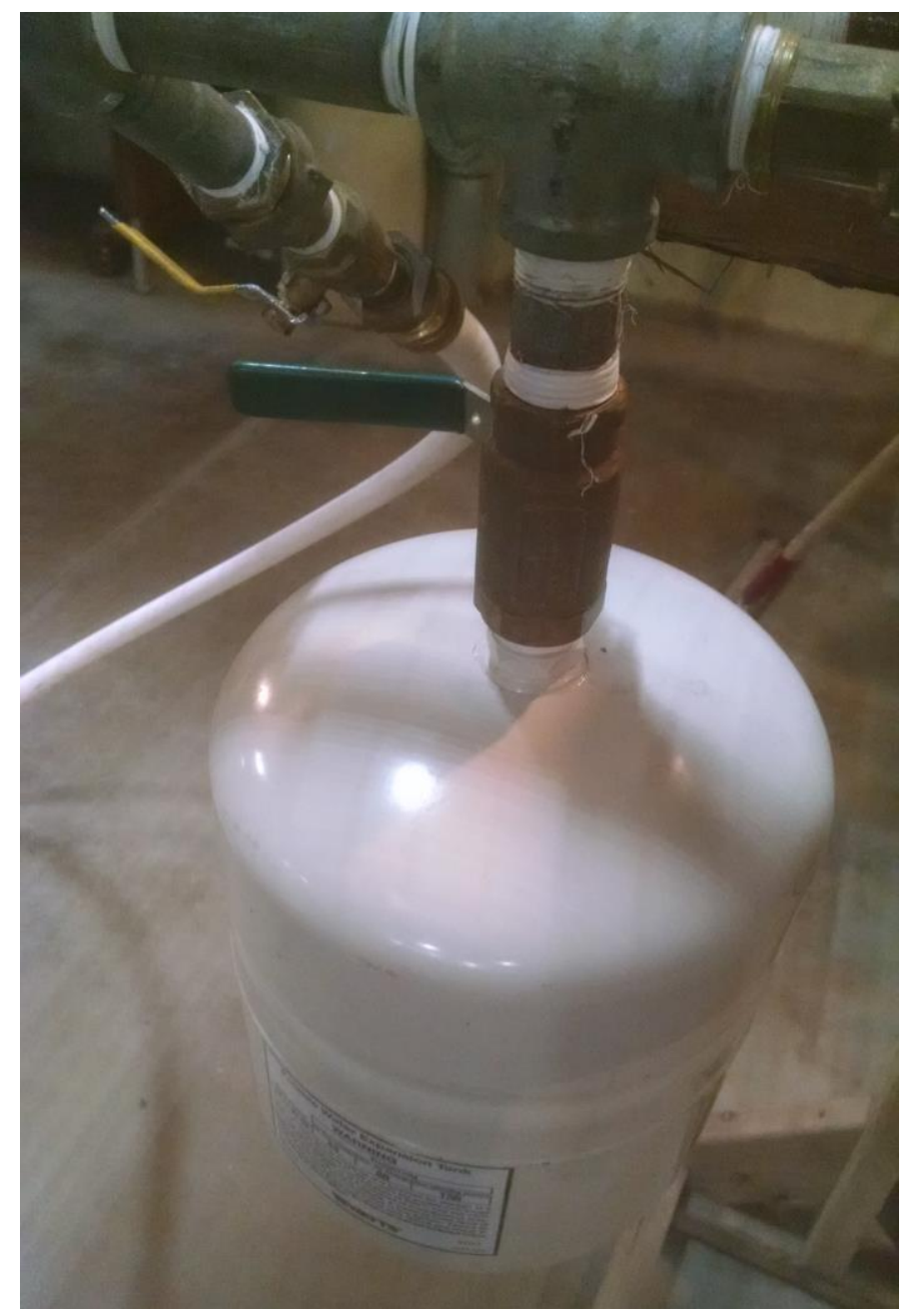

Figure 2. Thermal expansion tank included in test setup downstream of meters.

prevent water from flowing back up toward the water main, causing an increase in pressure in the water heater. To eliminate pressure buildup, thermal expansion tanks are installed directly upstream of water heaters. Thermal expansion tanks have a diaphragm separating a chamber of pressurized air (manually set equivalent to the static water pressure) from a chamber that can fill up with the water that would otherwise expand back up the system. A thermal expansion tank was included for some of the tests to evaluate how the suppressing characteristics of the tank affect the pulsing tendency of the 
burst flows as recorded by the water meter. The tank chosen for these tests was the smallest tank that is manufactured. Tank sizes are determined from the total system volume; the test setup downstream from the tank was about 9.6 gallons. The tank was installed at a lower elevation than the line to allow for any air pockets in the bladder of the tank to escape from the system.

One hundred feet of one-inch PEX piping was also included in the system downstream of the thermal expansion tank. PEX piping is used as an alternative to copper tubing. PEX piping can expand and contract radially based on pressure fluctuations in the system. Figure 3 shows the PEX tubing. The PEX tubing was used during some of the tests to evaluate how this non-rigid pipe type affects the meter accuracy as a result of intermittent or burst flow rates and corresponding line pressures.

The top opening of the gravimetric weight tank at the end of the system was covered to prevent evaporation. The pipe discharging into the weight tank did not touch the weight tank.

A solenoid valve with a response time ranging from 20 to 80 milliseconds was installed at the end of the line (where the water enters the weight tank). The solenoid valve had a 1/2-inch inner diameter. To better understand the actual release of flow volumes during a burst flow, individual bursts were collected in 500-mL beakers before any actual tests were performed. As these preliminary bursts of flow volume were collected, video was taken at 240 frames per second. Reviewing the video footage allowed for a precise measurement of the time the solenoid was actually open. The average ratio for the solenoid opening to the time programmed on the computer was found to be 1.14. It appeared that this value was greater than 1.0 because the residual 


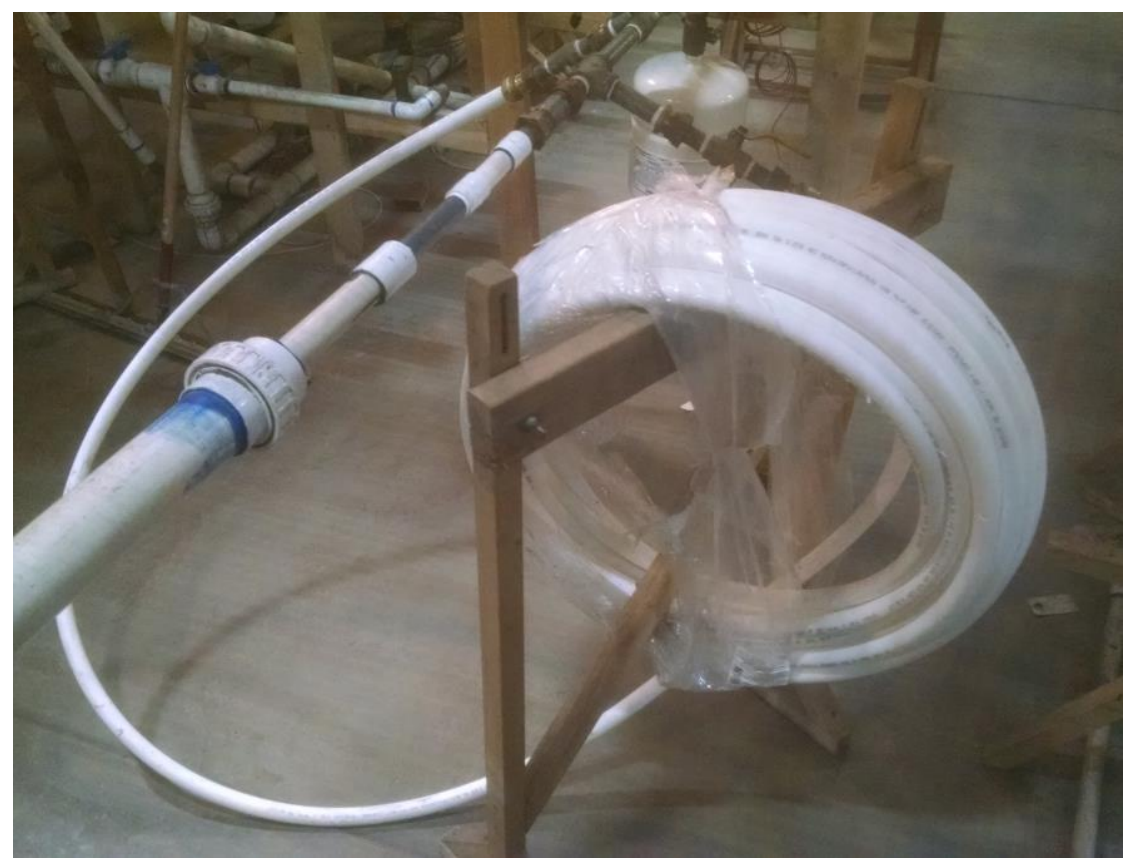

Figure 3. PEX tubing included in test setup downstream of thermal expansion tank.

pressure, which causes the solenoid valve to open, took time to build up.

The response time for the solenoid valve can also be seen by looking at a graph of flow over time. A graph with example values is shown in Figure 4. The positive-sloped portion of the graph represents the opening of the valve until maximum flow is reached. The time when maximum flow occurs is represented by the flat, middle portion of the graph. The negative-sloped portion represents the closing of the valve.

Complete cycles were timed and were found to last almost exactly the time they were programmed for. Therefore, if the time with the solenoid valve open was slightly longer than nominal, the time with the solenoid valve closed was slightly shorter than nominal. For a nominal cycle of one second open (or on) and three seconds closed (or off), the time off was determined to be approximately 2.86 seconds.

A software program was used to set the solenoid opening and closing cycles. The 


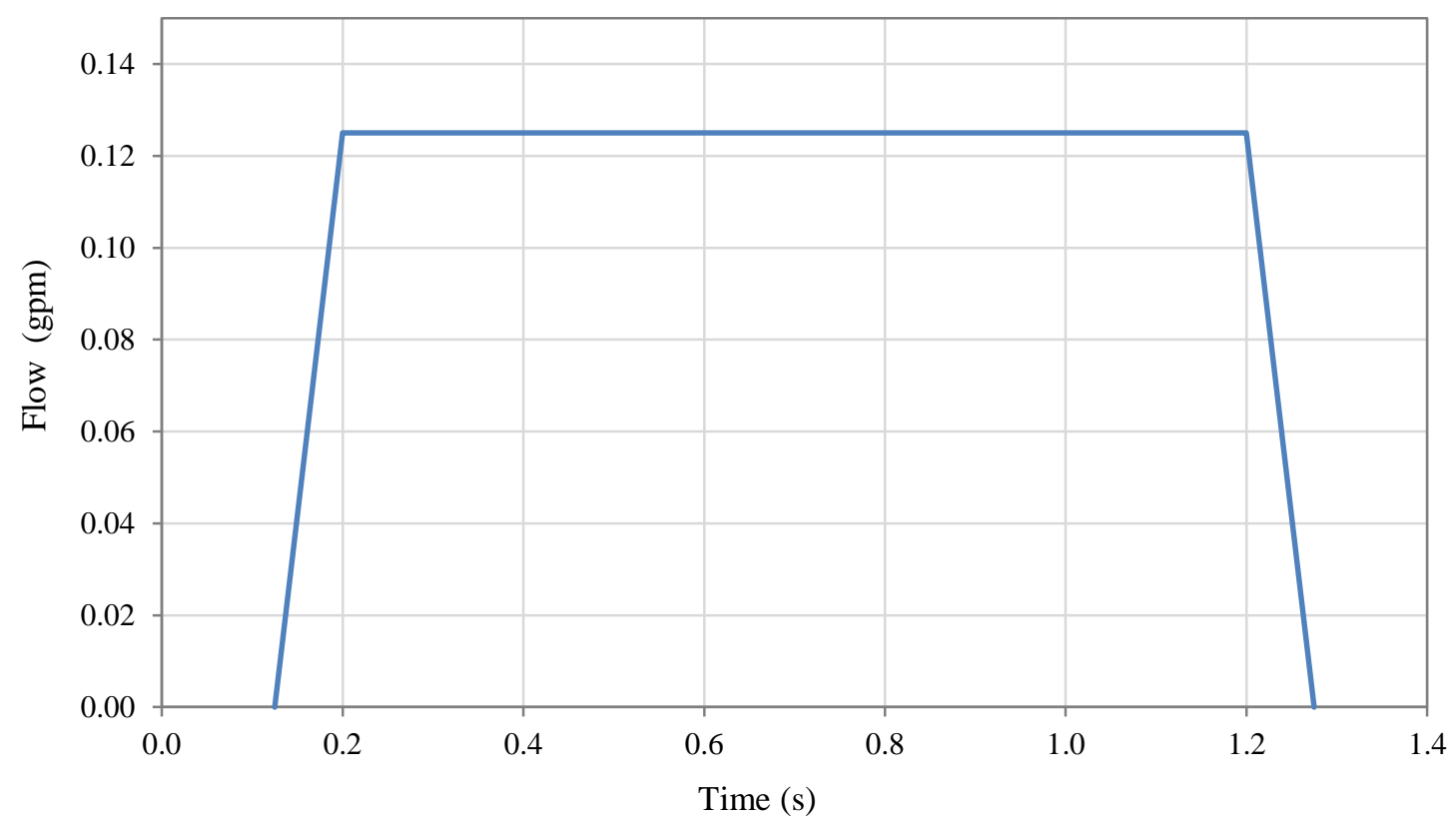

Figure 4. Example of flow change for solenoid valve over a short time.

desired amount of time on and the desired amount of time off was able to be programmed by the user. Three time combinations were used during the tests for data collection. They were: (1) one-half second on, three seconds off; (2) one second on, four seconds off; (3) one second on, three seconds off. Determining time combinations that would accurately reflect meters' responses to burst flows was challenging. Ideally, time-on values ranging from one second up to ten seconds would be used (with one second intervals), but using this many intervals was determined to be not practical. The use of one-half second and one second time-on values was thought to represent well the lower end of the spectrum of durations of burst flows.

Determining the time off component (and corresponding total burst cycle length) also presented challenges, mainly due to ultrasonic meter technology. Ultrasonic meters measure flow by emitting an ultrasonic wave every fixed amount of time (known as the 
sampling rate) between transducers in the meter chamber. The water velocity through an ultrasonic meter is calculated from the differential transit time of ultrasonic waves travelling in both directions. Knowing the velocity and duration of the flow allows for finding the flow rate and throughput.

One ultrasonic model in this study had a sampling rate of four seconds, and the other ultrasonic model had a sampling rate of one second. The meter model with a sampling rate of four seconds was found to grossly over- or under-register the amount of actual throughput, depending on the synchronization of the sampling rate with the third time combination mentioned previously.

Three flows of 4 gpm, 2 gpm, and 0.25 gpm were used during the study. The smaller two flow rates were used in part because they are AWWA standard flows for 5/8" x 3/4" meters, but also because they represent flows that often occur in a burst condition in a residential setting. The 4-gpm flow was selected because it better represents higher flows that occur for individual appliances in a household setting than the AWWA standard of 15 gpm for maximum flow for 5/8" x 3/4" meters.

The American Water Works Association specifies that either 10 gallons or 1 cubic foot should be collected when testing 5/8" x 3/4" meters at flows of $2 \mathrm{gpm}$ and $0.25 \mathrm{gpm}$. (AWWA, 2012.) A minimum of ten gallons were always collected for each test using the gravimetric laboratory scale.

Each meter had a resolution of 0.01 gallons. Because at least ten gallons of throughput occurred for each test, the uncertainty of each meter was no greater than $0.1 \%$ (dividing the resolution by the minimum amount collected). The weight tank had a resolution of 0.05 pounds. Because at least 83.4 pounds (ten gallons) were collected, the 
uncertainty of the weight tank was no greater than $0.06 \%$. It can be seen that uncertainties for both the meters and the weight tank were very small for all tests.

Four different test setups were used to test the meters: (1) the thermal expansion tank ("Tank") included, (2) the PEX tubing ("PEX") included, (3) both the thermal expansion tank and the PEX tubing ("Both") included, and (4) neither the thermal expansion tank nor the PEX tubing ("Neither") included. The four setups were tested because each test scenario includes system components that are found in different households across the United States. Thermal expansion tanks are more recent inclusions in household water systems as cities adopt codes requiring them. PEX tubing is recently becoming more common in the United States as a replacement for copper tubing. (While the standard setup for the bursts tests used PVC tubing instead of copper tubing, it was assumed that PVC tubing represented well the rigid characteristics exhibited by copper tubing.) It is possible for a house to have a thermal expansion tank or PEX tubing, both, or neither. As such, it was deemed necessary to include all four test setups in the study.

\section{Procedure}

The test flow and static system pressure were set simultaneously using a quarterturn valve located downstream of the meters and before the solenoid valve. It was determined that the actual flow rates tested should be within 5\% of the desired flow (in the continuous flow condition). A reference electromagnetic flow meter was used to initially approximate the continuous flow. The flow rate was confirmed by using a stopwatch to record the amount of time the gravimetric weight tank was filled. The total water weight was recorded and converted to a volume based on the unit weight of the 
water (a function of water temperature). If necessary, the flow was adjusted until it was in the acceptable $\pm 5 \%$ range of the target flow rate. When the continuous flow and the static system pressure were set, another quarter-turn valve just downstream of the calibration valve was closed to shut off the flow. The initial readings of the meters were then recorded. Following the initial meter reading, the computer program was set to the proper time combination. A specific test began as the stopwatch was started and the solenoid valve began to cycle open and closed. Temperatures were recorded at the beginning and end of the test to calculate an average unit weight of the water.

At the end of the test, the solenoid cycle and stopwatch were stopped simultaneously. The total weight was used to determine the total test volume. The total throughput on the meters was also recorded. The difference between the initial throughput and the final throughput yielded the net throughput for the test for each meter. The net throughputs were each compared to the actual volume calculated from the weight tank weight. The accuracy of the meters (the meters' registry divided by the weight tank's registry) was recorded as a percentage.

A summary of the burst tests is shown in Table 2. As stated previously, the meters were divided into two test groups of 21 meters each to prevent excessive head loss. With three flow rates, four test setups, and three time combinations, there were a total of 36 tests that each test group participated in. Table 2 does not represent the actual order the tests were carried out in. 
Table 2. Test scenarios.

\begin{tabular}{|c|c|c|c|}
\hline $\begin{array}{l}\text { Test } \\
\text { No. }\end{array}$ & $\begin{array}{l}\text { Flow } \\
\text { (gpm) }\end{array}$ & $\begin{array}{c}\text { Test } \\
\text { Setup }\end{array}$ & $\begin{array}{c}\text { Time Combination } \\
\text { (seconds on, } \\
\text { seconds off) }\end{array}$ \\
\hline 1 & 0.25 & Neither & 1,3 \\
\hline 2 & 0.25 & Tank & 1,3 \\
\hline 3 & 0.25 & PEX & 1,3 \\
\hline 4 & 0.25 & Both & 1,3 \\
\hline 5 & 0.25 & Neither & 1,4 \\
\hline 6 & 0.25 & Tank & 1,4 \\
\hline 7 & 0.25 & PEX & 1,4 \\
\hline 8 & 0.25 & Both & 1,4 \\
\hline 9 & 0.25 & Neither & $0.5,3$ \\
\hline 10 & 0.25 & Tank & $0.5,3$ \\
\hline 11 & 0.25 & PEX & $0.5,3$ \\
\hline 12 & 0.25 & Both & $0.5,3$ \\
\hline 13 & 2 & Neither & 1,3 \\
\hline 14 & 2 & Tank & 1,3 \\
\hline 15 & 2 & PEX & 1,3 \\
\hline 16 & 2 & Both & 1,3 \\
\hline 17 & 2 & Neither & 1,4 \\
\hline 18 & 2 & Tank & 1,4 \\
\hline 19 & 2 & PEX & 1,4 \\
\hline 20 & 2 & Both & 1,4 \\
\hline 21 & 2 & Neither & $0.5,3$ \\
\hline 22 & 2 & Tank & $0.5,3$ \\
\hline 23 & 2 & PEX & $0.5,3$ \\
\hline 24 & 2 & Both & $0.5,3$ \\
\hline 25 & 4 & Neither & 1,3 \\
\hline 26 & 4 & Tank & 1,3 \\
\hline 27 & 4 & PEX & 1,3 \\
\hline 28 & 4 & Both & 1,3 \\
\hline 29 & 4 & Neither & 1,4 \\
\hline 30 & 4 & Tank & 1,4 \\
\hline 31 & 4 & PEX & 1,4 \\
\hline 32 & 4 & Both & 1,4 \\
\hline 33 & 4 & Neither & $0.5,3$ \\
\hline 34 & 4 & Tank & $0.5,3$ \\
\hline 35 & 4 & PEX & $0.5,3$ \\
\hline 36 & 4 & Both & $0.5,3$ \\
\hline
\end{tabular}


CHAPTER IV

\section{LABORATORY TEST RESULTS}

\section{Accuracy by meter model for continuous flow tests}

All results present the data by individual meter model, not by meter type. Because different meter models of the same meter type (especially the two ultrasonic meter models) had varied results, it was necessary to separate the results to highlight the differences between models.

Before any intermittent flow tests were performed, tests at ten different continuous flows were conducted on each of the subject meters. The flow rates that were tested were 0.0625 (1/16) gpm, 0.125 (1/8) gpm, 0.25 gpm, 0.5 gpm, 2 gpm, 4 gpm, 6 gpm, 8 gpm, 15 gpm, and 20 gpm. The average accuracies for each meter model are shown from Figure 5 to Figure 8. The vertical red lines represent the three AWWA test flows for 5/8" x 3/4" meters (0.25 gpm, 2 gpm, and $15 \mathrm{gpm})$.

The ultrasonic and electromagnetic meters reported near $100 \%$ registry at all flow rates. The nutating disc and oscillating piston meters indicated decreased accuracies at the 1/8-gpm and the 1/16-gpm continuous flow rates.

Accuracy standards for displacement (nutating disc and oscillating piston) meters are as follows. At 2 gpm, the accuracy limits are within $98.5 \%$ and $101.5 \%$ of the throughput recorded from the weight tank. At $0.25 \mathrm{gpm}$, the accuracy limits for new and rebuilt meters are between $95 \%$ and $101 \%$ of the actual throughput. (For repaired meters, the minimum accuracy limit is $90 \%$ ). (AWWA, 2012.) Currently, no formalized accuracy standards exist for electronic (electromagnetic and ultrasonic) meters. 


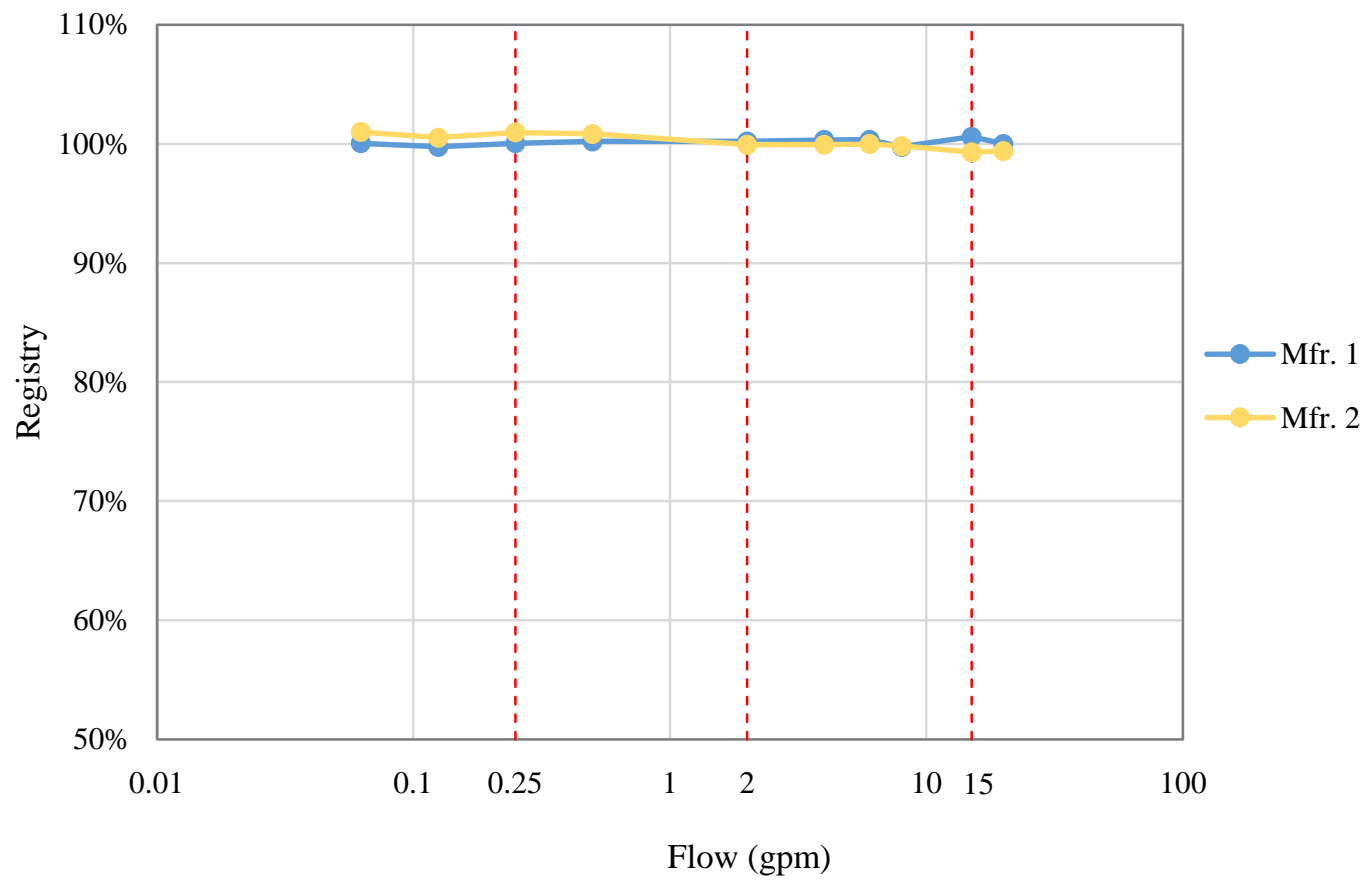

Figure 5. Average accuracy of ultrasonic meters for continuous flow tests (log scale on xaxis).

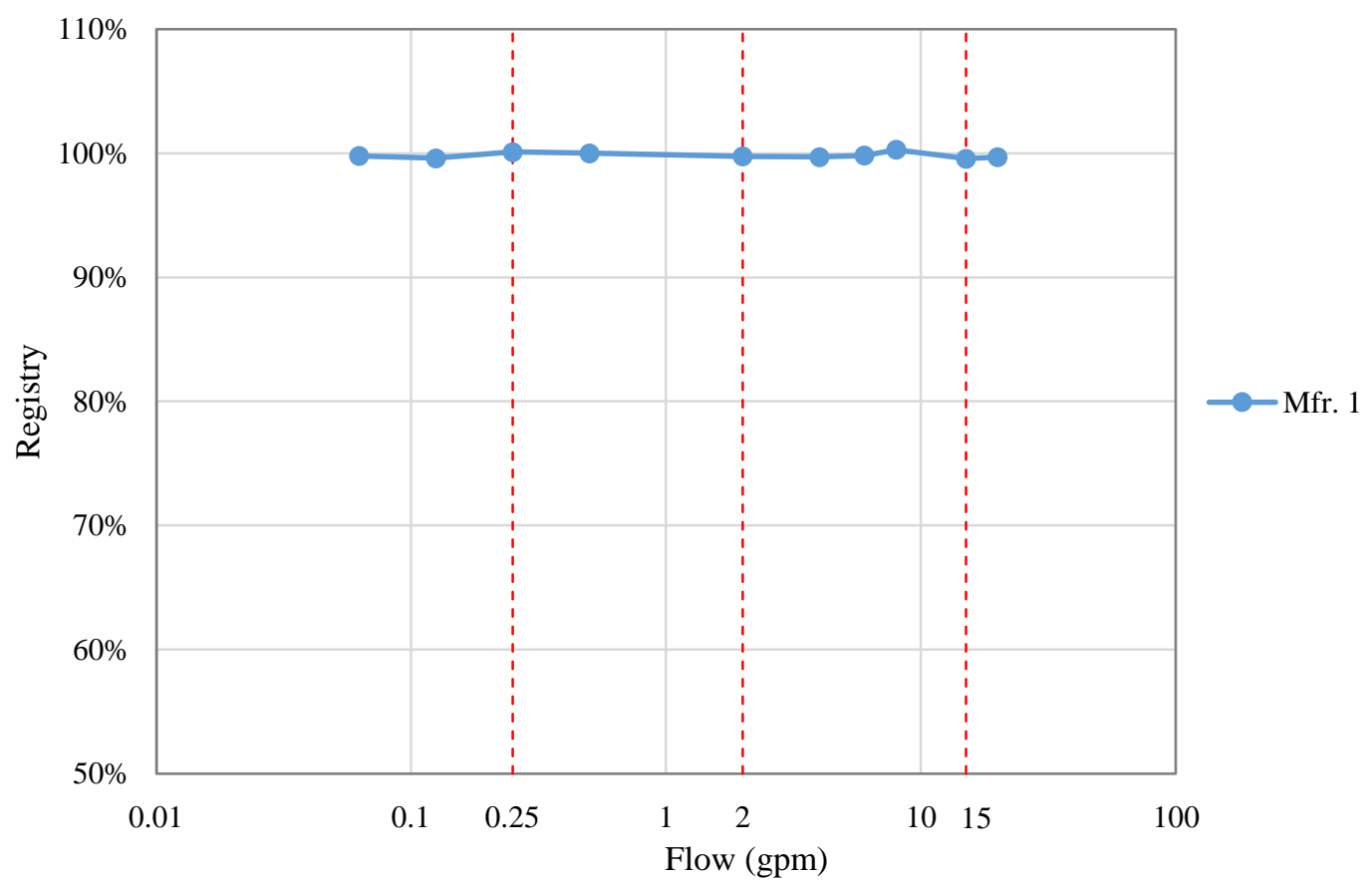

Figure 6. Average accuracy of electromagnetic meters for continuous flow tests (log scale on $\mathrm{x}$-axis). 


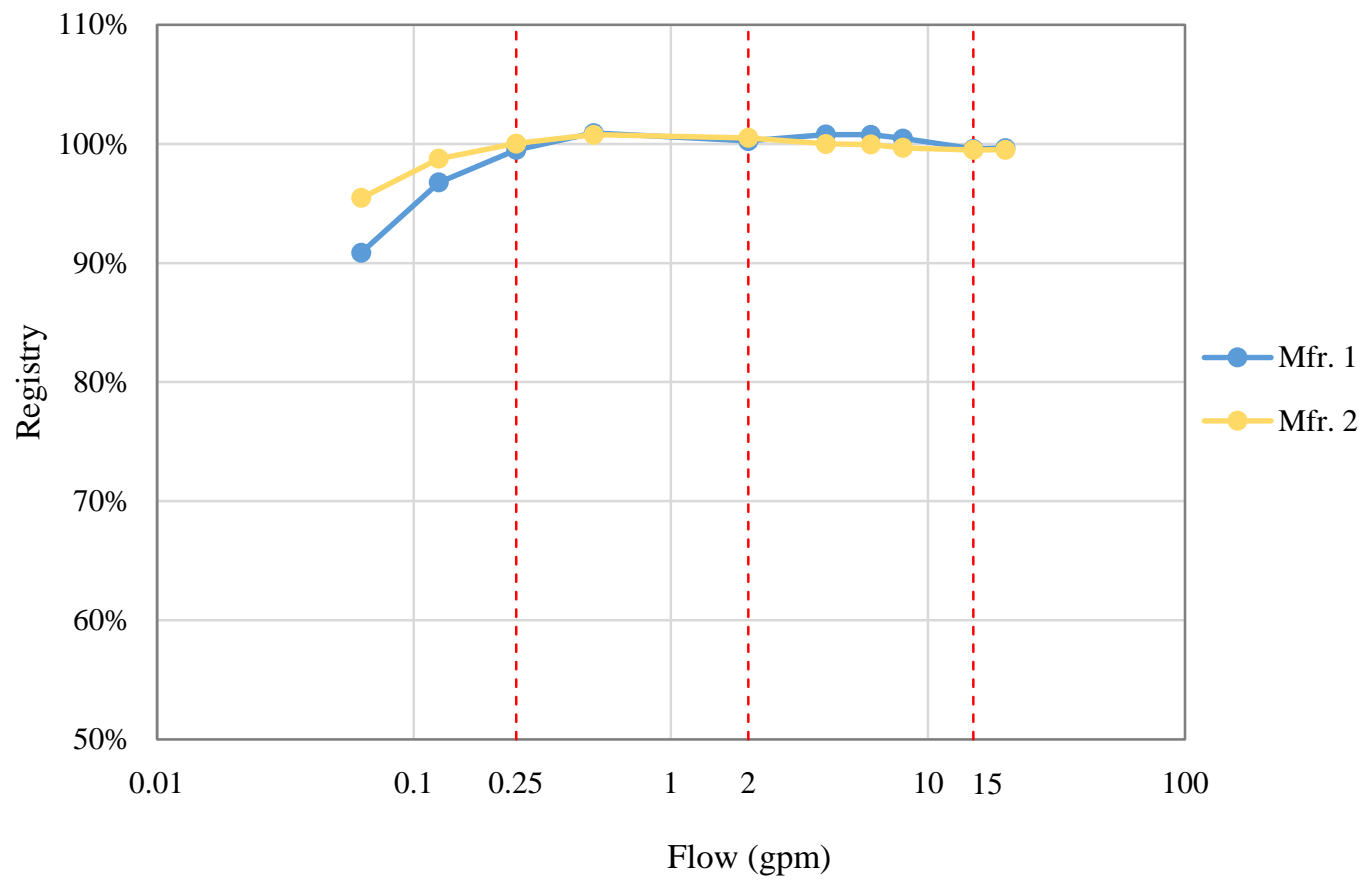

Figure 7. Average accuracy of nutating disc meters for continuous flow tests (log scale on $\mathrm{x}$-axis).

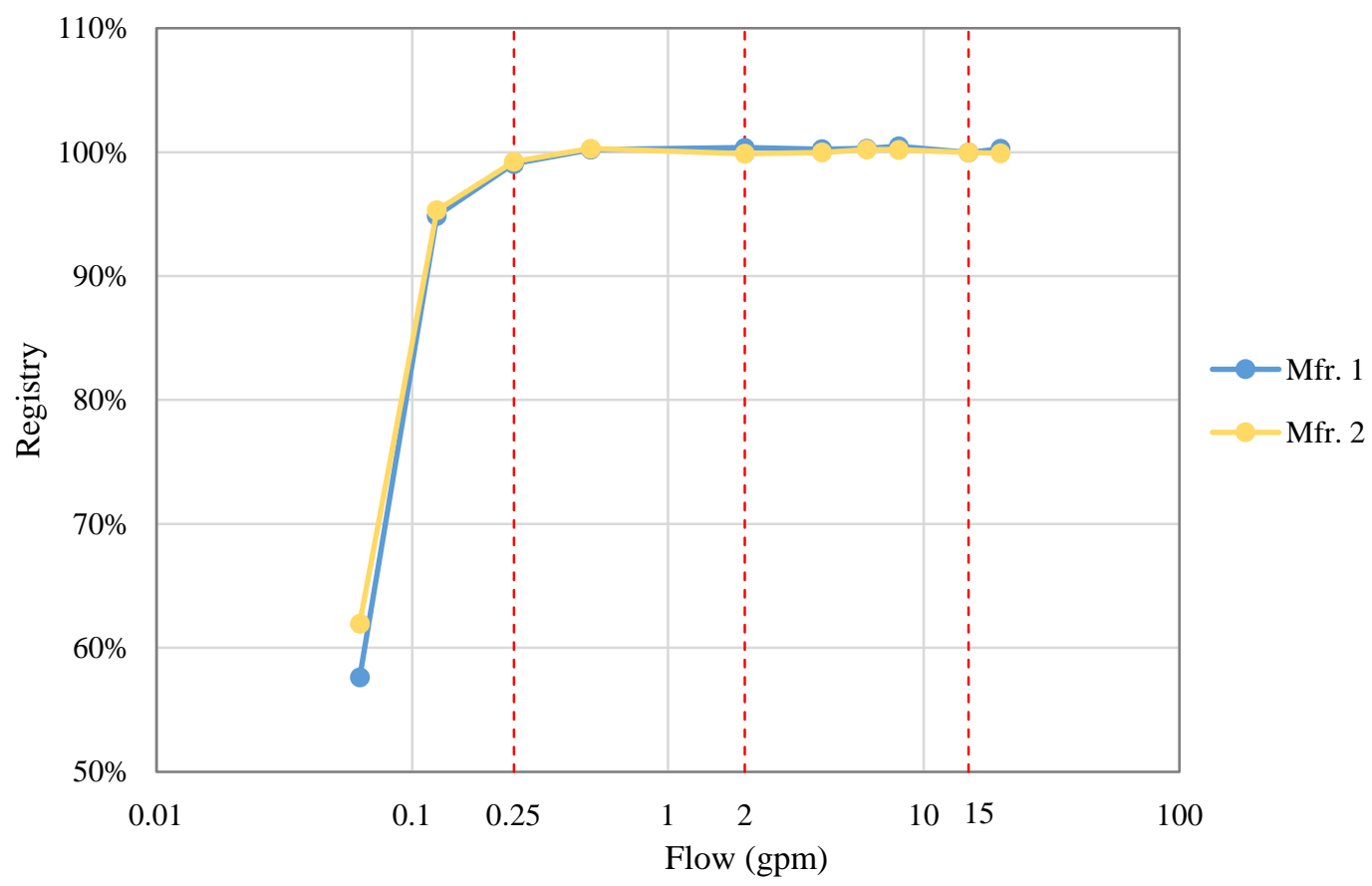

Figure 8. Average accuracy of oscillating piston meters for continuous flow tests (log scale on $\mathrm{x}$-axis). 
For the continuous flows (4 gpm, $2 \mathrm{gpm}$, and $0.25 \mathrm{gpm}$ ), all meter models had accuracies that averaged near $100 \%$, as seen in Table 3. It should be remembered that the 4-gpm flow is not an AWWA standard flow.

Table 3. Accuracy by flow and meter model for continuous flow tests.

\begin{tabular}{cccccccc}
\hline $\begin{array}{c}\text { Flow } \\
\text { (gpm) }\end{array}$ & \multicolumn{7}{c}{ Meter Model } \\
\hline & US1 & US2 & EM1 & ND1 & ND2 & OP1 & OP2 \\
0.25 & $100.06 \%$ & $100.96 \%$ & $100.11 \%$ & $99.48 \%$ & $100.03 \%$ & $99.05 \%$ & $99.23 \%$ \\
2 & $100.20 \%$ & $99.92 \%$ & $99.75 \%$ & $100.24 \%$ & $100.51 \%$ & $100.36 \%$ & $99.88 \%$ \\
4 & $100.32 \%$ & $99.93 \%$ & $99.70 \%$ & $100.78 \%$ & $99.99 \%$ & $100.24 \%$ & $99.98 \%$ \\
Average & $100.19 \%$ & $100.27 \%$ & $99.85 \%$ & $100.16 \%$ & $100.18 \%$ & $99.88 \%$ & $99.70 \%$
\end{tabular}

Of all the meters tested in the continuous flow condition, only one ultrasonic meter failed the 0.25 -gpm test. (See data for Meter 5 in Table 16 in Appendix C.) All other meters had passing accuracies for the $0.25 \mathrm{gpm}$ and $2 \mathrm{gpm}$ tests.

\section{Burst flow test results}

The remainder of Chapter IV will present results from burst flow tests. Table 4 shows the average length of each test for each time combination and flow rate, as well as the average number of cycles required for the given flow rate and time combination.

Table 4. Average length of burst flow tests and average number of cycles required for tests.

\begin{tabular}{ccccc}
\hline $\begin{array}{c}\text { Flow } \\
\text { (gpm) }\end{array}$ & \multirow{2}{*}{ Units } & \multicolumn{2}{c}{ Time Combination (seconds on, seconds off) } \\
& & $\mathbf{0 . 5 , 3}$ & $\mathbf{1 , 4}$ & $\mathbf{1 , 3}$ \\
\hline \multirow{2}{*}{$\mathbf{. 2 5}$} & Time (h:mm) & $4: 34$ & $3: 09$ & $2: 30$ \\
& Cycles & 4,694 & 2,264 & 2,243 \\
\hline \multirow{2}{*}{$\mathbf{2}$} & Time (h:mm) & $0: 33$ & $0: 25$ & $0: 20$ \\
& Cycles & 558 & 296 & 303 \\
\hline \multirow{2}{*}{$\mathbf{4}$} & Time (h:mm) & $0: 16$ & $0: 12$ & $0: 10$ \\
& Cycles & 273 & 149 & 149
\end{tabular}




\section{Accuracy by flow and meter model}

Table 5 shows accuracies of meters by model. The values in Table 5 are averages of all the tests performed, including all test setups and time combinations.

Table 5. Accuracy by flow and meter model for burst flow tests.

\begin{tabular}{cccccccc}
\hline Flow (gpm) & & \multicolumn{7}{c}{ Meter Model } \\
\hline & US1 & US2 & EM1 & ND1 & ND2 & OP1 & OP2 \\
0.25 & $97.30 \%$ & $99.06 \%$ & $99.68 \%$ & $90.52 \%$ & $91.36 \%$ & $88.64 \%$ & $89.98 \%$ \\
2 & $97.74 \%$ & $99.56 \%$ & $99.84 \%$ & $100.14 \%$ & $100.65 \%$ & $99.53 \%$ & $99.43 \%$ \\
4 & $88.49 \%$ & $99.36 \%$ & $99.94 \%$ & $100.56 \%$ & $100.34 \%$ & $100.27 \%$ & $99.95 \%$ \\
Average & $94.51 \%$ & $99.33 \%$ & $99.82 \%$ & $97.07 \%$ & $97.45 \%$ & $96.14 \%$ & $96.46 \%$
\end{tabular}

The varying meter types responded differently to the three flows. For example, the ultrasonic Manufacturer 1 meters reported the lowest accuracy at the 4-gpm flow. The nutating disc and oscillating piston meters reported the lowest accuracies at the 0.25 -gpm flow.

The largest standard deviation occurred within the ultrasonic meter group, $3.40 \%$. The nutating disc meter model accuracies had a standard deviation of $0.27 \%$ and the oscillating piston meter models had a standard deviation of $0.22 \%$.

Figure 9 through Figure 12 summarize results found in Table 3 and Table 5. The vertical red lines represent the AWWA test flows. The two smaller flows, 0.25 gpm and 2 gpm, are AWWA minimum and intermediate test flows, respectively. 


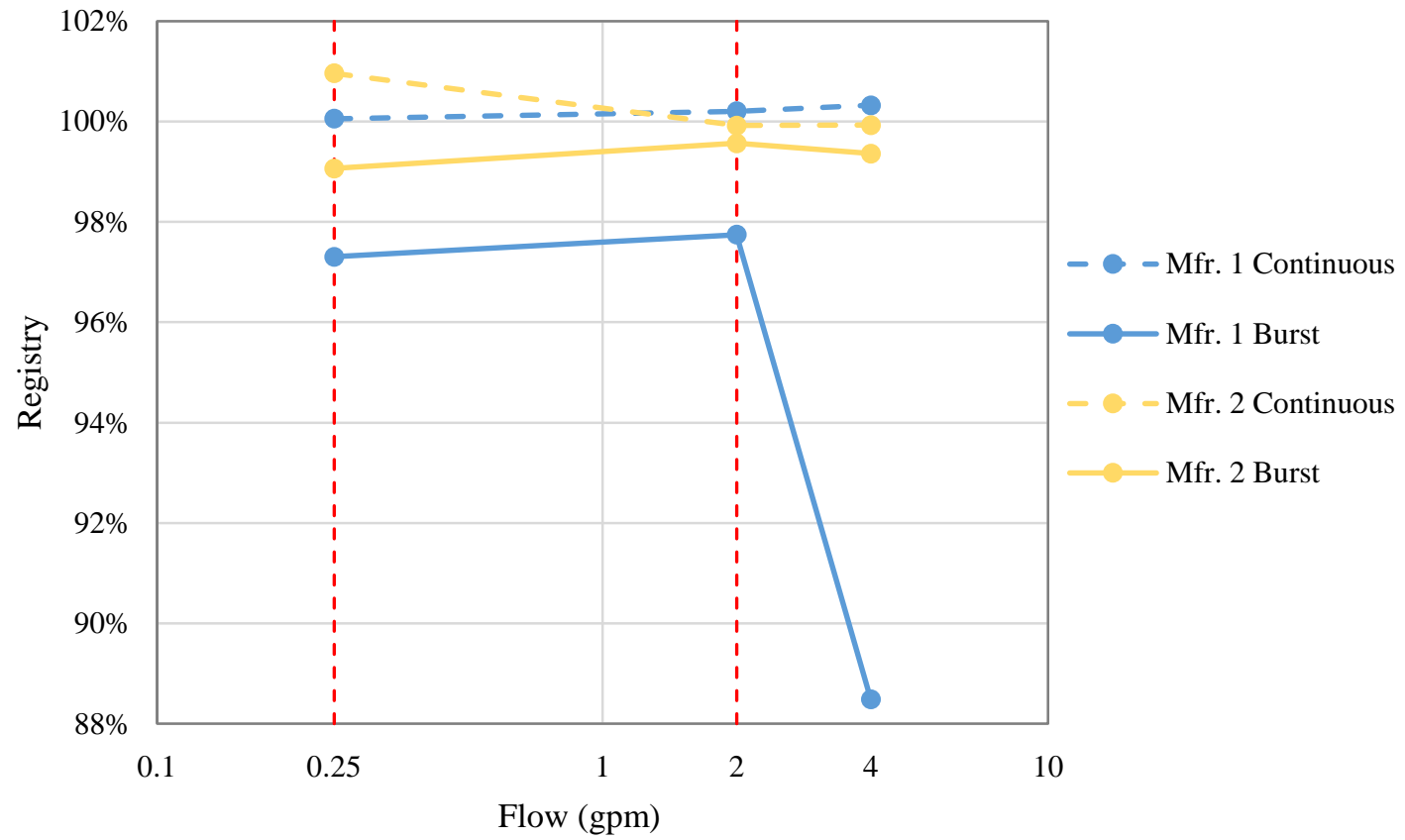

Figure 9. Comparison of continuous and burst accuracies of ultrasonic meters (log scale on $\mathrm{x}$-axis).

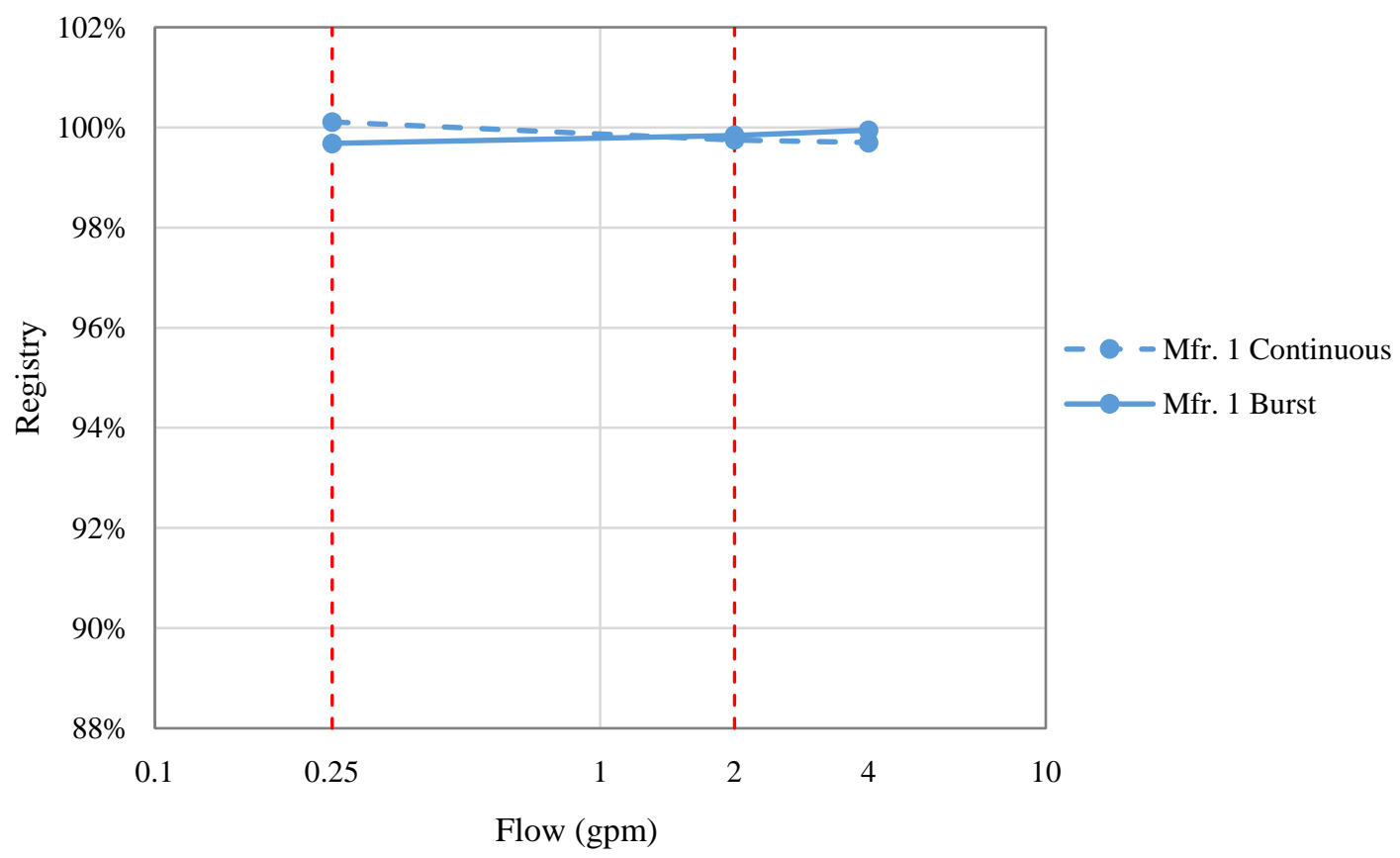

Figure 10. Comparison of continuous and burst accuracies of electromagnetic meters (log scale on $\mathrm{x}$-axis). 


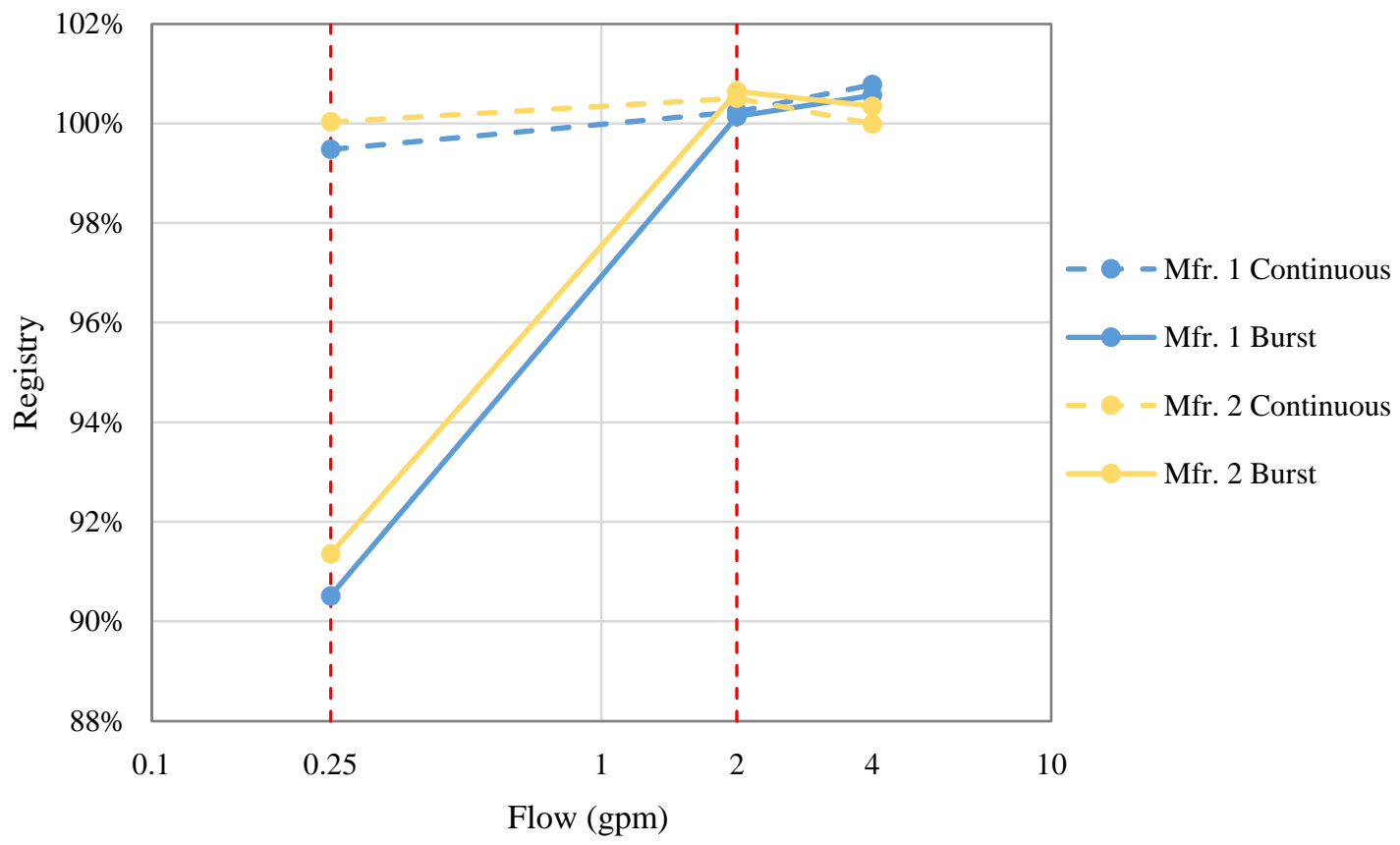

Figure 11. Comparison of continuous and burst accuracies of nutating disc meters (log scale on $\mathrm{x}$-axis).

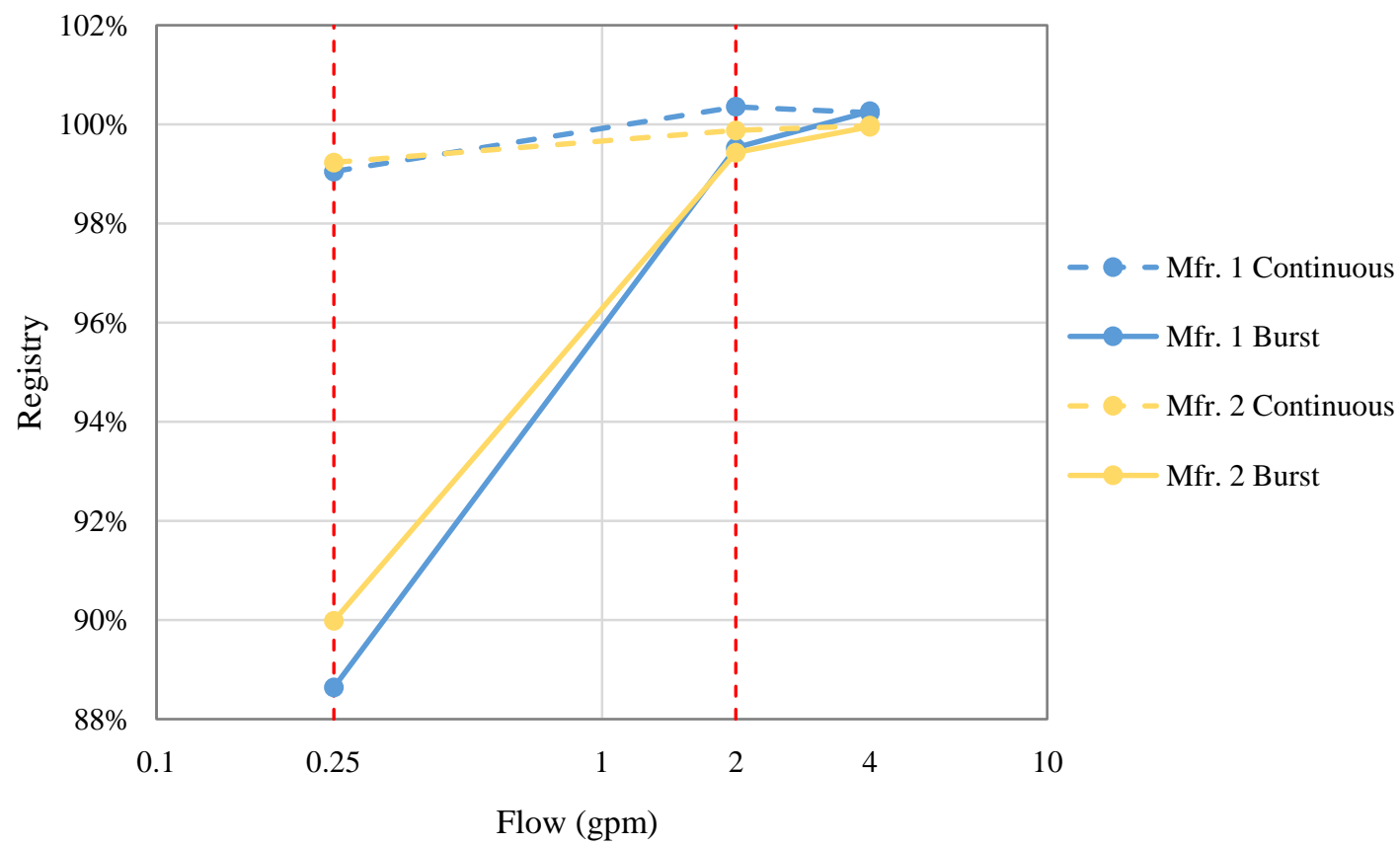

Figure 12. Comparison of continuous and burst accuracies of oscillating piston meters (log scale on $\mathrm{x}$-axis). 


\section{Accuracy by test setup and meter model}

Table 6 shows the average accuracies when comparing test setup and meter model. The values presented in Table 6 are averages of all the tests performed, including all time combinations.

Table 6 . Accuracy by test setup and meter model.

\begin{tabular}{|c|c|c|c|c|c|c|c|c|}
\hline \multirow{2}{*}{$\begin{array}{c}\text { Test } \\
\text { Setup }\end{array}$} & \multirow{2}{*}{$\begin{array}{c}\text { Flow } \\
\text { (gpm) }\end{array}$} & \multicolumn{7}{|c|}{ Meter Model } \\
\hline & & US1 & US2 & EM1 & ND1 & ND2 & OP1 & OP2 \\
\hline \multirow{3}{*}{ Neither } & 0.25 & $96.50 \%$ & $99.28 \%$ & $99.91 \%$ & $90.51 \%$ & $91.48 \%$ & $89.94 \%$ & $90.94 \%$ \\
\hline & 2 & $98.41 \%$ & $99.71 \%$ & $99.97 \%$ & $100.08 \%$ & $100.57 \%$ & $98.94 \%$ & $98.83 \%$ \\
\hline & 4 & $99.85 \%$ & $99.26 \%$ & $99.93 \%$ & $100.25 \%$ & $100.31 \%$ & $100.23 \%$ & $99.87 \%$ \\
\hline \multirow{3}{*}{ Tank } & 0.25 & $96.87 \%$ & $99.16 \%$ & $99.70 \%$ & $89.43 \%$ & $90.16 \%$ & $86.61 \%$ & $88.38 \%$ \\
\hline & 2 & $86.84 \%$ & $99.73 \%$ & $100.02 \%$ & $100.25 \%$ & $100.76 \%$ & $98.94 \%$ & $98.93 \%$ \\
\hline & 4 & $86.07 \%$ & $99.93 \%$ & $99.83 \%$ & $100.38 \%$ & $100.31 \%$ & $100.20 \%$ & $99.90 \%$ \\
\hline \multirow{3}{*}{ PEX } & 0.25 & $97.76 \%$ & $98.88 \%$ & $99.57 \%$ & $91.44 \%$ & $92.17 \%$ & $89.66 \%$ & $90.71 \%$ \\
\hline & 2 & $106.75 \%$ & $99.50 \%$ & $99.60 \%$ & $99.99 \%$ & $100.68 \%$ & $100.25 \%$ & $100.07 \%$ \\
\hline & 4 & $73.90 \%$ & $98.92 \%$ & $99.92 \%$ & $100.93 \%$ & $100.34 \%$ & $100.33 \%$ & $100.03 \%$ \\
\hline \multirow{3}{*}{ Both } & 0.25 & $98.07 \%$ & $98.93 \%$ & $99.53 \%$ & $90.68 \%$ & $91.62 \%$ & $88.33 \%$ & $89.90 \%$ \\
\hline & 2 & $98.98 \%$ & $99.32 \%$ & $99.78 \%$ & $100.24 \%$ & $100.59 \%$ & $100.00 \%$ & $99.89 \%$ \\
\hline & 4 & $94.14 \%$ & $99.32 \%$ & $100.10 \%$ & $100.70 \%$ & $100.41 \%$ & $100.30 \%$ & $100.02 \%$ \\
\hline
\end{tabular}

The ultrasonic Manufacturer 1, nutating disc, and oscillating piston meters produced lower accuracies when just the thermal expansion tank was installed in the test setup, compared to other test setups. The electromagnetic meters reported virtually the same accuracy for each test setup.

The results from Table 6 are shown in Figure 13 below. 


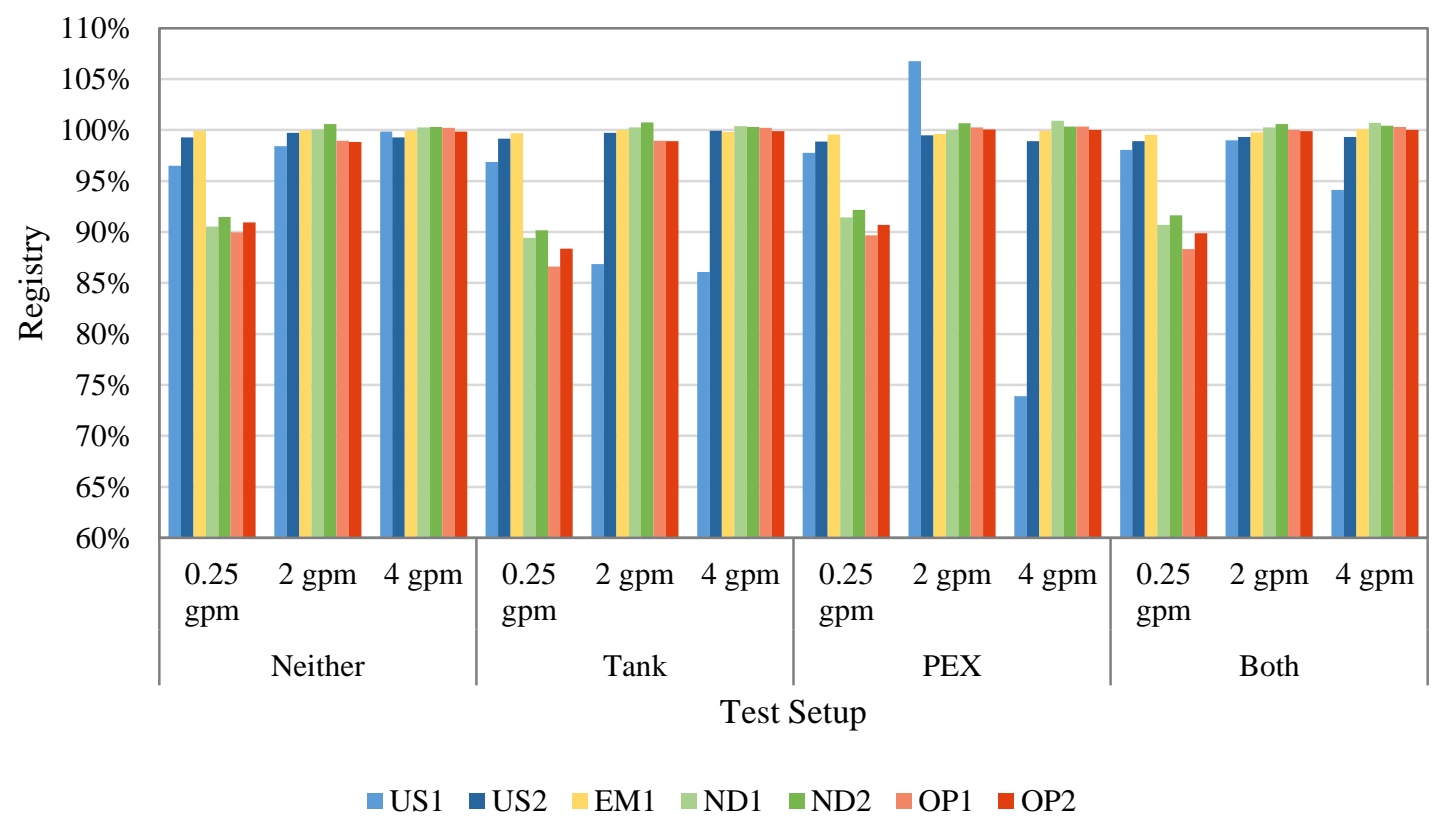

Figure 13. Burst flow results categorized by test setup.

\section{Accuracy by time combination and meter model}

Table 7 shows the average accuracies when comparing time combination and meter model. The values presented in Table 7 are averages of all the tests performed, including all test setups.

Table 7. Accuracy by time combination and meter model.

\begin{tabular}{ccccccccc}
\hline $\begin{array}{c}\text { Time } \\
\text { Comb. }\end{array}$ & $\begin{array}{c}\text { Flow } \\
\text { (gpm) }\end{array}$ & & \multicolumn{7}{c}{ Meter Model } \\
\hline & & US1 & US2 & EM1 & ND1 & ND2 & OP1 & OP2 \\
\hline $0.5 \mathrm{~s}$ & 0.25 & $99.31 \%$ & $101.45 \%$ & $99.36 \%$ & $89.95 \%$ & $89.40 \%$ & $84.62 \%$ & $86.70 \%$ \\
on, 3 s & 2 & $99.41 \%$ & $99.42 \%$ & $100.06 \%$ & $100.38 \%$ & $100.69 \%$ & $99.28 \%$ & $99.16 \%$ \\
off & 4 & $100.92 \%$ & $99.02 \%$ & $99.99 \%$ & $100.69 \%$ & $100.38 \%$ & $100.24 \%$ & $99.85 \%$ \\
\hline \multirow{2}{*}{ 1 s on, } & 0.25 & $97.61 \%$ & $97.56 \%$ & $99.93 \%$ & $91.29 \%$ & $92.19 \%$ & $92.57 \%$ & $92.88 \%$ \\
4 s off & 2 & $99.74 \%$ & $99.57 \%$ & $100.04 \%$ & $100.28 \%$ & $100.68 \%$ & $99.78 \%$ & $99.65 \%$ \\
& 4 & $100.14 \%$ & $99.32 \%$ & $100.31 \%$ & $100.77 \%$ & $100.42 \%$ & $100.32 \%$ & $100.09 \%$ \\
\hline \multirow{2}{*}{ 1 s on, } & 0.25 & $94.98 \%$ & $98.18 \%$ & $99.74 \%$ & $90.30 \%$ & $92.49 \%$ & $88.72 \%$ & $90.36 \%$ \\
3 s off & 2 & $94.09 \%$ & $99.69 \%$ & $99.42 \%$ & $99.77 \%$ & $100.58 \%$ & $99.53 \%$ & $99.47 \%$ \\
& 4 & $64.42 \%$ & $99.73 \%$ & $99.53 \%$ & $100.23 \%$ & $100.23 \%$ & $100.24 \%$ & $99.93 \%$
\end{tabular}


The results from Table 7 are shown in Figure 14.

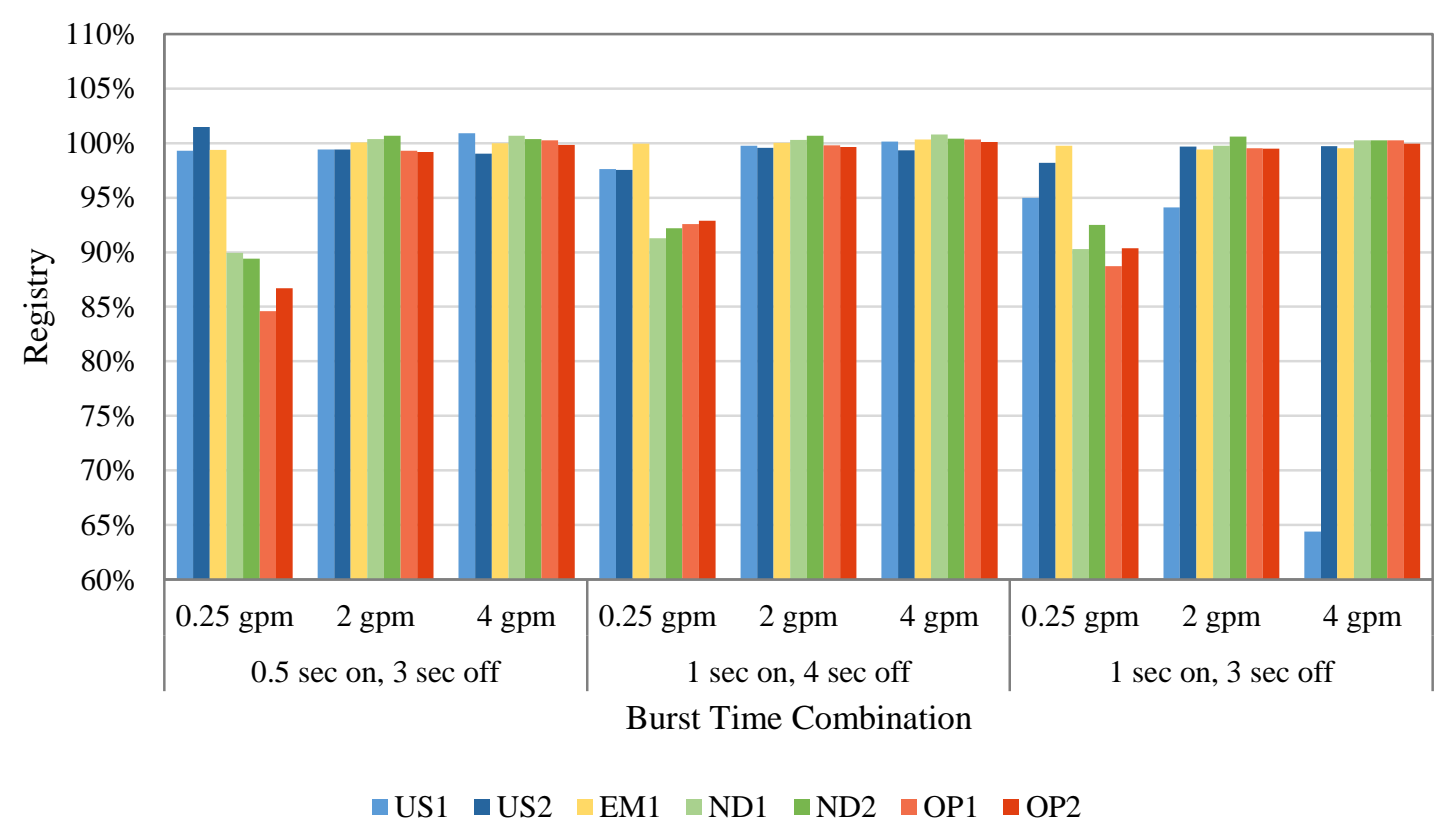

Figure 14. Burst flow results categorized by burst time combination. 


\section{CHAPTER V}

\section{DATA ANALYSIS AND DISCUSSION}

The test results show that the various meter types responded differently to the variety of test setups, time combinations, and flow rates.

The ultrasonic Manufacturer 1 meters saw a lower accuracy for each burst flow when compared to the continuous flow results, as seen in Figure 9.

Clearly, sampling rates of ultrasonic meters have an effect on accuracy. Because multiple meters of each ultrasonic model were used, multiple sampling rates occurring at different times recorded different portions of the burst flow cycle. For example, for test 14 in Table 8 in Appendix B, two of the ultrasonic meters each registered over 150\% throughput, while the other four meters each registered under $40 \%$ throughput (with two of those meters registering less than 3\% throughput). The average registry for the six ultrasonic meters for the test was $61.43 \%$. Even though the meters were of the same meter type, because their sampling rates occurred at different times, significantly different throughputs were recorded by each meter.

It appears that intermittent or burst flows may frequently be misread by ultrasonic meters. One possible scenario is that a burst flow will occur between ultrasonic waves emitted by the transducers, causing the meter to not collect the meter reading at all (or to record a very low registry). This case can be seen for the last data point for the ultrasonic Manufacturer 1 meter type in Figure 15 (also reported as Figure 39 in Appendix A), where the meters registered an average of just over $20 \%$ of the actual throughput recorded.

Conversely, the second possible scenario is that an ultrasonic wave generated by 


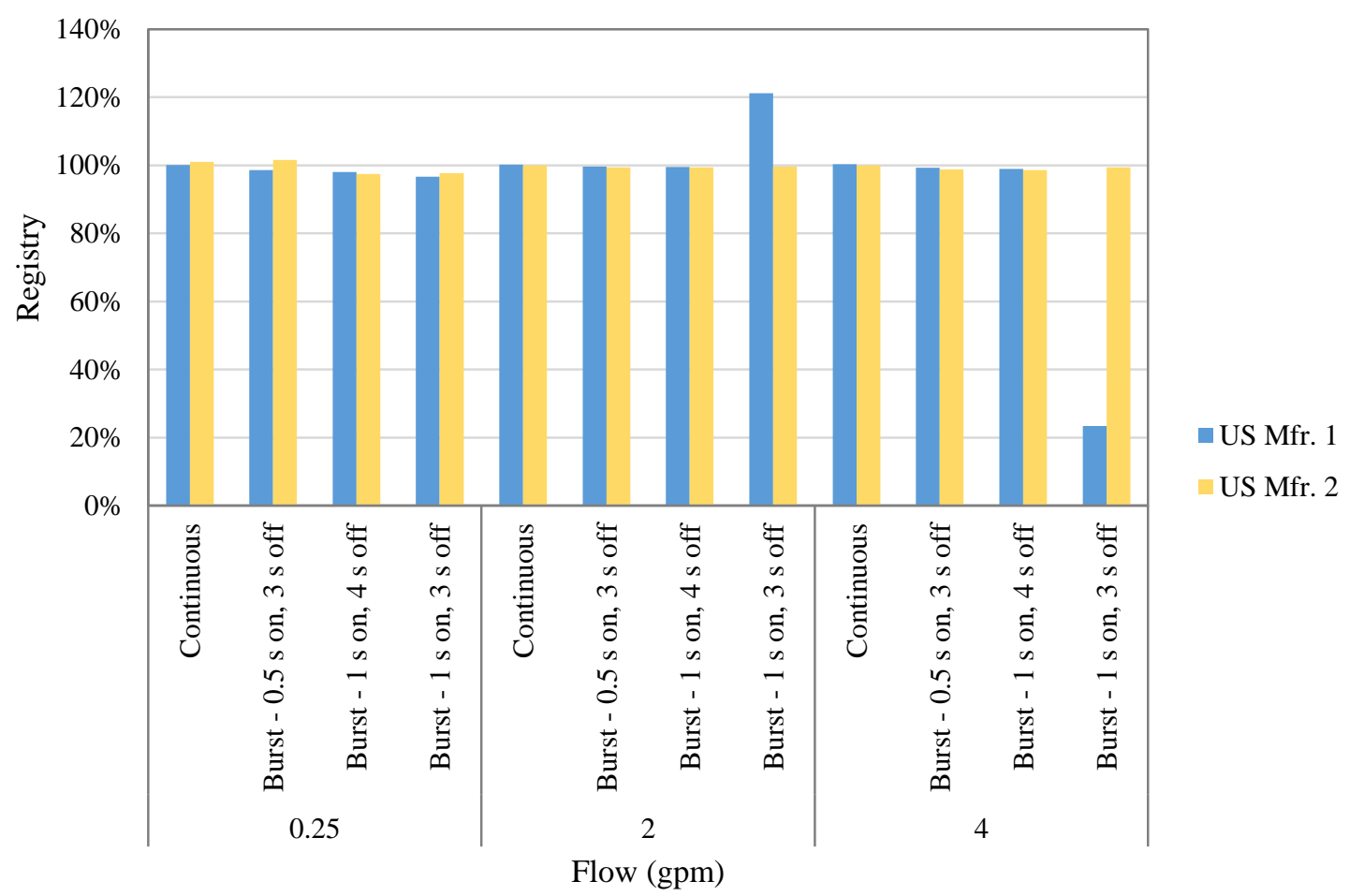

Figure 15. Average accuracy of ultrasonic meters in continuous and burst (PEX tubing) conditions.

the transducers will occur when a burst is occurring, but will not record the absence of flow immediately before and after the burst flow occurred. Depending on the length of the burst flow and the meter's sampling rate, the meter could report a significantly higher flow than actually occurred. This scenario is not as likely to occur as the first, because multiple burst flows in a short amount of time will not occur as often as a single burst flow. However, this scenario was also seen in the test results for the ultrasonic meters, as highlighted by the eighth meter of Manufacturer 1 in Figure 15. An ultrasonic meter's reading of the random occurrence of burst flows is hard to predict, but it can be seen from the results that burst flows will affect an ultrasonic meter's accuracy.

Overall, the electromagnetic meters saw almost no change in accuracy (see Figure 
$10)$.

Both the nutating disc and oscillating piston meter types saw decreased accuracy for the 0.25-gpm burst flow, but generally the same accuracy for the 2- and 4-gpm burst flows (see Figure 11 and Figure 12). As an example, Figure 16 (also reported as Figure 22 in Appendix A) shows the negative effects of burst flows at the 0.25-gpm flow rate for oscillating piston meters.

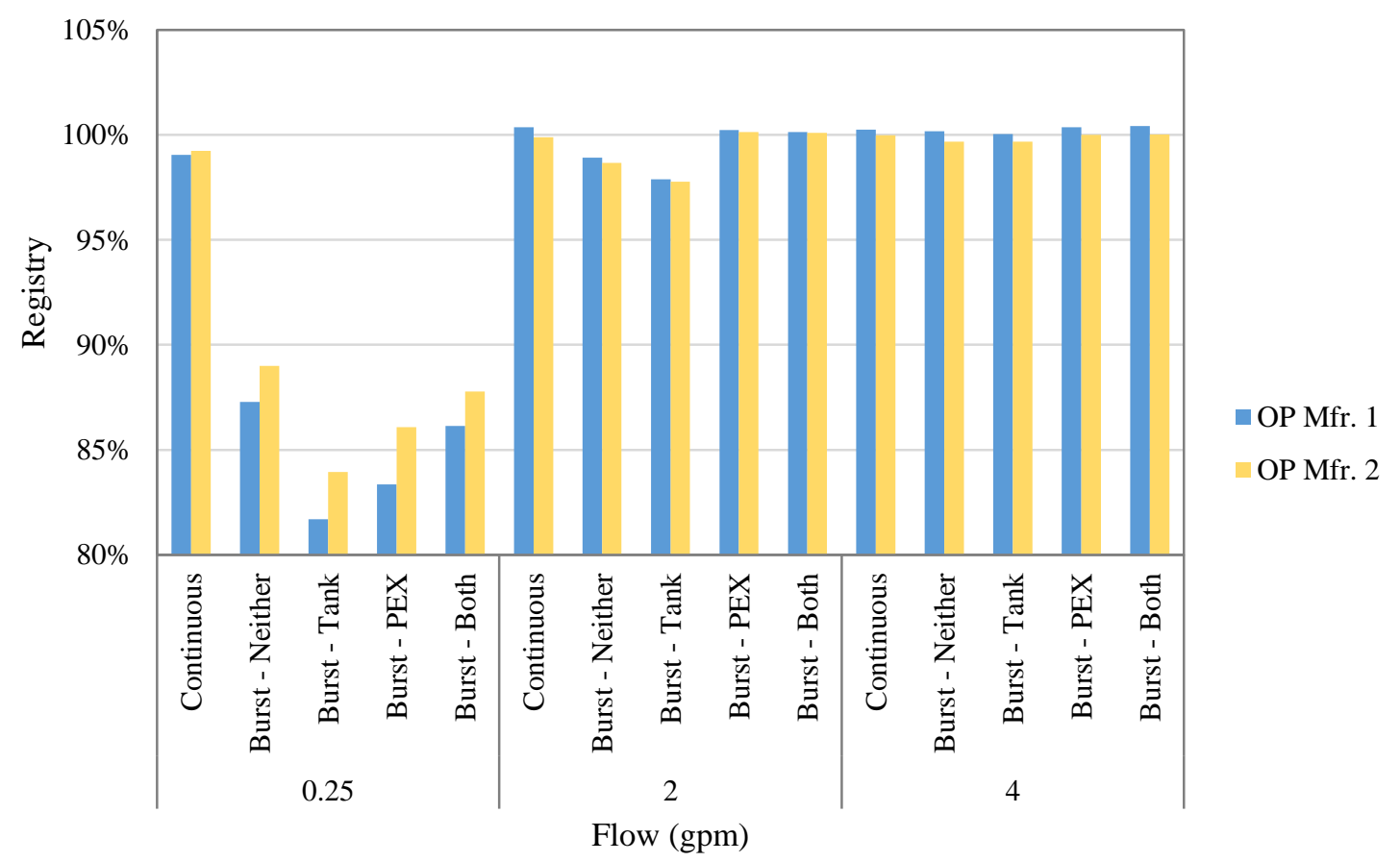

Figure 16. Average accuracy of oscillating piston meters in continuous and burst $(1 / 2$ second on, 3 seconds off) conditions.

It is interesting to note the decreased accuracies experienced by the mechanical meters for the burst flow tests at $0.25 \mathrm{gpm}$. For continuous flow tests, a previous study noted the adverse effects of low flows on mechanical meters. "As flow rates become smaller and smaller, the bearing, friction and drag forces within the metering mechanism 
become proportionally larger" (Barfuss, Johnson, and Neilsen, 2011). Not only are those forces proportionally larger for low flows when water has already begun to flow, but the force required to overcome the inertia of a disc at rest in nutating disc meters or a piston at rest in oscillating piston meters is also thought to be proportionally larger and must be overcome to allow flow to begin. In a continuous flow, the force required to begin moving the mechanical parts of a meter must only overcome static friction forces once. However, every burst flow that occurs requires the repeated overcoming of static friction forces. (Generally, static friction forces are higher than kinetic friction forces.) Since each test for this study included multiple bursts (see Table 4), the negative effects caused by the disproportionality of low flow rates to static friction forces possibly compounded the meters' decreased ability to correctly record the throughput.

Since electronic meters have no moving parts, they are generally able to register lower flows with greater accuracy (see the continuous flow results from Figure 5 to Figure 8).

A major limitation of this study was the small number of flows and time combinations used. Test flows were selected to represent ideal burst flows, although both larger and smaller flows could have been tested. Any number of time combinations could have also been selected. Time combinations were necessary to transform a real-world situation into a testing scenario.

Among the ultrasonic meters, Manufacturer 1 presented results that were much more varied than Manufacturer 2. For example, in Figure 17 (also reported as Figure 27 in Appendix A) it can be seen that Manufacturer 1 reported registries ranging from $23.47 \%$ to $121.14 \%$. Under the same scenario, Manufacturer 2 reported registries ranging 
from $97.69 \%$ to $100.96 \%$.

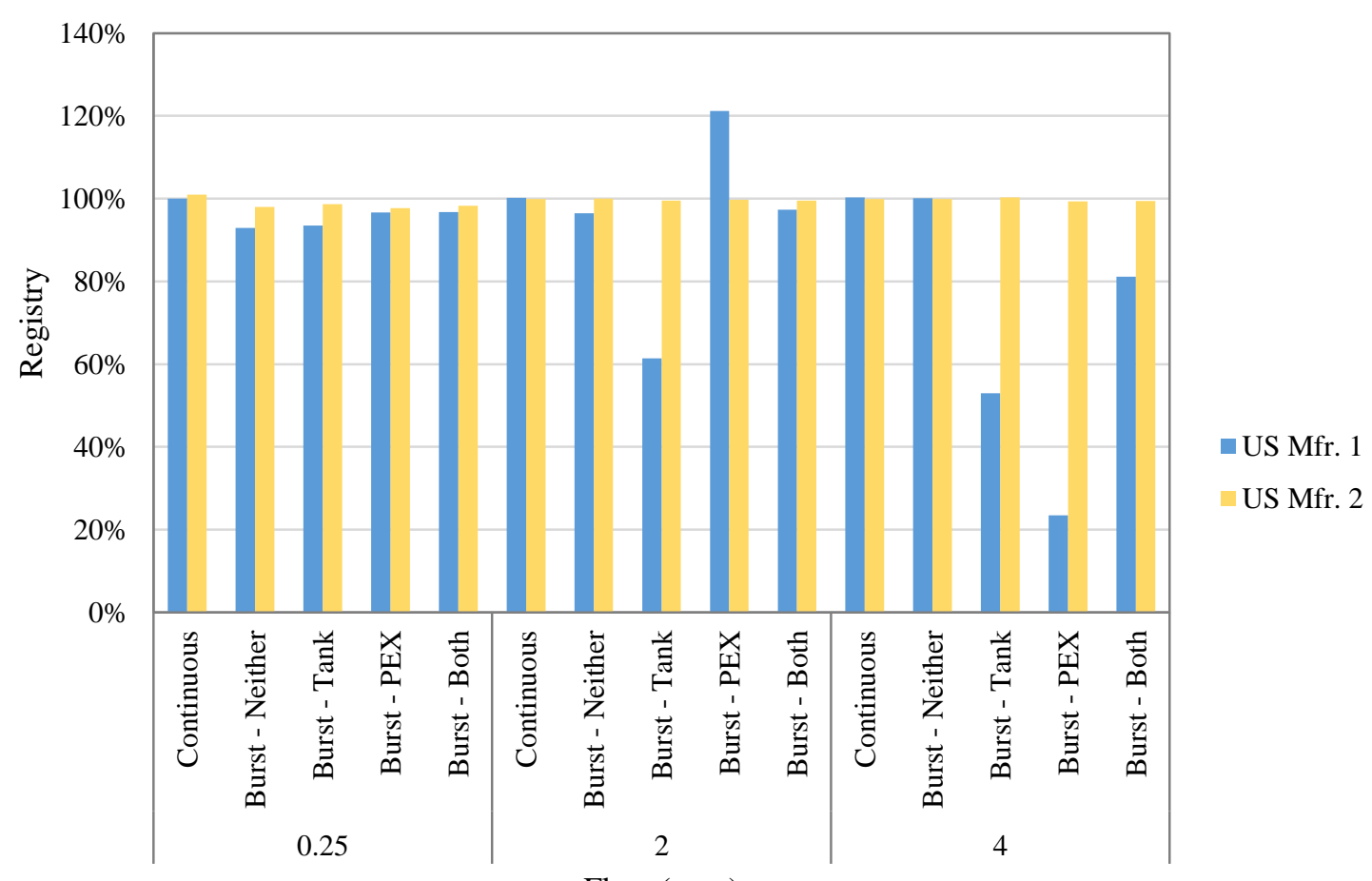

Flow (gpm)

Figure 17. Average accuracy of ultrasonic meters in continuous and burst (1 second on, 3 seconds off) conditions.

Ultrasonic Manufacturer 1 also produced lower accuracies for certain time combinations. Specifically, when the time combination was one second on and three seconds off, Manufacturer 1 had much more varied results than Manufacturer 2. Samples of the varied results for the one second on, three seconds off time combination are found for all test setups in Figure 31, Figure 35, Figure 39, and Figure 43 of Appendix A. Figure 35 is also shown below as Figure 18.

Among all the electromagnetic meter data points collected, the minimum registry recorded was $97.55 \%$ and the maximum registry recorded was $102.38 \%$ (see

Table 10 in Appendix B). This tight range shows that, while burst flows did affect 


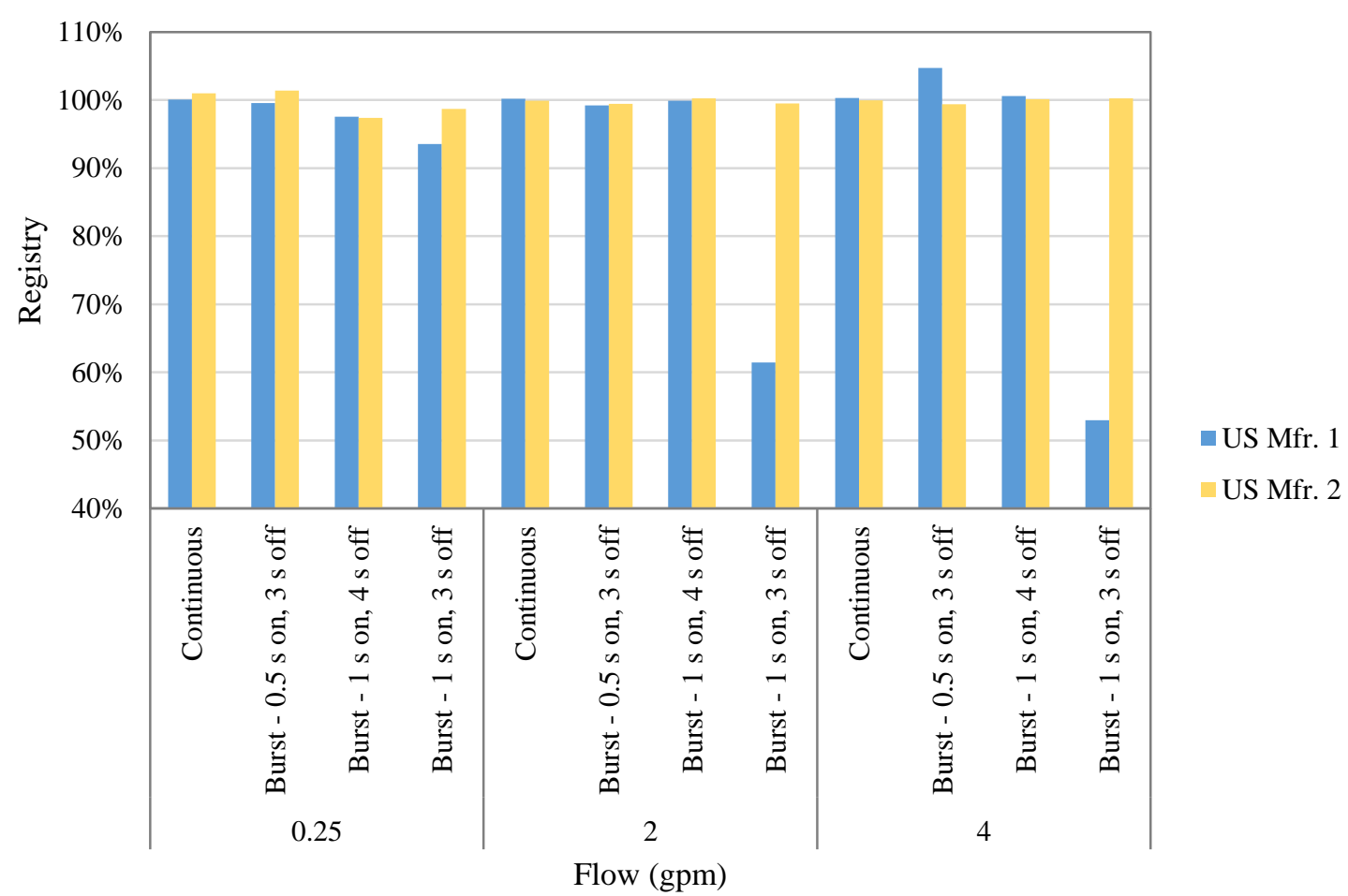

Figure 18. Average accuracy of ultrasonic meters in continuous and burst (thermal expansion tank) conditions.

electromagnetic meters, the effects were relatively small.

The maximum registries for each of the two nutating disc meter types and each of the two oscillating piston meter types was each below 102\% (see Table 11 through Table 14 in Appendix B). The minimum readings for each of the mechanical meter types was between $68.51 \%$ (oscillating piston Manufacturer 1) and $78.40 \%$ (nutating disc Manufacturer 1). It can be seen that for burst flows, mechanical meters generally underregister, rather than over-register. 
CHAPTER VI

\section{CONCLUSION AND FURTHER RESEARCH}

Water meters must be capable of measuring throughput in a variety of circumstances. The purpose of this thesis was to compare accuracies of different residential water meter types in response to short, intermittent flows.

Both mechanical and electronic water meters were tested for this study. Ultrasonic, electromagnetic, nutating disc, and oscillating piston meters were used.

Meters were tested under different scenarios that simulated typical household systems. Standard PVC pipe was used as a baseline in half of the tests to simulate copper tubing, commonly found in homes. Alternatively, PEX tubing was added in the other half of the tests to simulate households that have PEX tubing systems. For half of each of the tests for the different tubing setups, a thermal expansion tank was included. For the other half of testing, the thermal expansion tank was not included. This resulted in four testing scenarios noted in the study as: Neither, PEX, Tank, and Both.

One of the ultrasonic models was found to be more affected by burst flows than the other ultrasonic model. Electromagnetic meters showed no change in accuracy due to burst flows. Mechanical meter types (oscillating piston and nutating disc) showed decreased accuracies for burst flows at the lowest flow, but generally the same accuracies for the higher two flows when compared to the continuous flow tests.

It is the recommendation of the author to conduct further research concerning intermittent and burst flows with higher flow rates and different time combinations as wells as other metering types and models to see if those results are found to be consistent with the results found in this study. 


\section{REFERENCES}

Al-Hoqani, N., and S. H. Yang. 2015. Adaptive sampling for wireless household water consumption monitoring. Procedia Engineering, 119: 1356-1365.

Anderson, J. S., and Watson, K. S. 1967. Patterns of Household Water Usage. Journal AWWA, 59(10): 1228-1237.

Aquacraft. 2005. Water and Energy Savings from High Efficiency Fixtures and Appliances in Single Family Homes. Aquacraft.

AWWA. 2012. Water Meters—Selection, Installation, Testing, and Maintenance, Manual of Water Supply Practices M6 ( $5^{\text {th }}$ edition). AWWA, Denver.

Barfuss, S. L., M. C. Johnson, and M. A. Neilsen. 2011. Accuracy of In-Service Water Meters at Low and High Flow Rates. Water Research Foundation.

Britton, T., G. Cole, R. Stewart, and D Wiskar. 2008. Remote diagnosis of leakage in residential households. Water, 2008(7): 56-60.

Cole, G., and R. A. Stewart. 2013. Smart meter enabled disaggregation of urban peak water demand: precursor to effective urban water planning. Urban Water Journal, 10(3): 174-194.

Creaco, E., R. Farmani, L. Vamvakeridou-Lyroudia, S. G. Buchberger, Z. Kapelan, and D. A. Savić. 2015. Correlation or not correlation? This is the question in modelling residential water demand pulses. Procedia Engineering, 119: 1455-1462.

DeOreo, W. B. 2011. Analysis of Water Use in New Single-Family Homes. Aquacraft.

DeOreo, W. B., P. W. Mayer, B. Dziegielewski, and J. Kiefer. 2016. Residential End Uses of Water, Version 2. Water Research Foundation.

DeOreo, W. B., P. W. Mayer, L. Martien, M. Hayden, A. Funk, M. Kramer-Duffield, and R. Davis. 2011. California SF Water Use Efficiency Study. Aquacraft.

Gan, K., and M. Redhead. 2013. Melbourne Residential Water Use Studies. Yarra Valley Water.

Hudson, W. D. 1978. Increasing Water System Efficiency Through Control of Unaccounted-for Water. Journal AWWA, 70(7): 362-365.

Janković-Nišić, B., Č. Maksimović, D. Butler, and N. J. D. Graham. 2004. Use of Flow Meters for Managing Water Supply Networks. Journal of Water Resources Planning and 
Management, 130(2): 171-179.

Larson, B. O., and Hudson, H. E., Jr. 1951. Residential Water Use and Family Income. Journal AWWA, 43(8).

Noss, R. R., G. J. Newman, and J. W. Male. 1987. Optimal Testing Frequency for Domestic Water Meters. Journal of Water Resources Planning and Management, 113(1): $1-14$.

Roberts, P. 2005. Residential End Use Measurement Study. Yarra Valley Water. 
APPENDICES 
APPENDIX A: Comparison of Continuous and Burst Flows 
Accuracy of meters as a function of flow and test setup

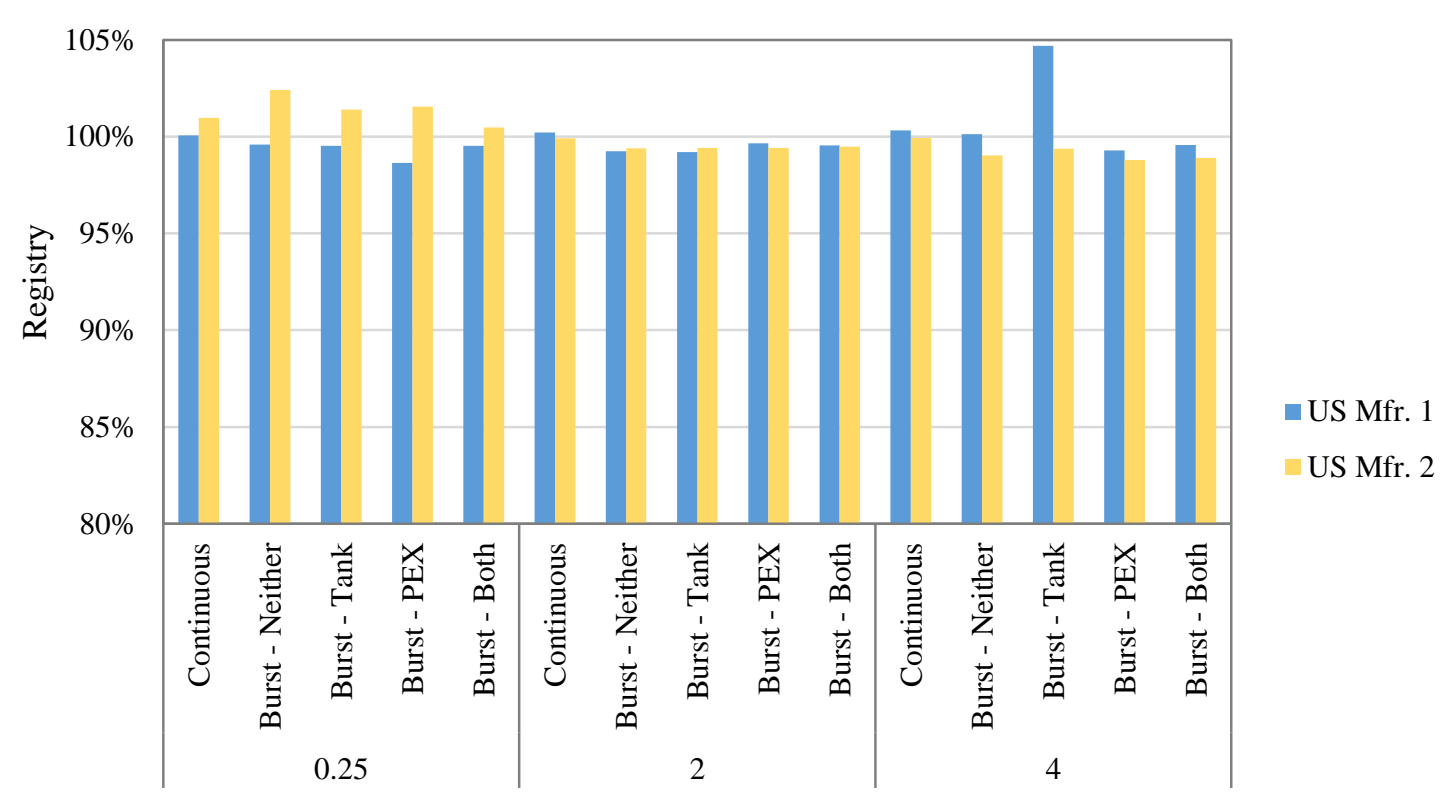

Flow (gpm)

Figure 19. Average accuracy of ultrasonic meters in continuous and burst (1/2 second on, 3 seconds off) conditions.

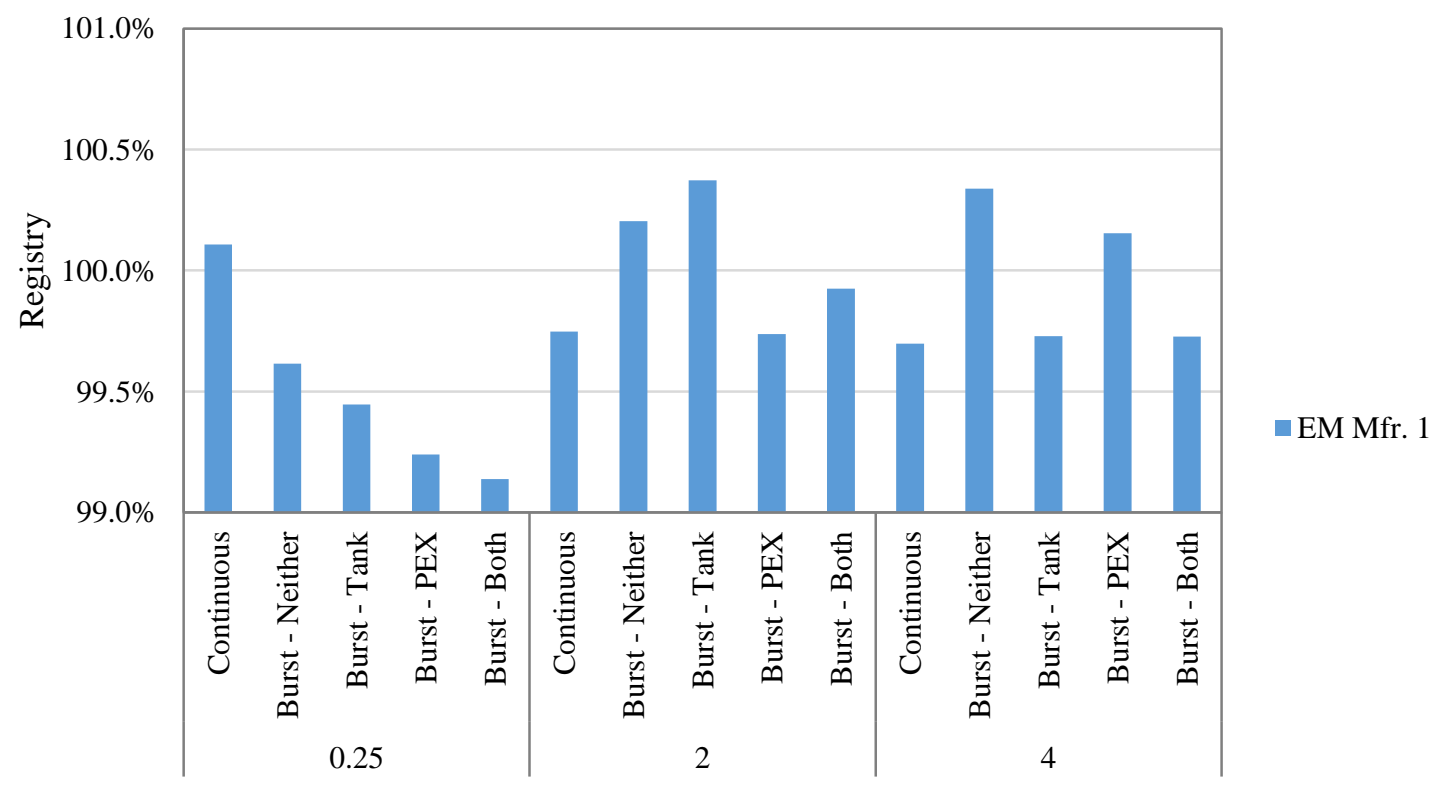

Flow (gpm)

Figure 20. Average accuracy of electromagnetic meters in continuous and burst (1/2 second on, 3 seconds off) conditions. 


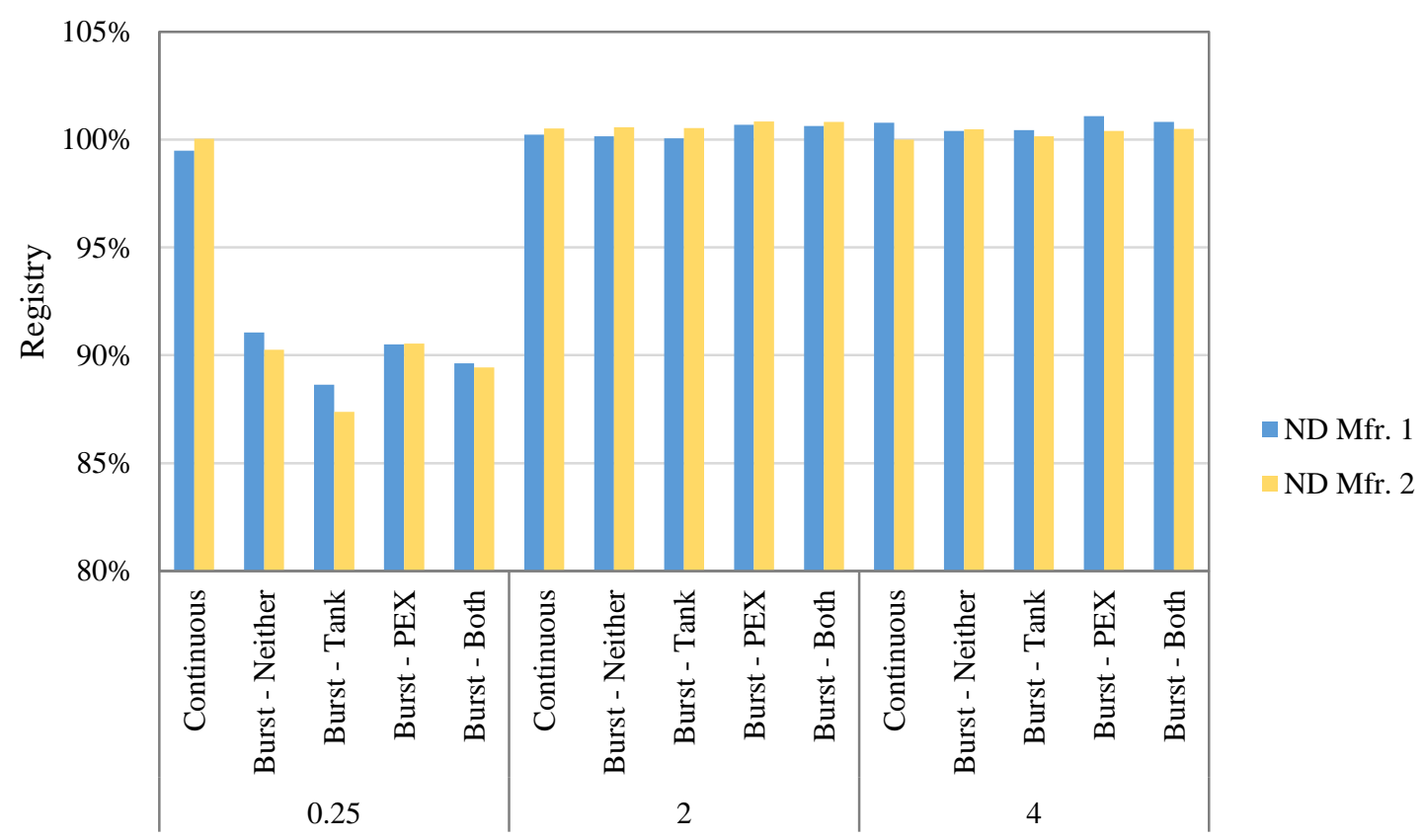

Flow (gpm)

Figure 21. Average accuracy of nutating disc meters in continuous and burst (1/2 second on, 3 seconds off) conditions.

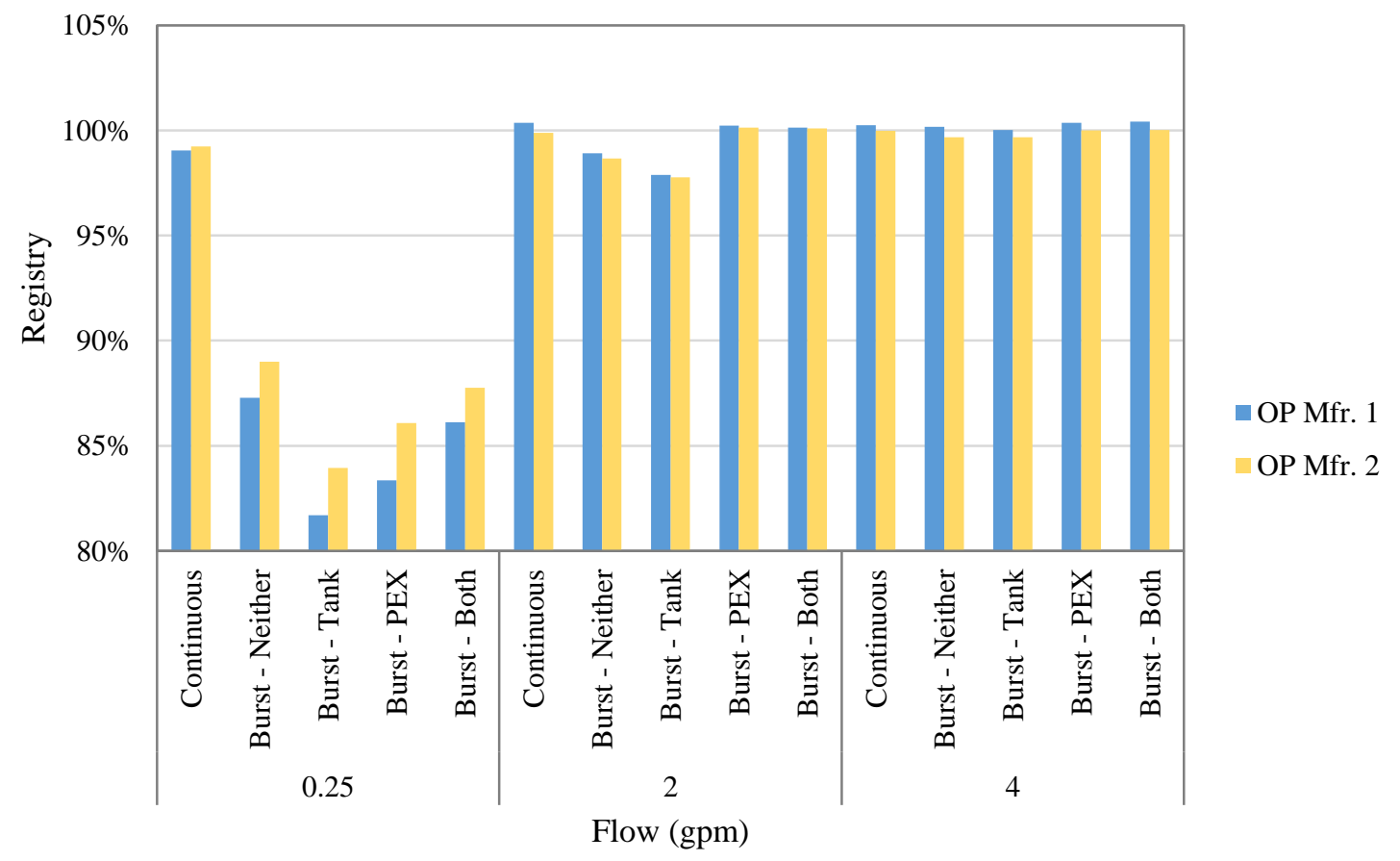

Figure 22. Average accuracy of oscillating piston meters in continuous and burst (1/2 second on, 3 seconds off) conditions. 


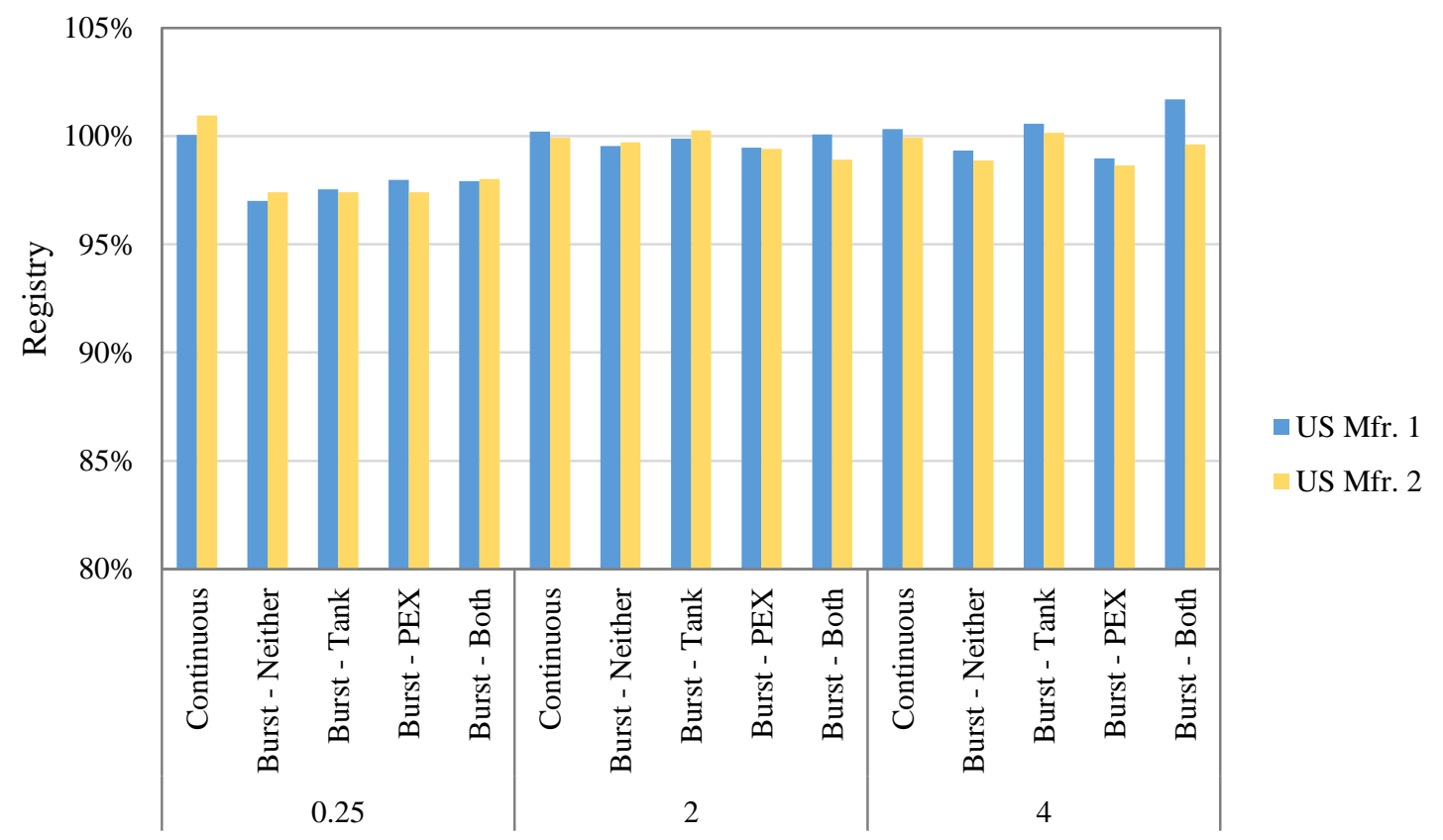

Flow (gpm)

Figure 23. Average accuracy of ultrasonic meters in continuous and burst ( 1 second on, 4 seconds off) conditions.

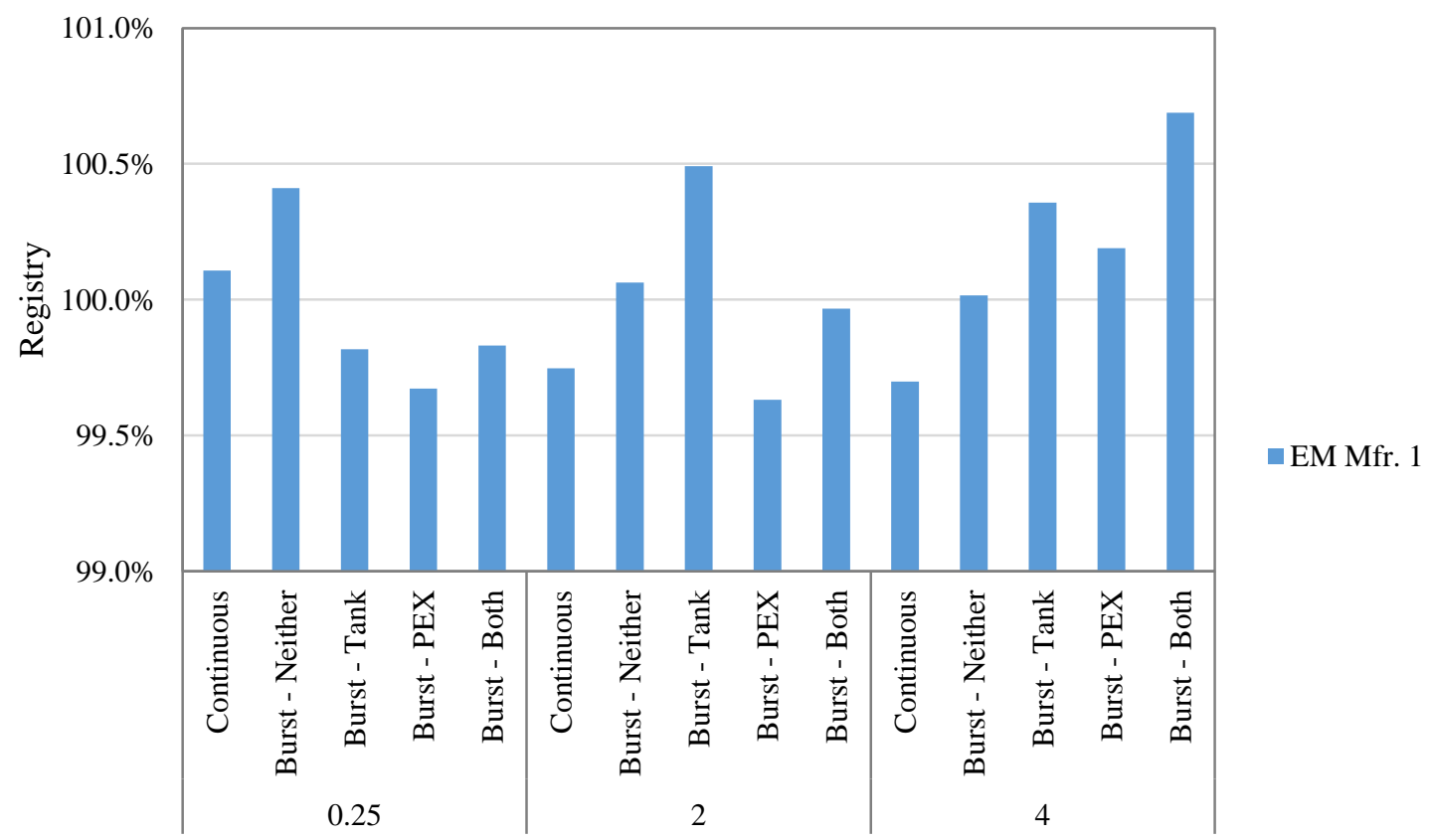

Flow (gpm)

Figure 24. Average accuracy of electromagnetic meters in continuous and burst (1 second on, 4 seconds off) conditions. 


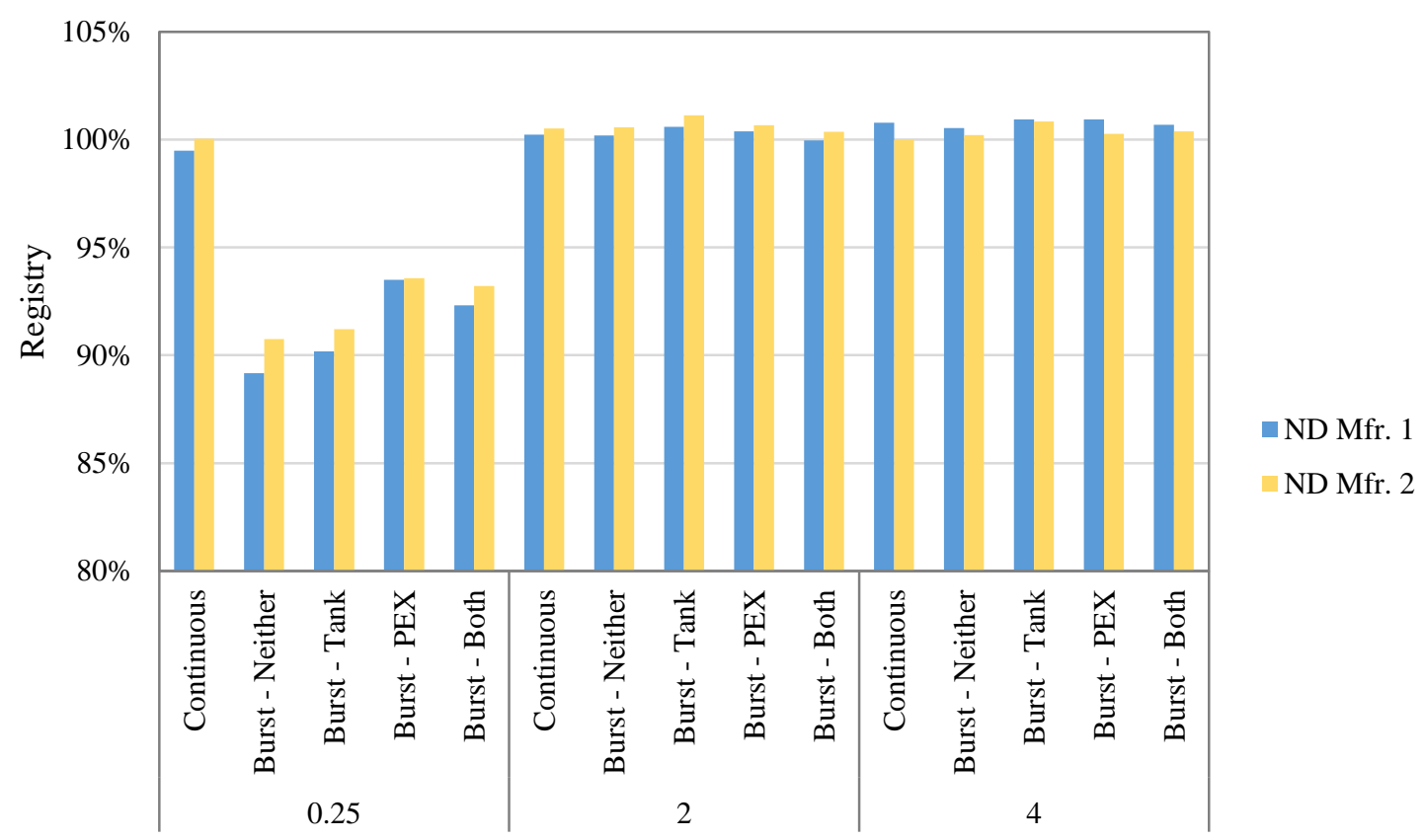

Flow (gpm)

Figure 25. Average accuracy of nutating disc meters in continuous and burst (1 second on, 4 seconds off) conditions.

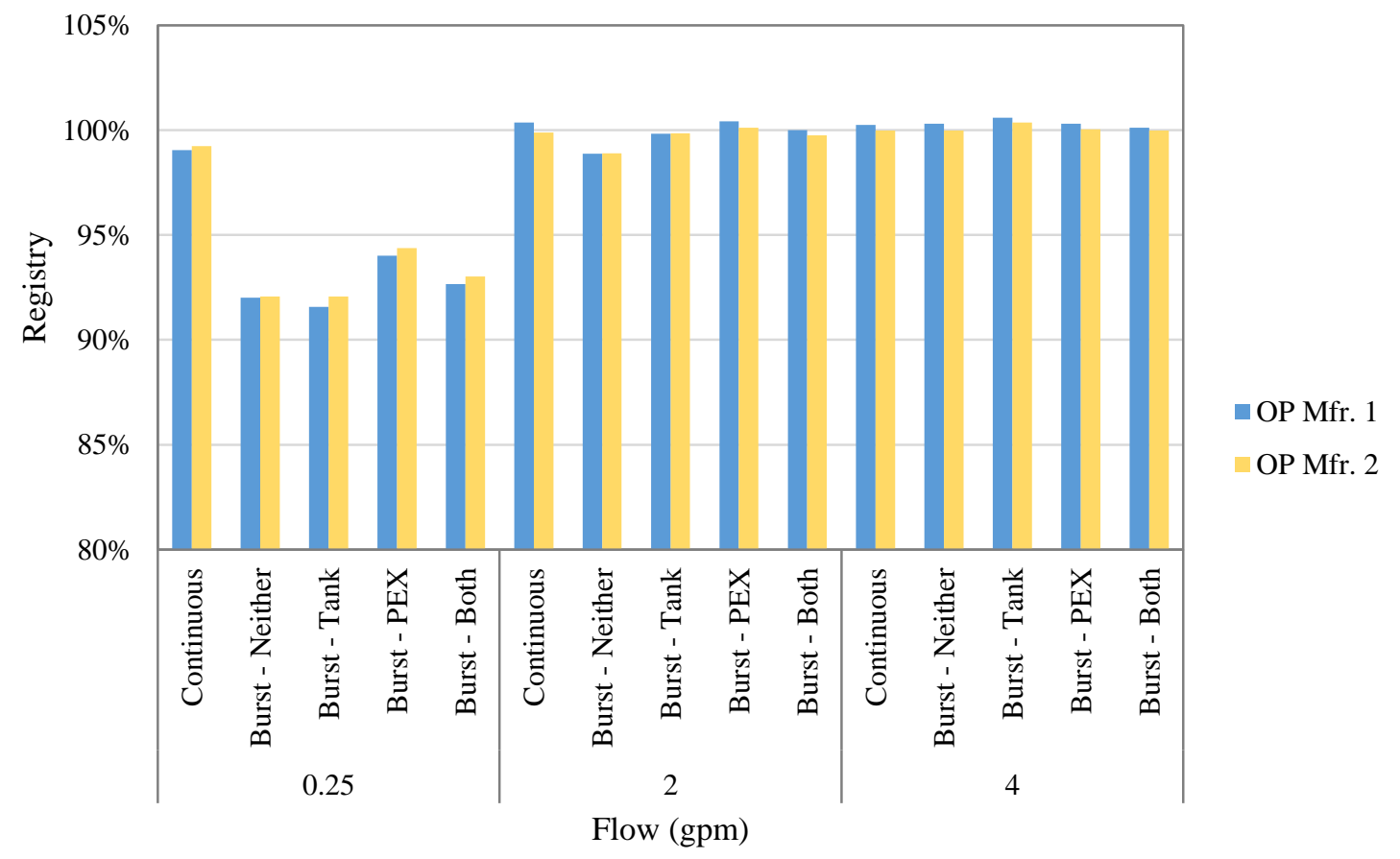

Figure 26. Average accuracy of oscillating piston meters in continuous and burst (1 second on, 4 seconds off) conditions. 


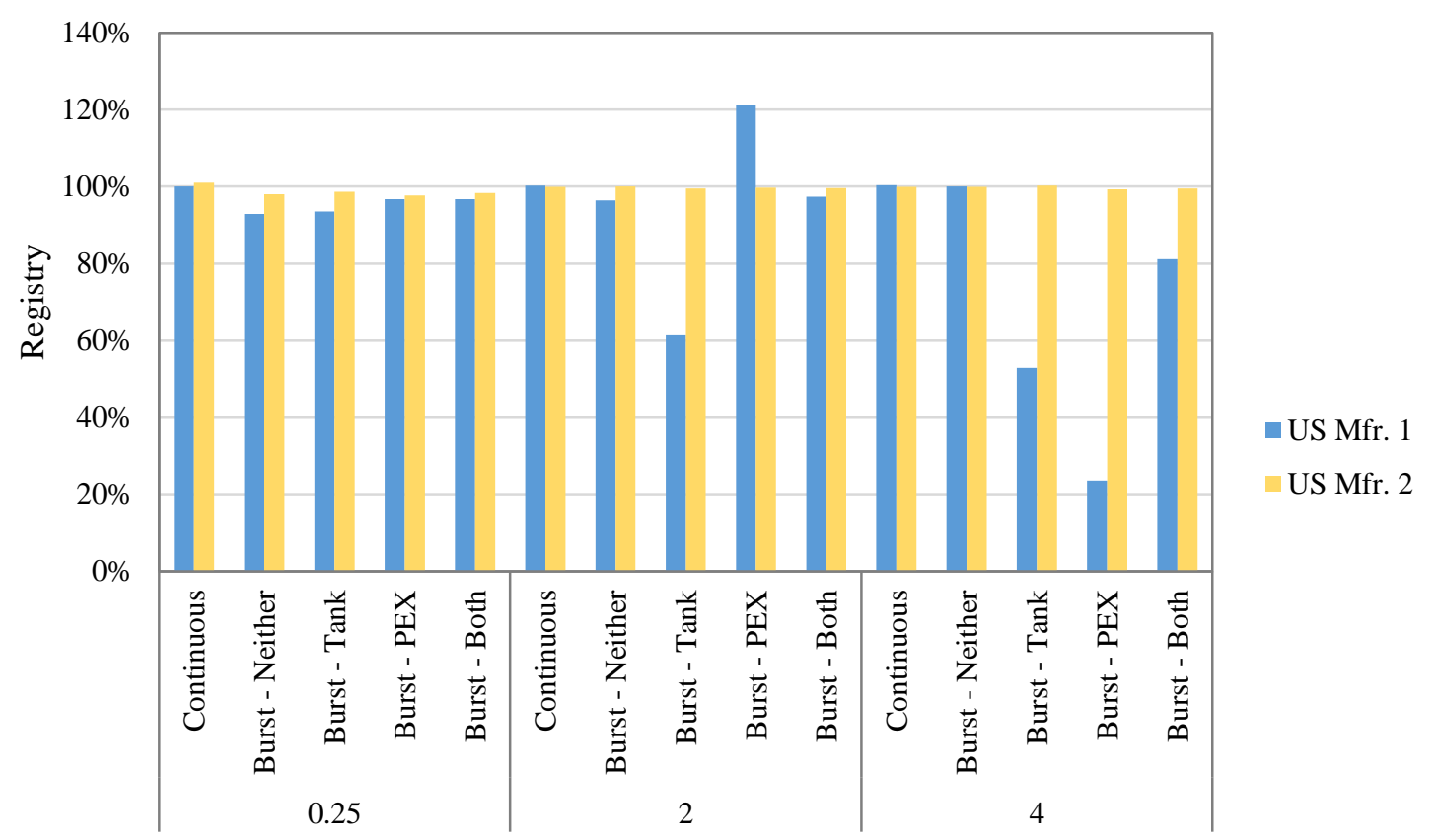

Flow (gpm)

Figure 27. Average accuracy of ultrasonic meters in continuous and burst ( 1 second on, 3 seconds off) conditions.

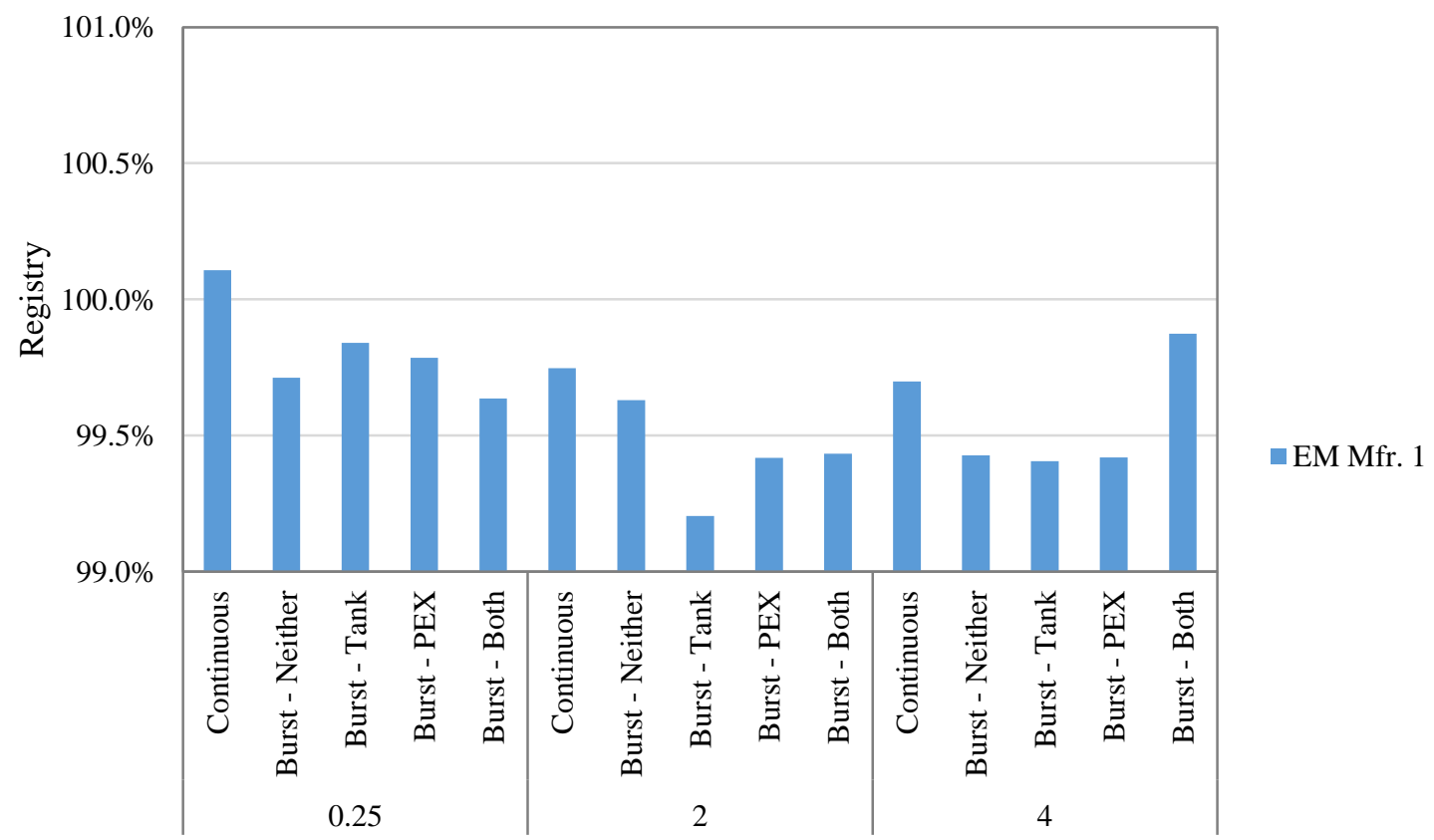

Flow (gpm)

Figure 28. Average accuracy of electromagnetic meters in continuous and burst (1 second on, 3 seconds off) conditions. 


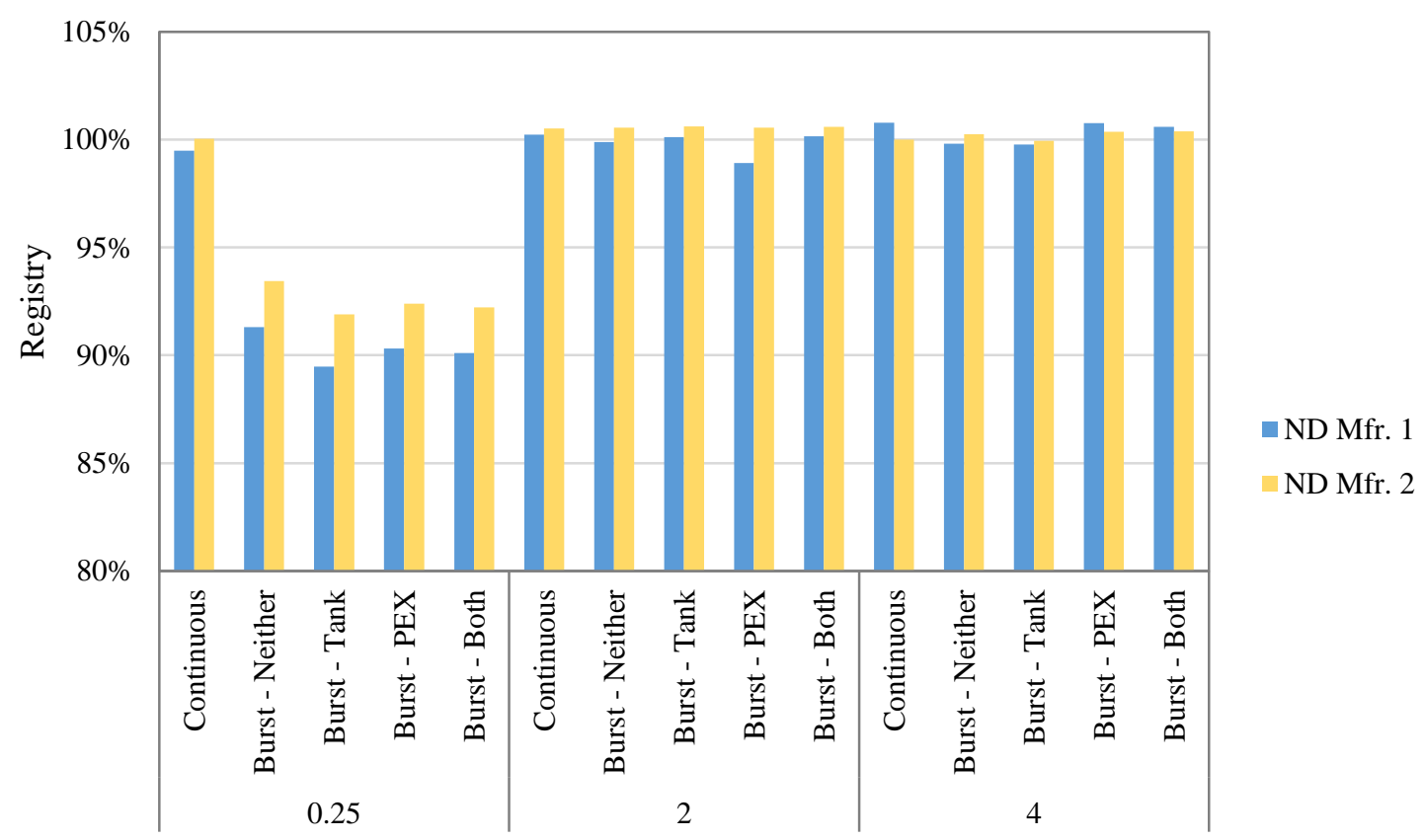

Flow (gpm)

Figure 29. Average accuracy of nutating disc meters in continuous and burst (1 second on, 3 seconds off) conditions.

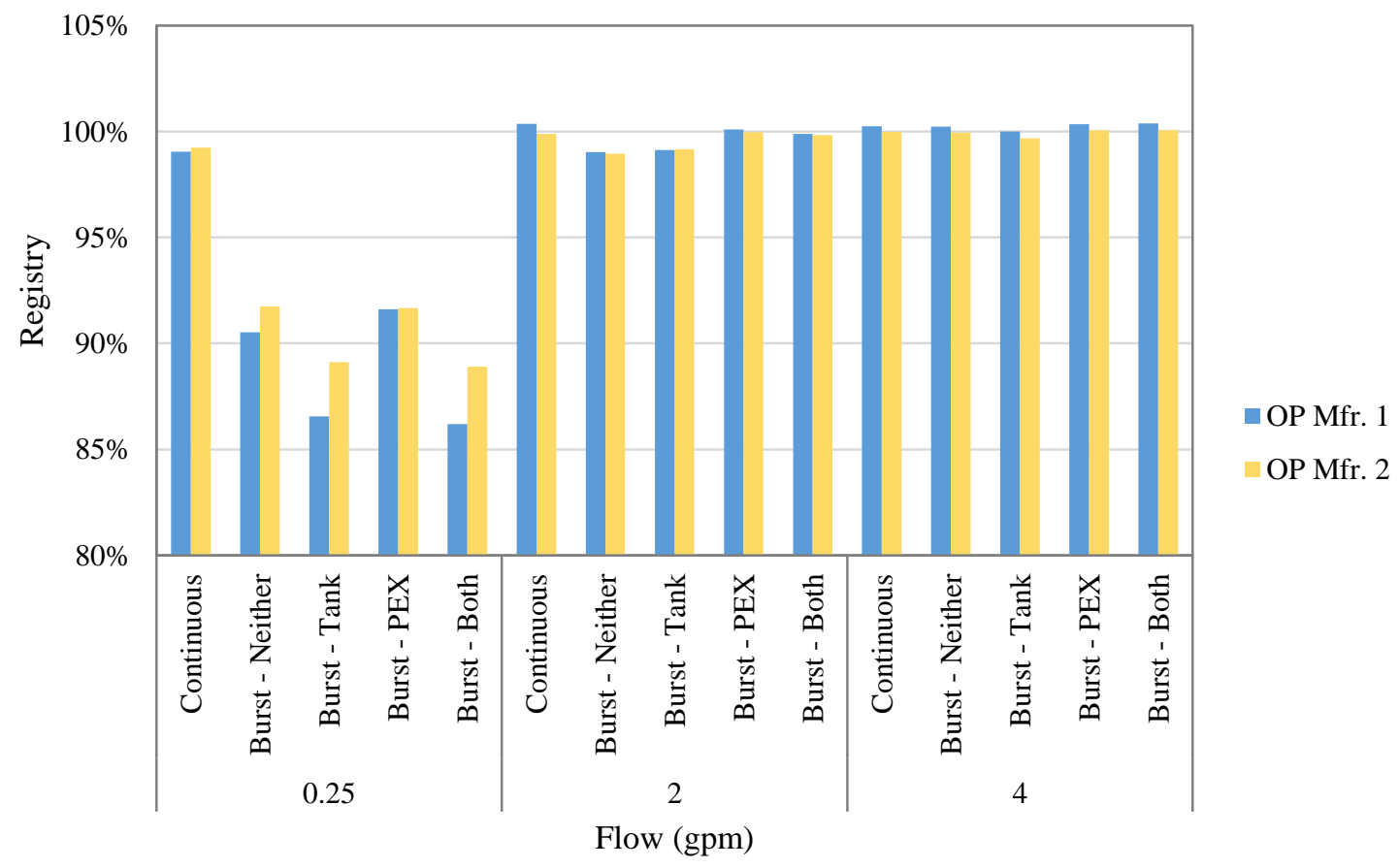

Figure 30. Average accuracy of oscillating piston meters in continuous and burst (1 second on, 3 seconds off) conditions. 


\section{Accuracy of meters as a function of flow and burst time combination}

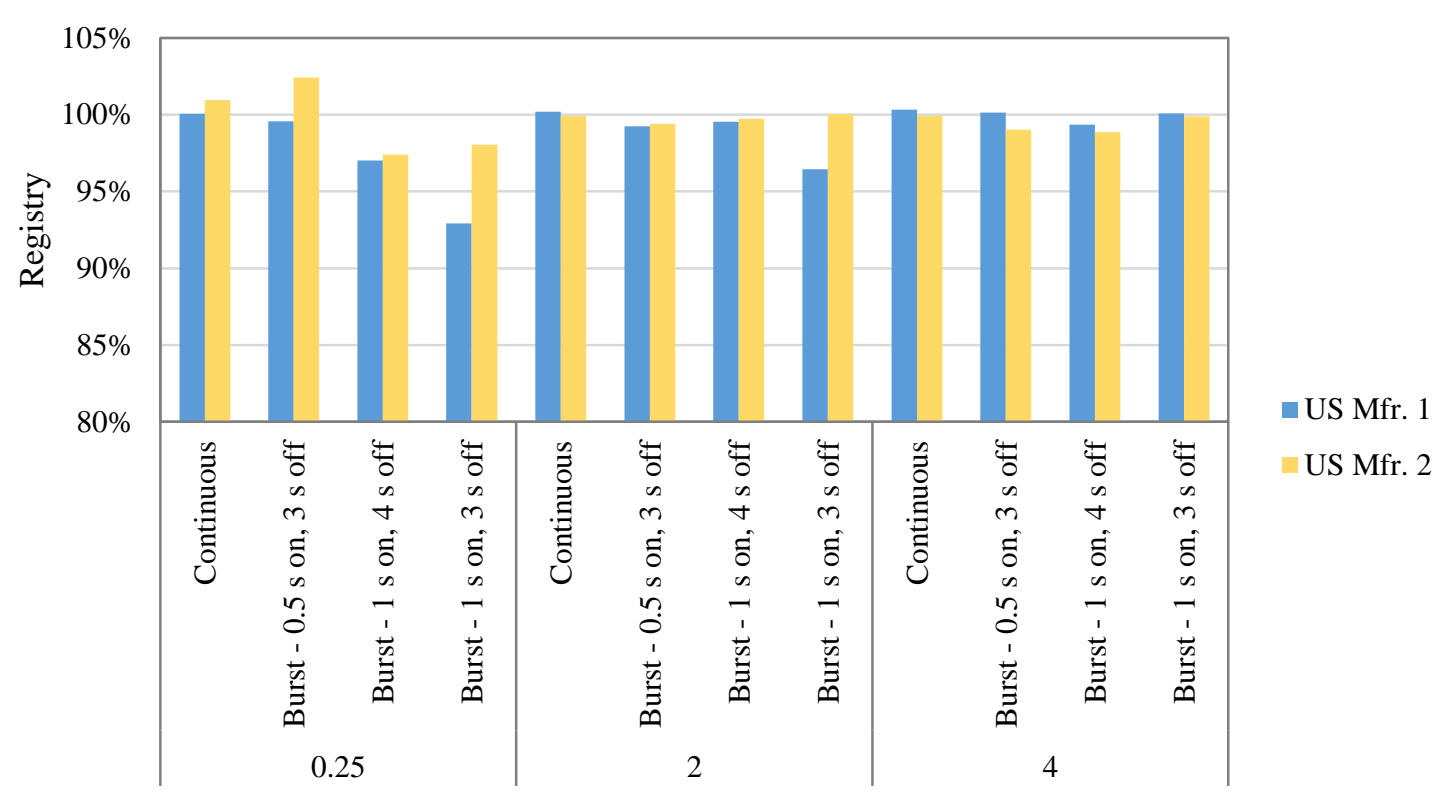

Flow (gpm)

Figure 31. Average accuracy of ultrasonic meters in continuous and burst (neither thermal expansion tank nor PEX tubing) conditions.

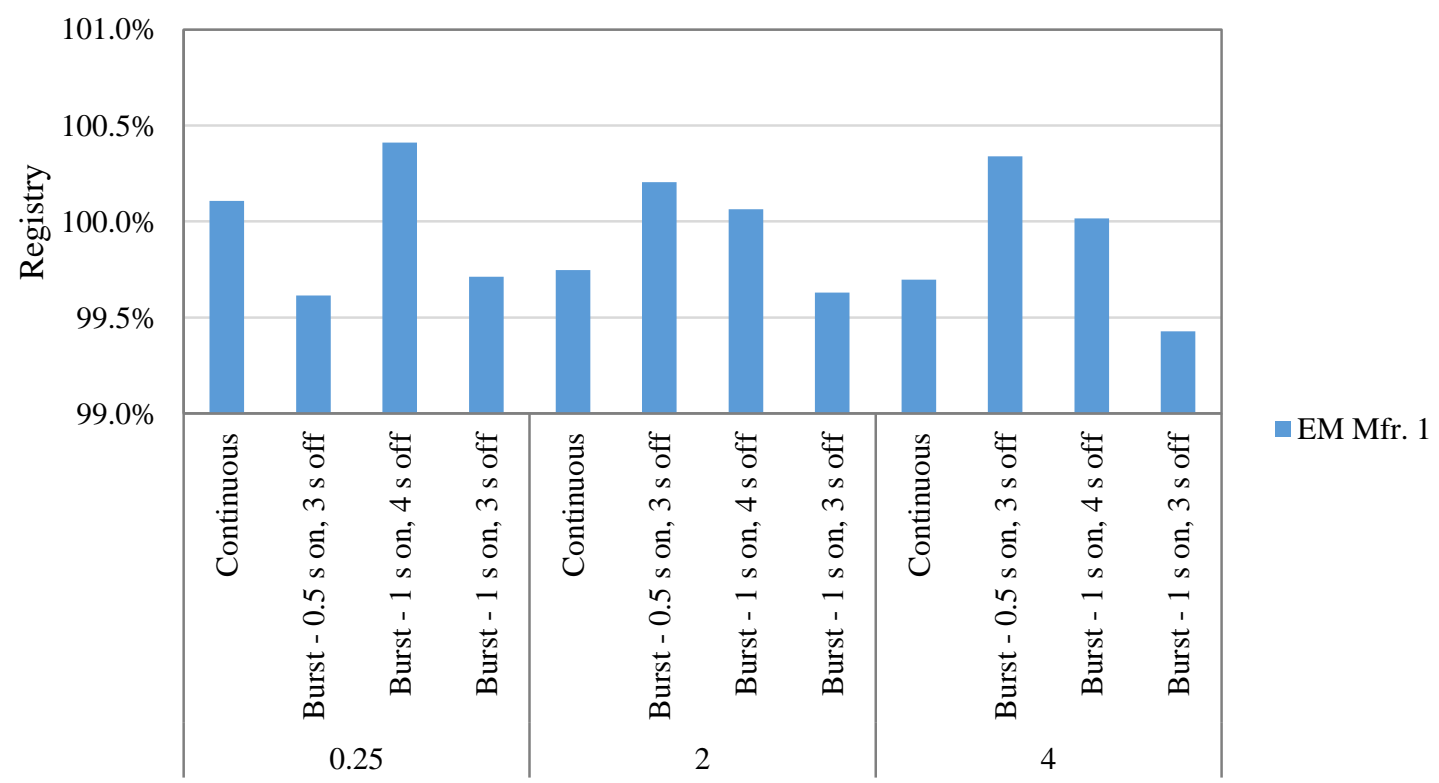

Flow (gpm)

Figure 32. Average accuracy of electromagnetic meters in continuous and burst (neither thermal expansion tank nor PEX tubing) conditions. 


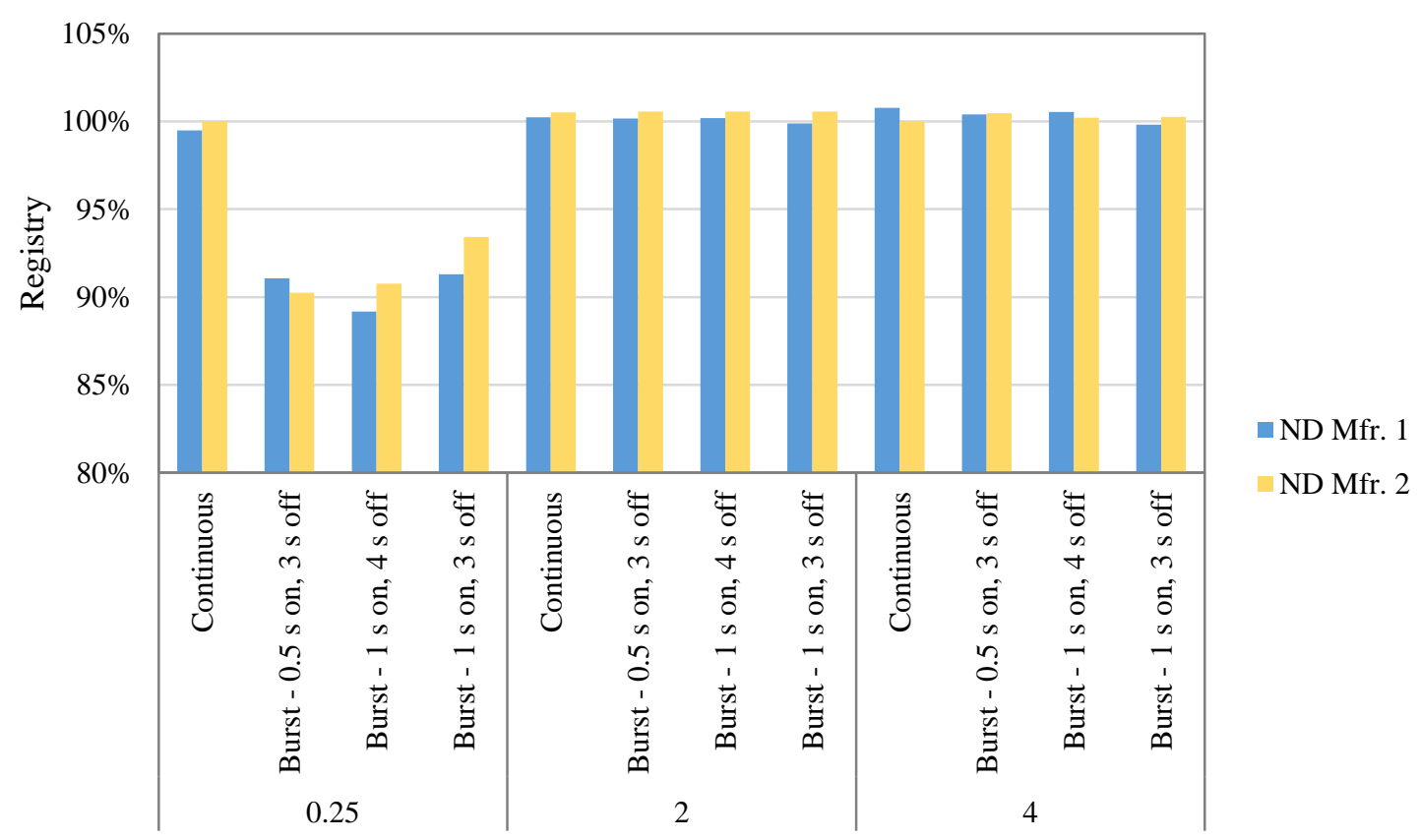

Flow (gpm)

Figure 33. Average accuracy of nutating disc meters in continuous and burst (neither thermal expansion tank nor PEX tubing) conditions.

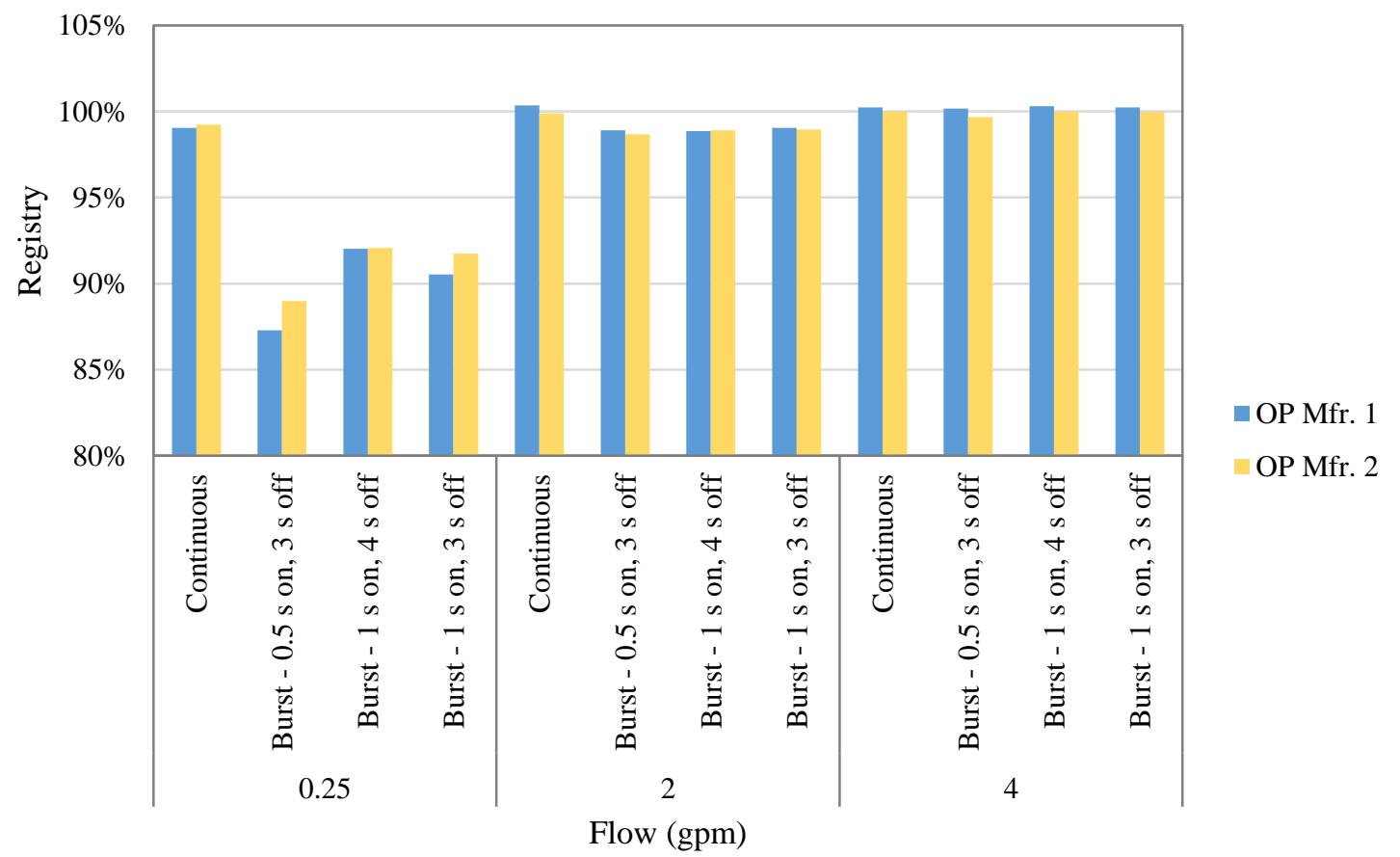

Figure 34. Average accuracy of oscillating piston meters in continuous and burst (neither thermal expansion tank nor PEX tubing) conditions. 


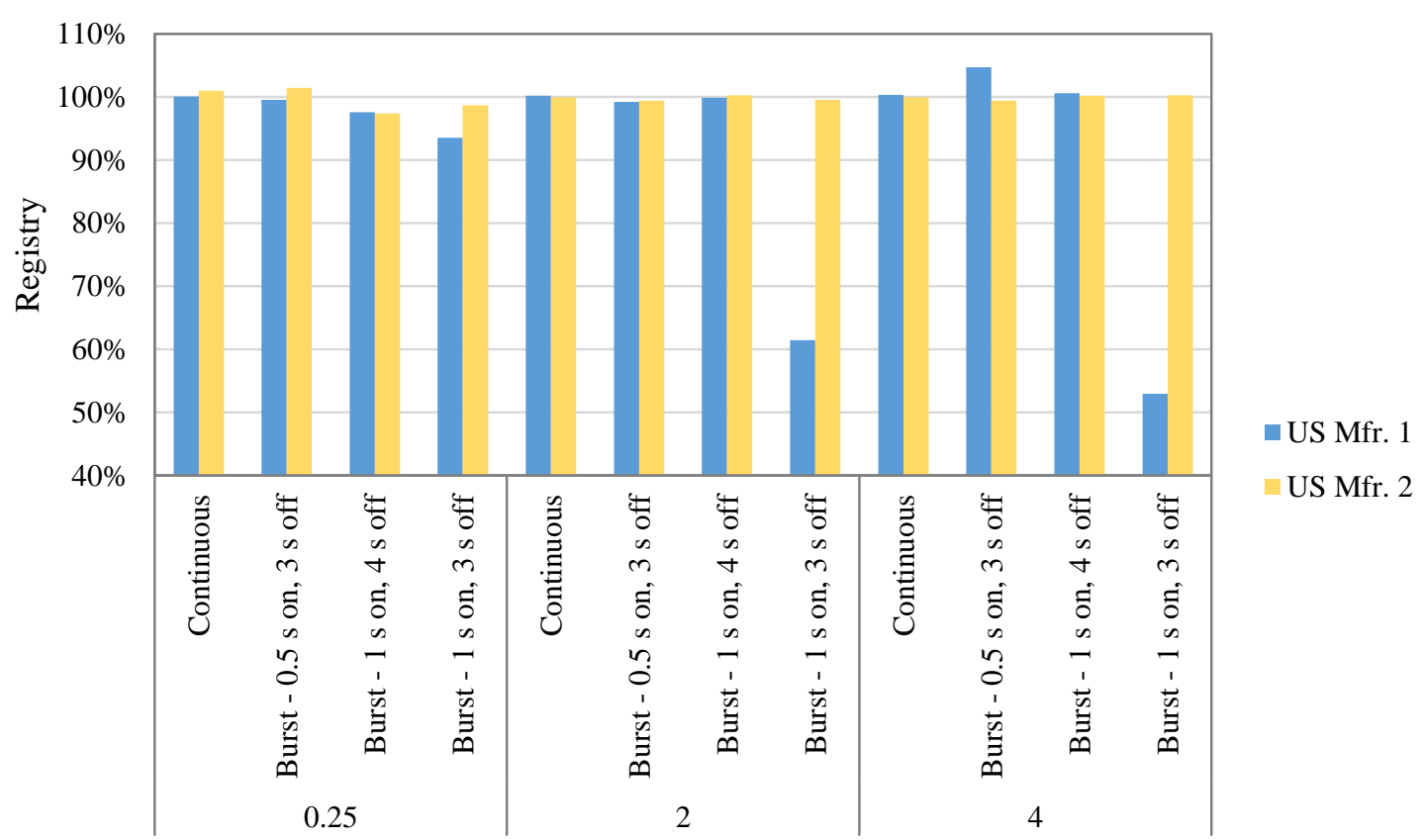

Flow (gpm)

Figure 35. Average accuracy of ultrasonic meters in continuous and burst (thermal expansion tank) conditions.

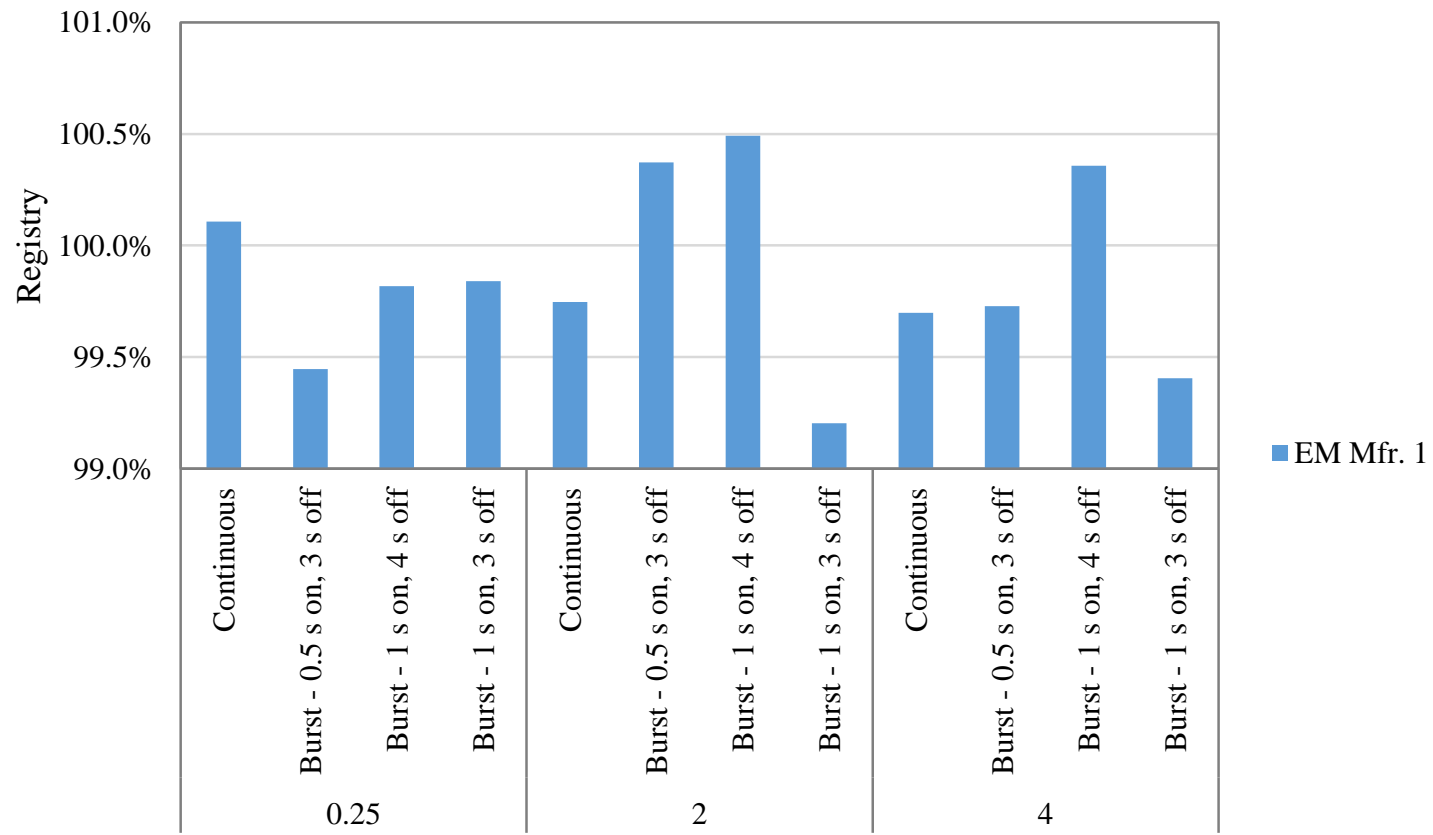

Flow (gpm)

Figure 36. Average accuracy of electromagnetic meters in continuous and burst (thermal expansion tank) conditions. 


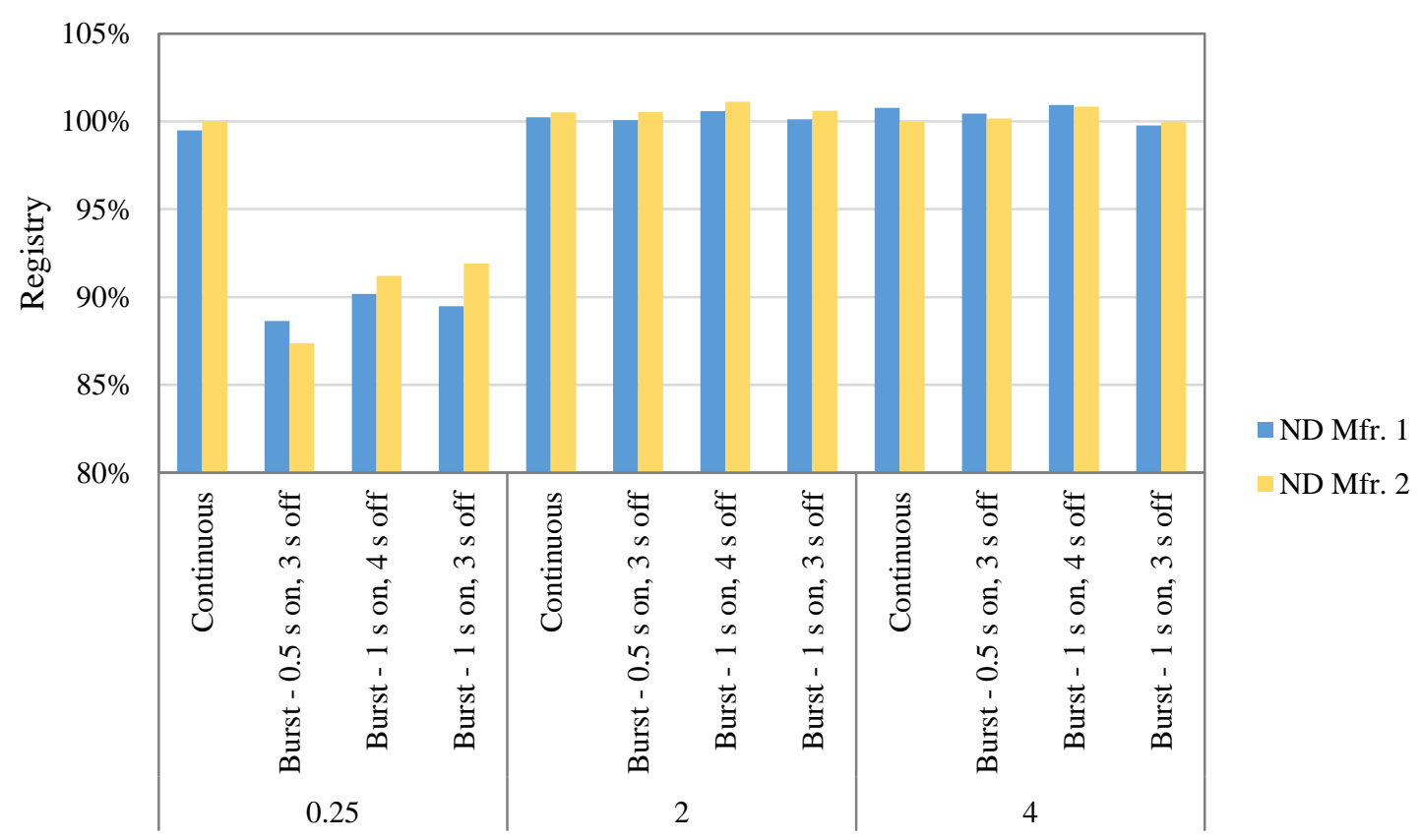

Flow (gpm)

Figure 37. Average accuracy of nutating disc meters in continuous and burst (thermal expansion tank) conditions.

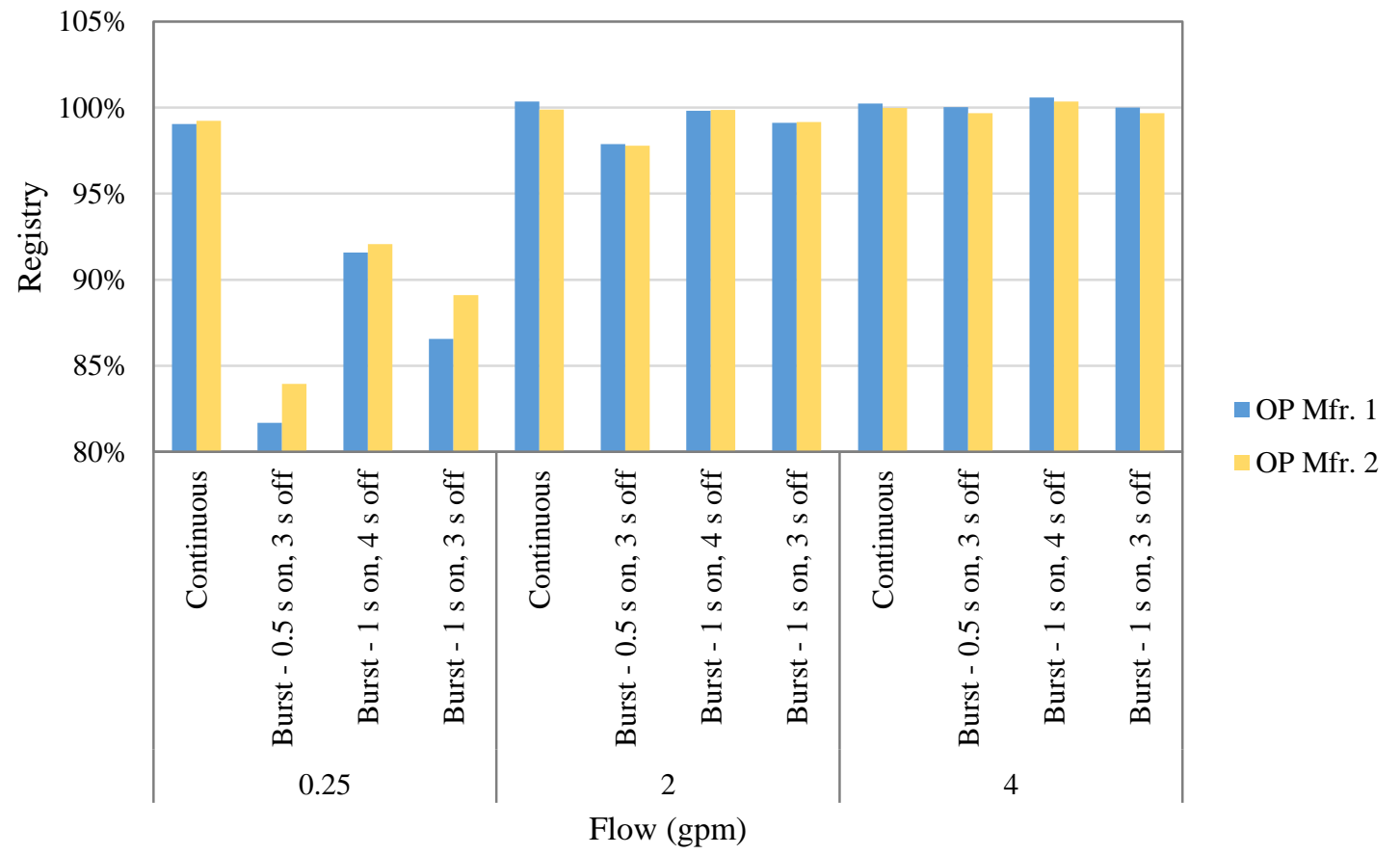

Figure 38. Average accuracy of oscillating piston meters in continuous and burst (thermal expansion tank) conditions. 


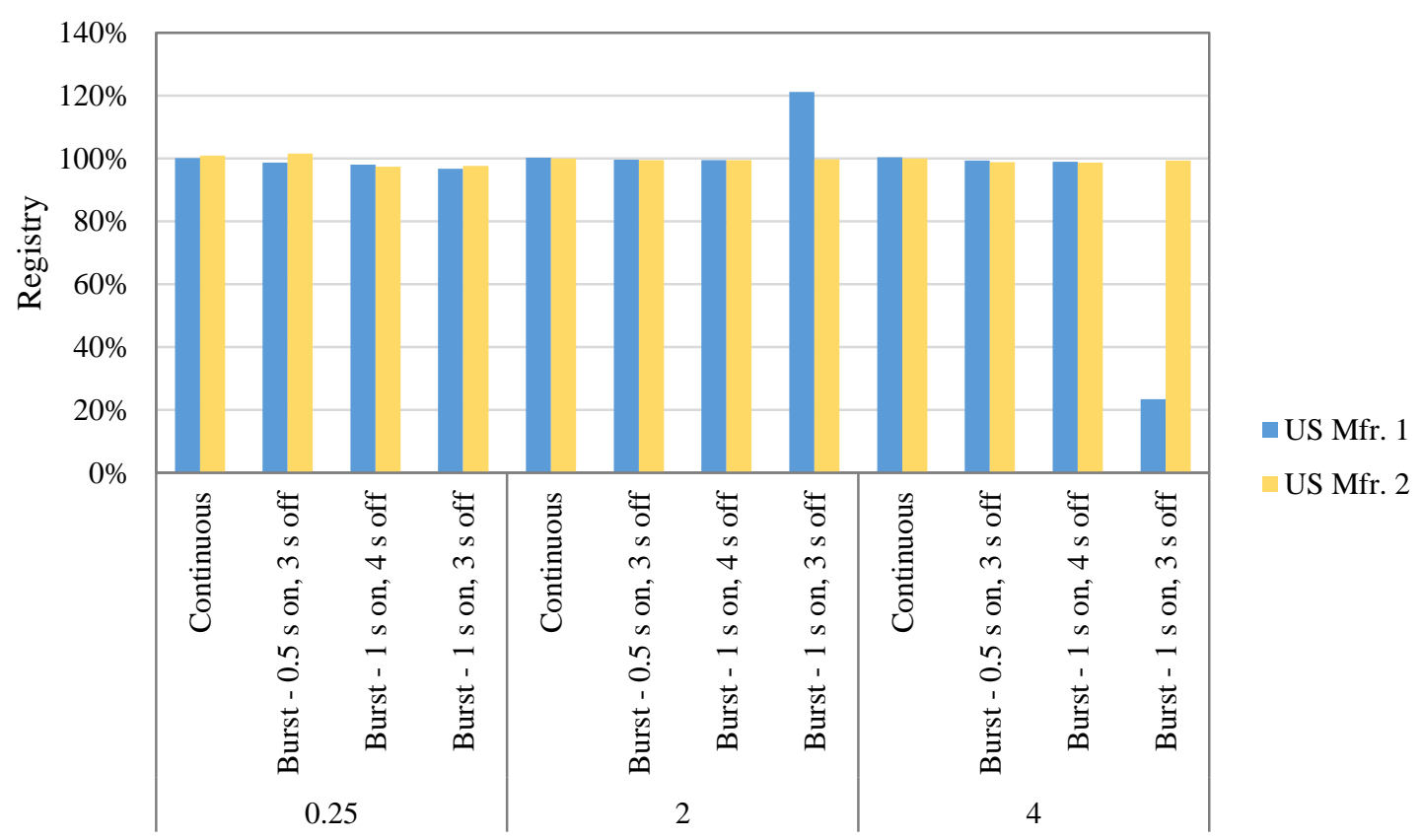

Flow (gpm)

Figure 39. Average accuracy of ultrasonic meters in continuous and burst (PEX tubing) conditions.

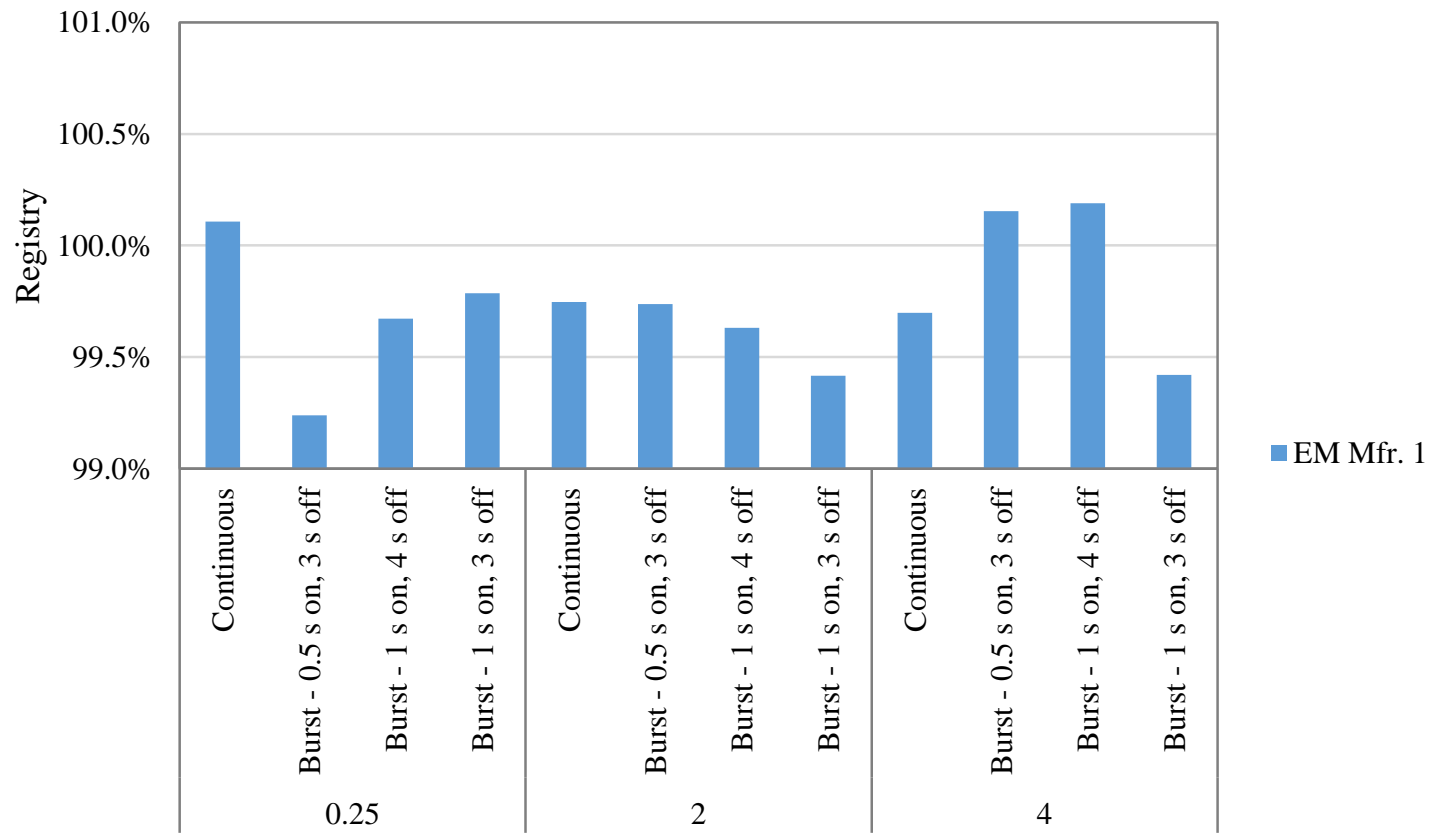

Flow (gpm)

Figure 40. Average accuracy of electromagnetic meters in continuous and burst (PEX tubing) conditions. 


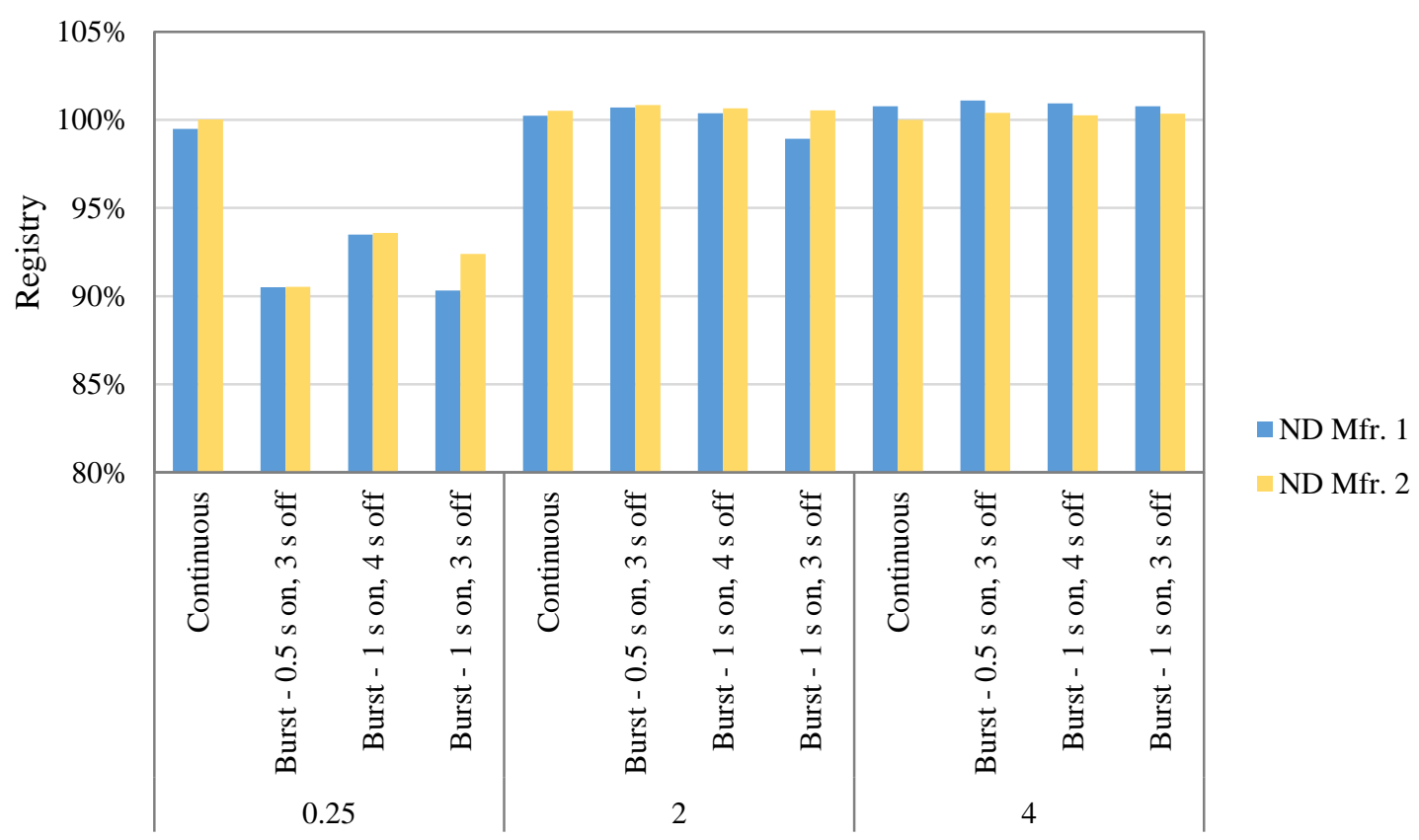

Flow (gpm)

Figure 41. Average accuracy of nutating disc meters in continuous and burst (PEX tubing) conditions.

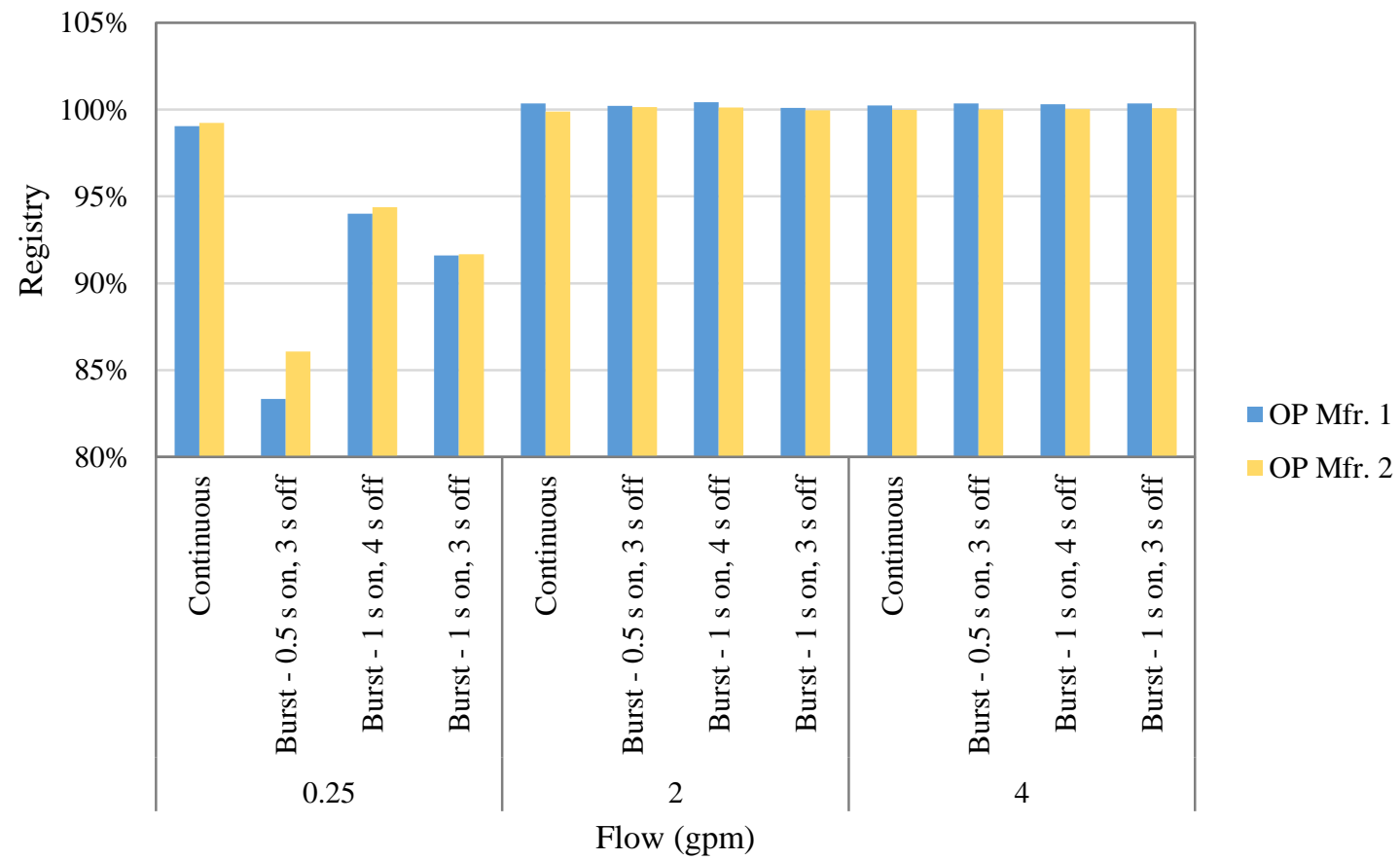

Figure 42. Average accuracy of oscillating piston meters in continuous and burst (PEX tubing) conditions. 


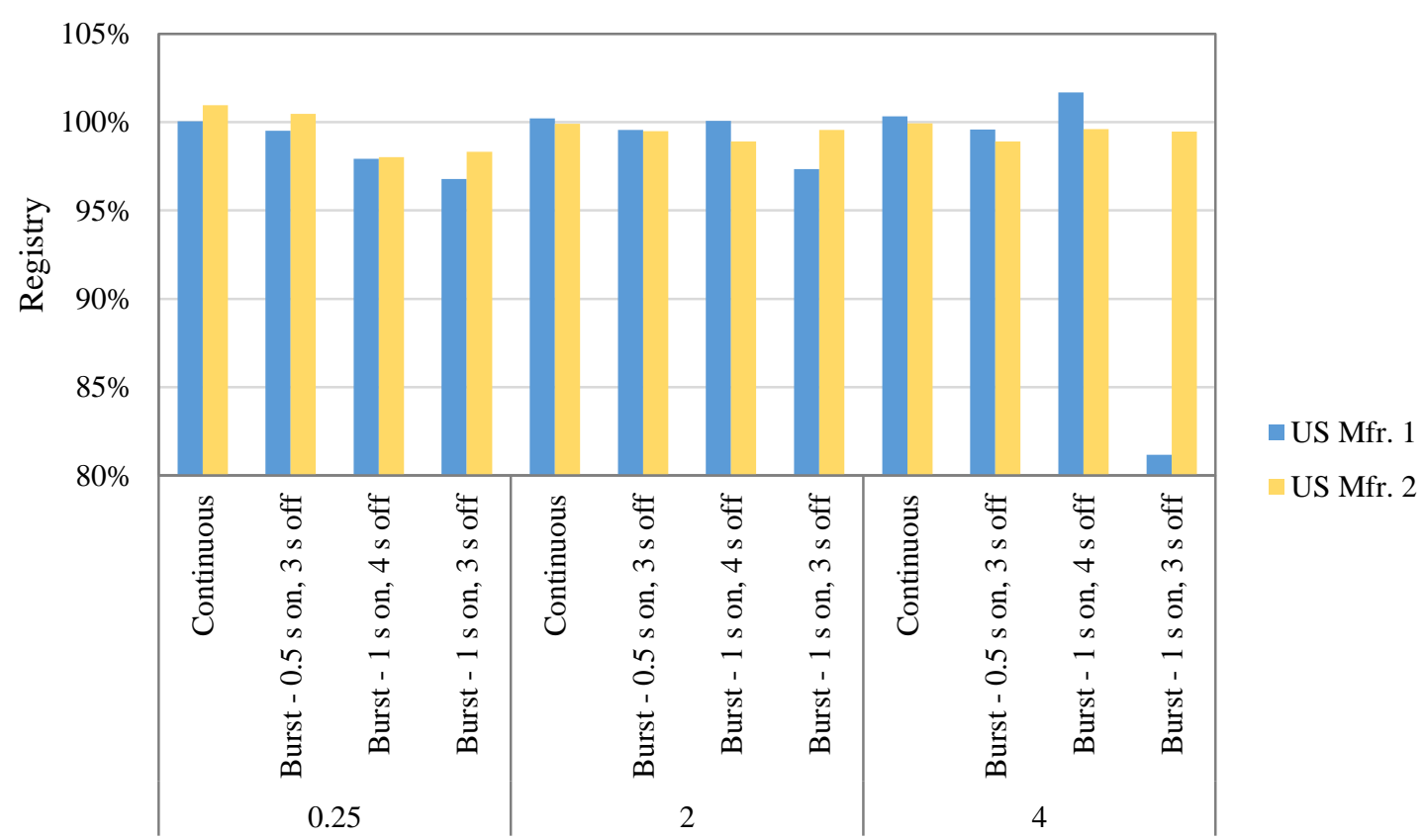

Flow (gpm)

Figure 43. Average accuracy of ultrasonic meters in continuous and burst (both thermal expansion tank and PEX tubing) conditions.

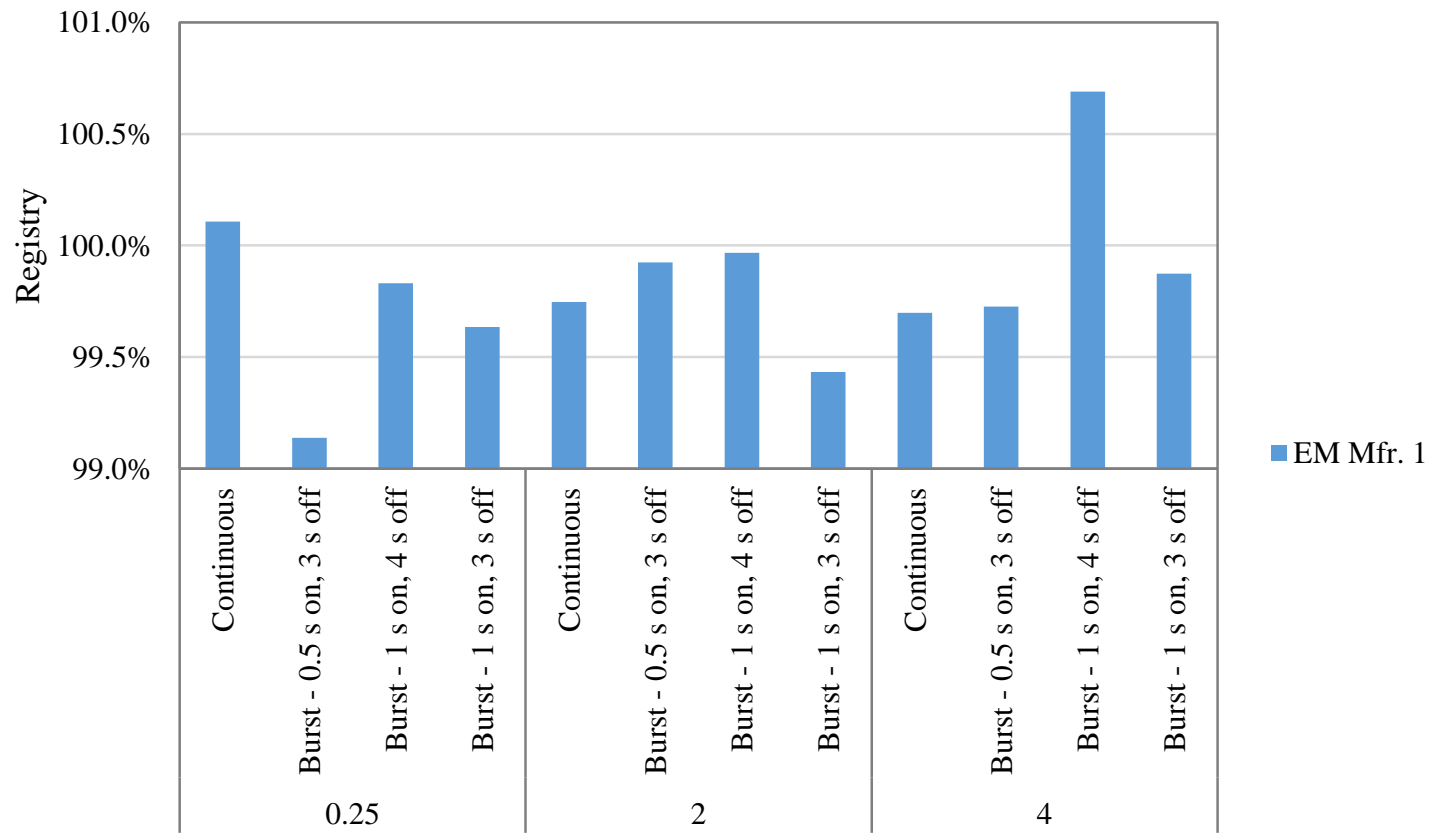

Flow (gpm)

Figure 44. Average accuracy of electromagnetic meters in continuous and burst (both thermal expansion tank and PEX tubing) conditions. 


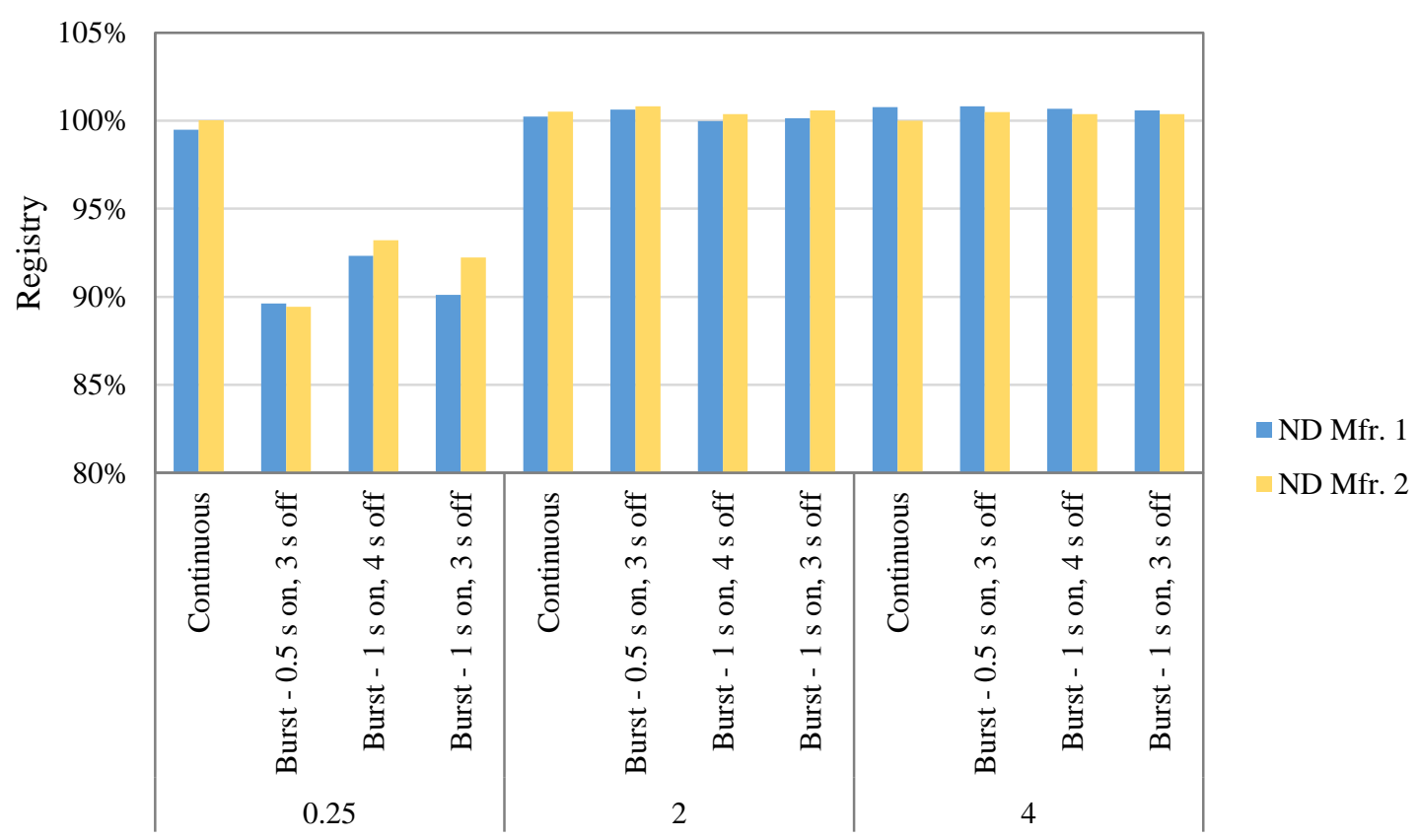

Flow (gpm)

Figure 45. Average accuracy of nutating disc meters in continuous and burst (both thermal expansion tank and PEX tubing) conditions.

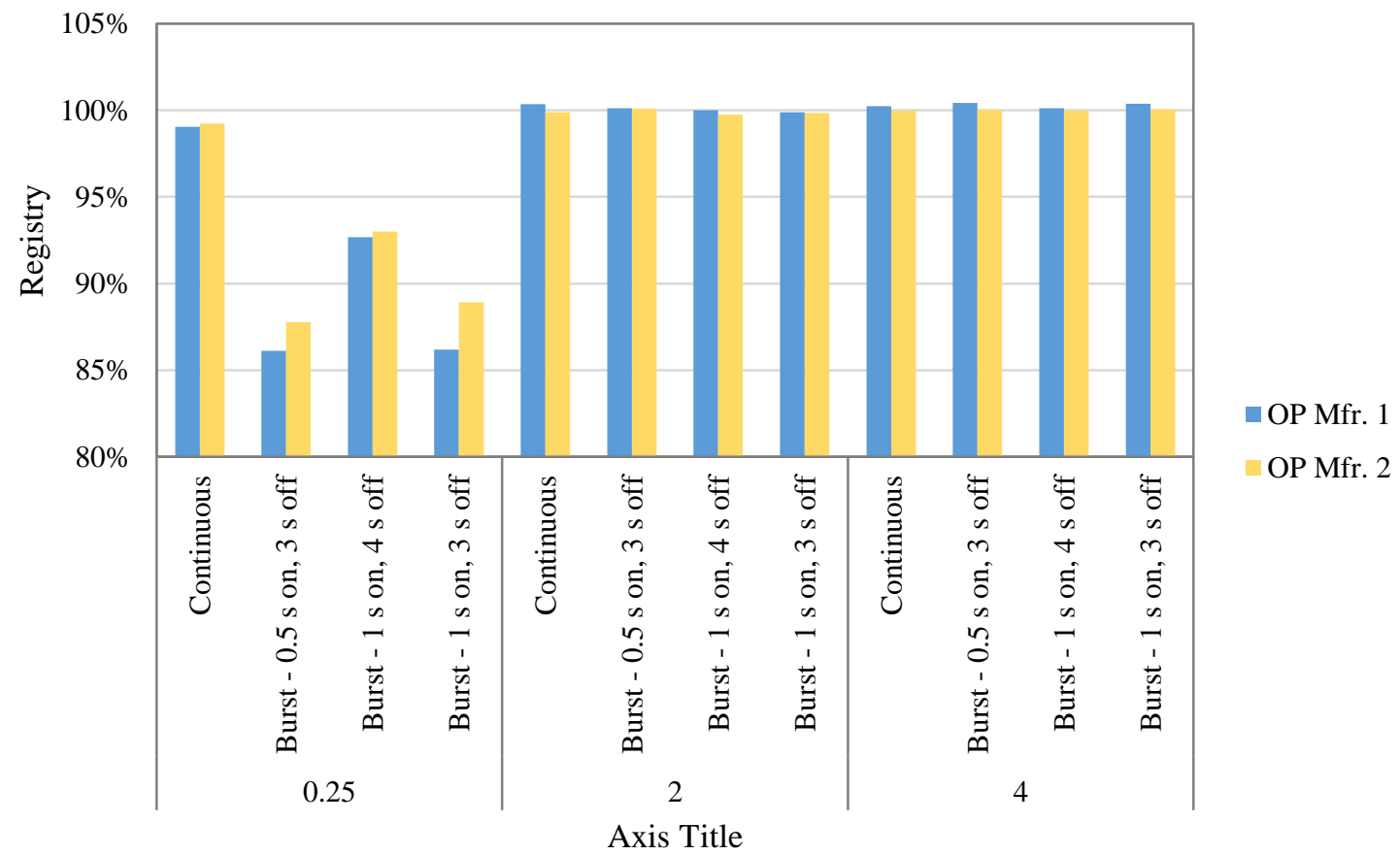

Figure 46. Average accuracy of oscillating piston meters in continuous and burst (both thermal expansion tank and PEX tubing) conditions. 
Accuracy of meters as a function of flow and meter type

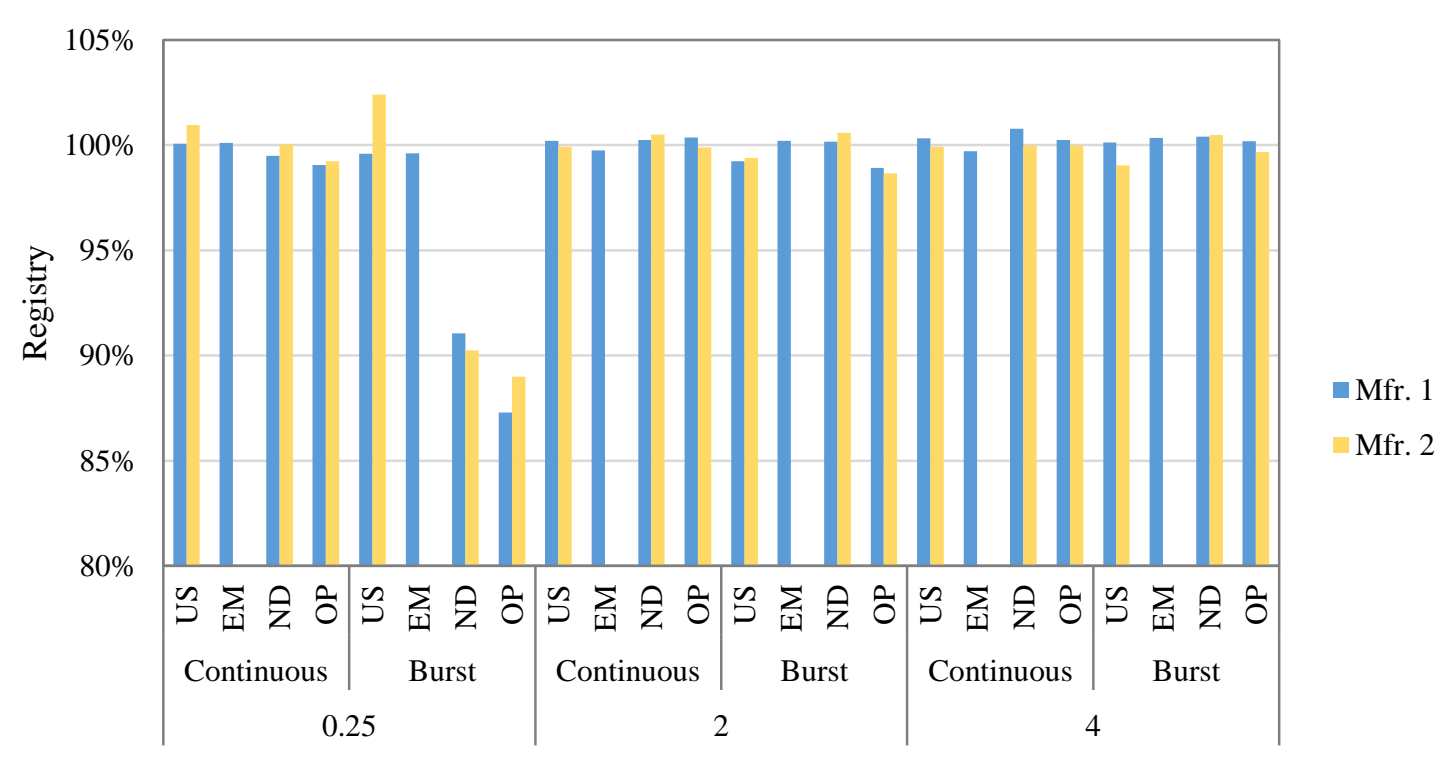

Flow (gpm)

Figure 47. Average accuracy of meters in continuous and burst (neither thermal expansion tank nor PEX tubing with time combination of 1/2 second on, 3 seconds off) conditions.

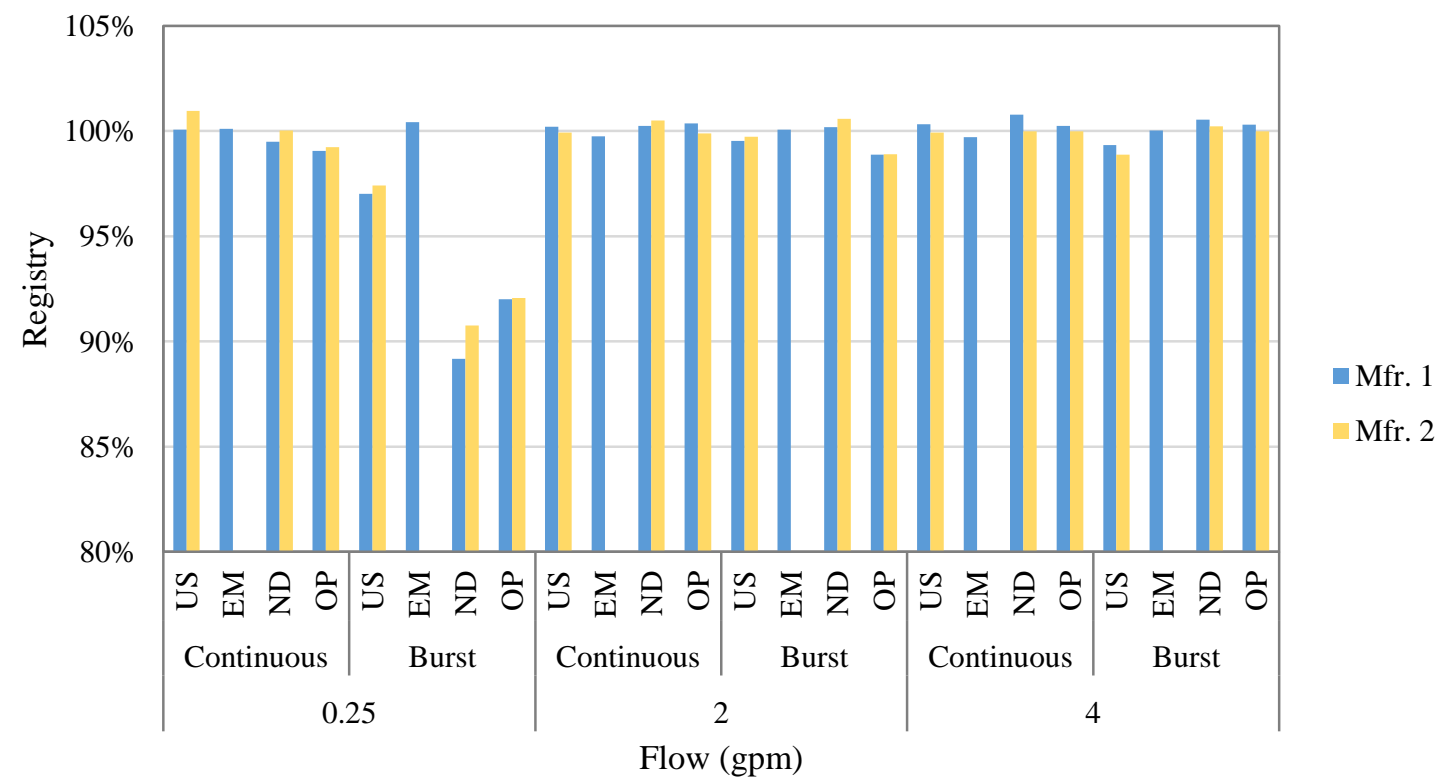

Figure 48. Average accuracy of meters in continuous and burst (neither thermal expansion tank nor PEX tubing with time combination of 1 second on, 4 seconds off) conditions. 


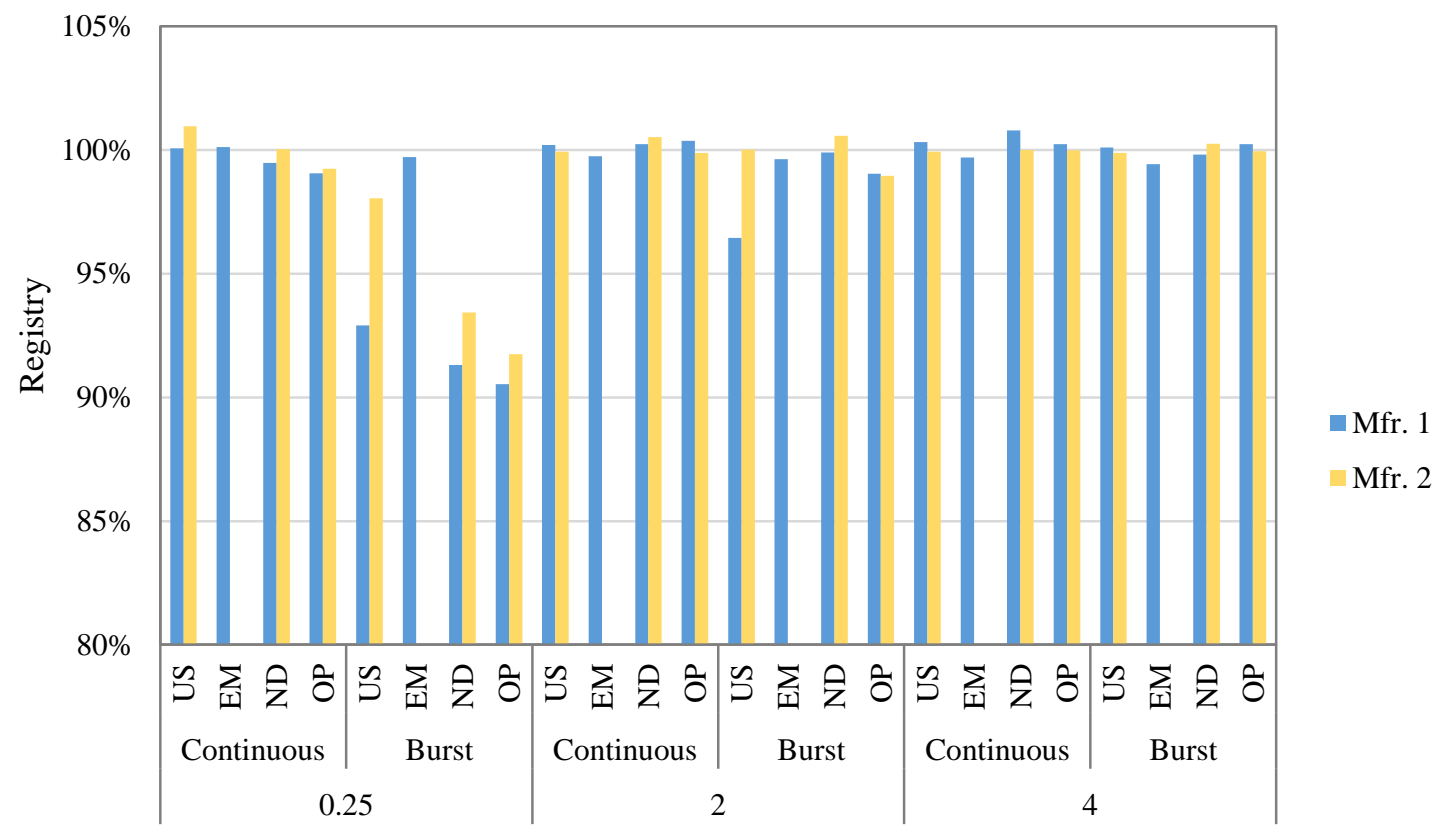

Flow (gpm)

Figure 49. Average accuracy of meters in continuous and burst (neither thermal expansion tank nor PEX tubing with time combination of 1 second on, 3 seconds off) conditions.

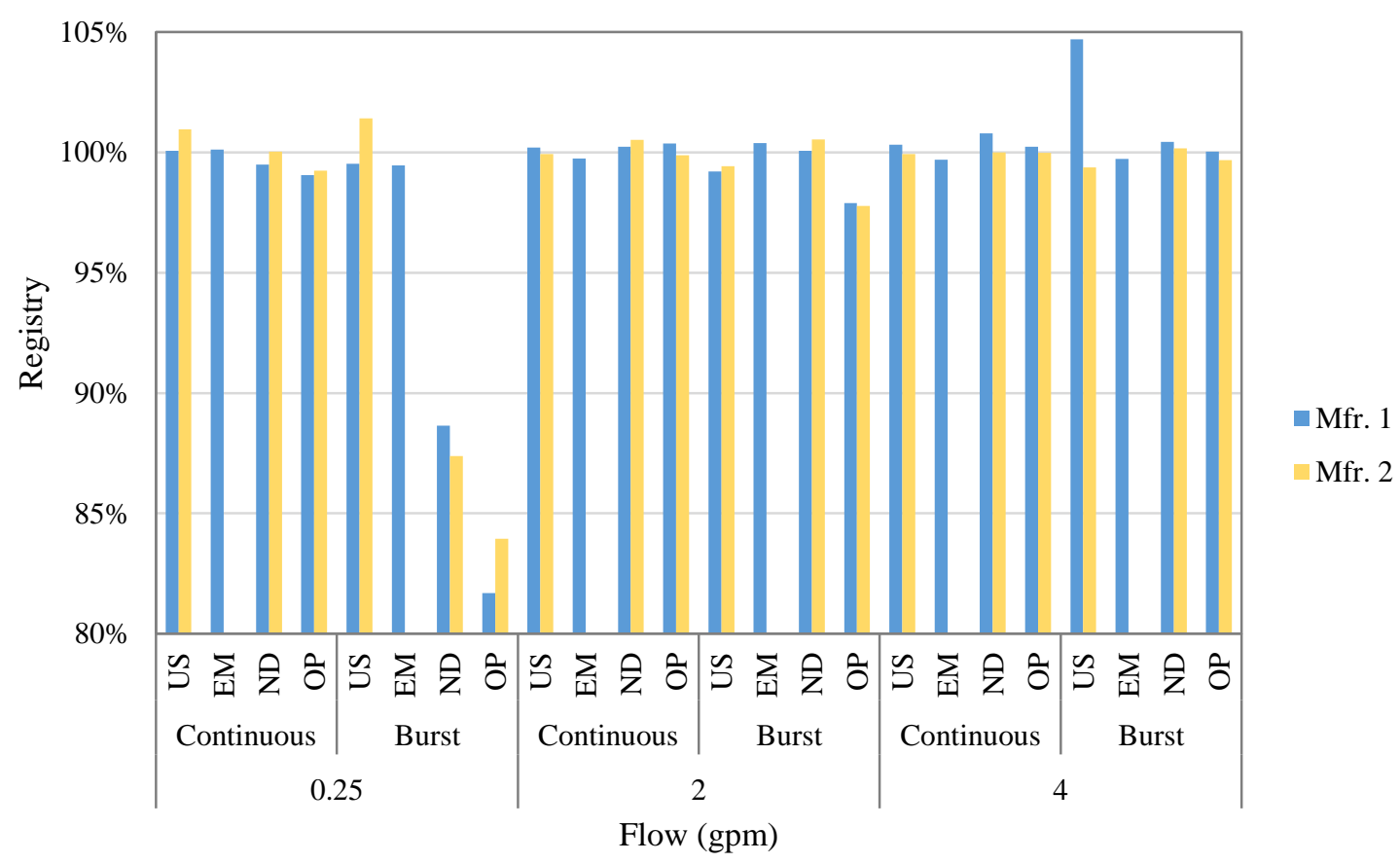

Figure 50. Average accuracy of meters in continuous and burst (thermal expansion tank with time combination of $1 / 2$ second on, 3 seconds off) conditions. 


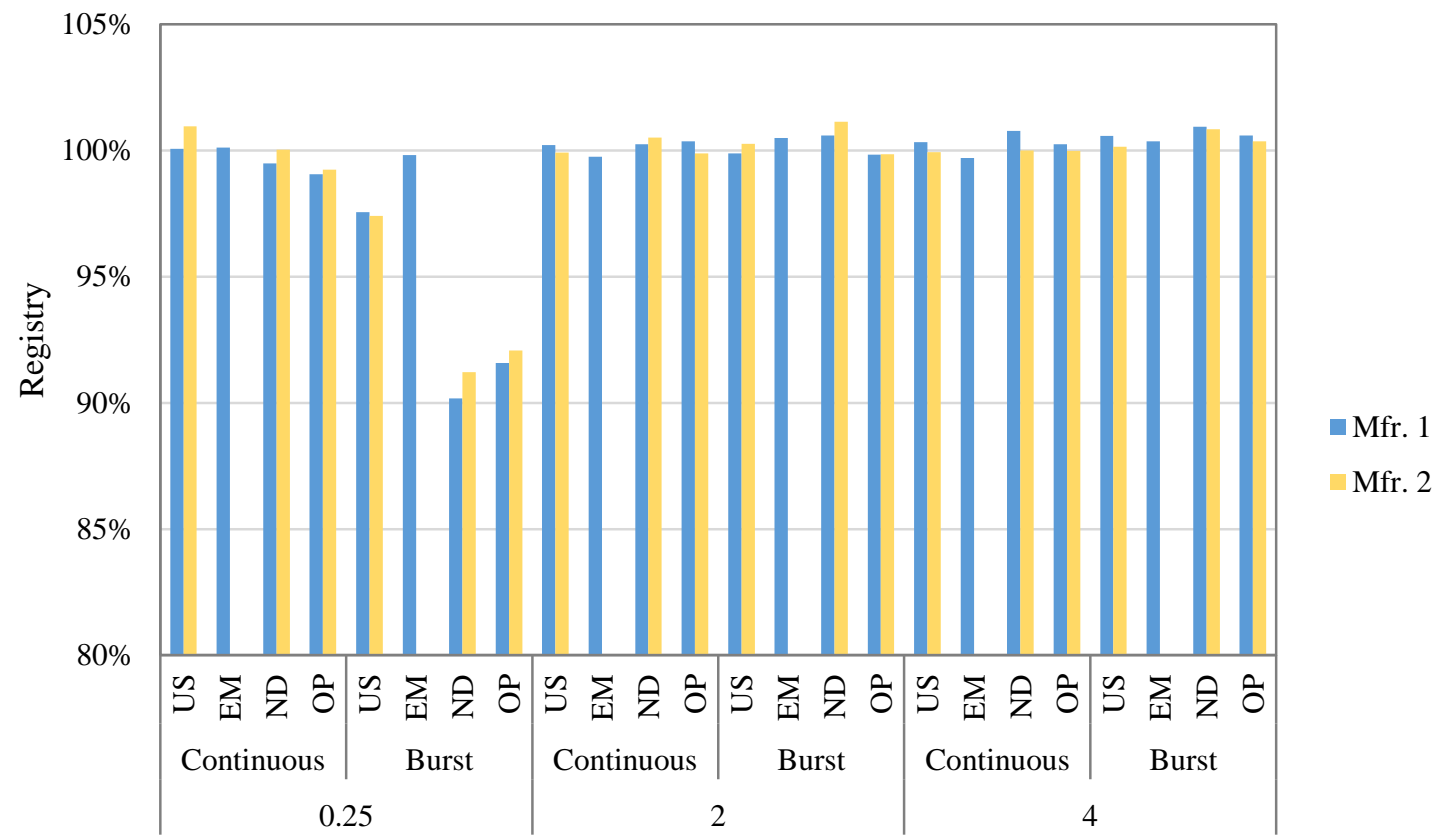

Flow (gpm)

Figure 51. Average accuracy of meters in continuous and burst (thermal expansion tank with time combination of 1 second on, 4 seconds off) conditions.

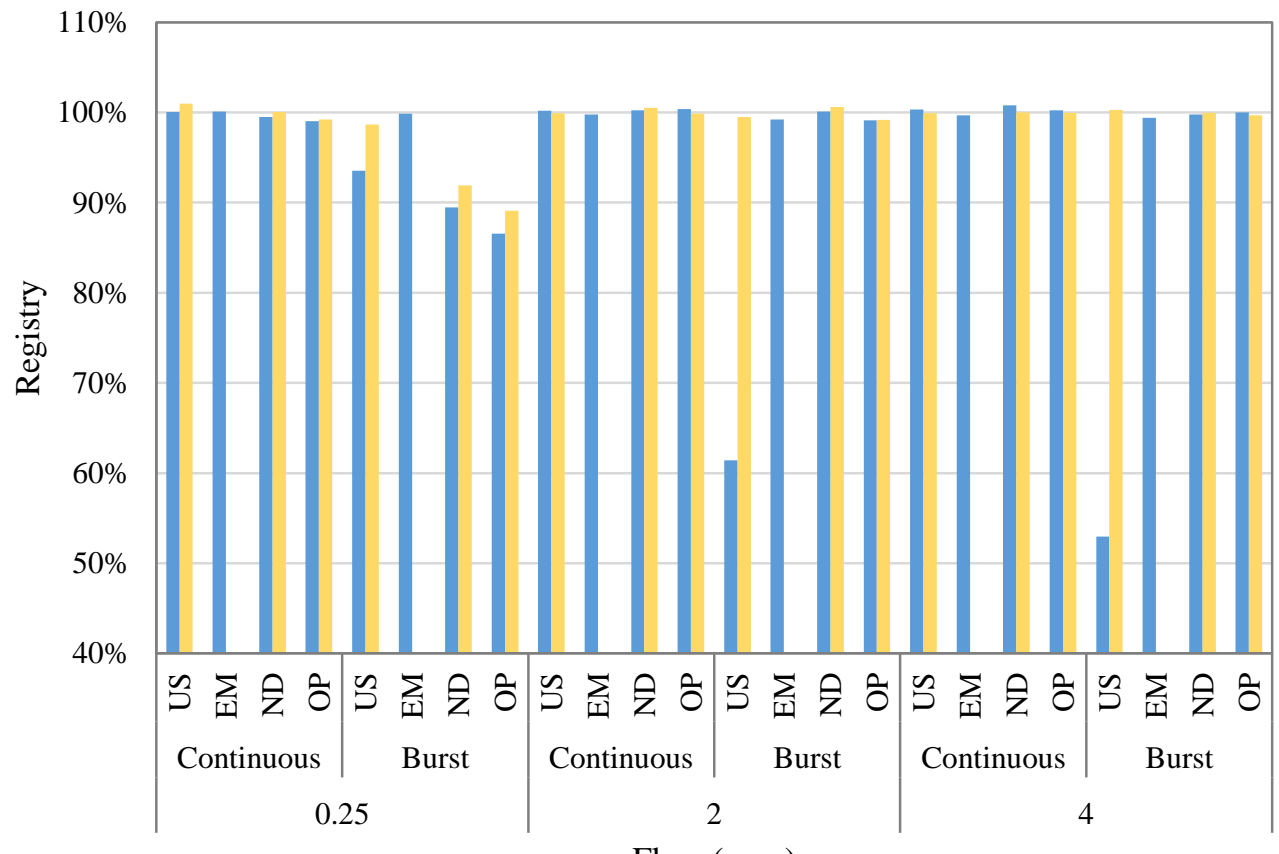

Mfr. 1

Mfr. 2

Figure 52. Average accuracy of meters in continuous and burst (thermal expansion tank with time combination of 1 second on, 3 seconds off) conditions. 


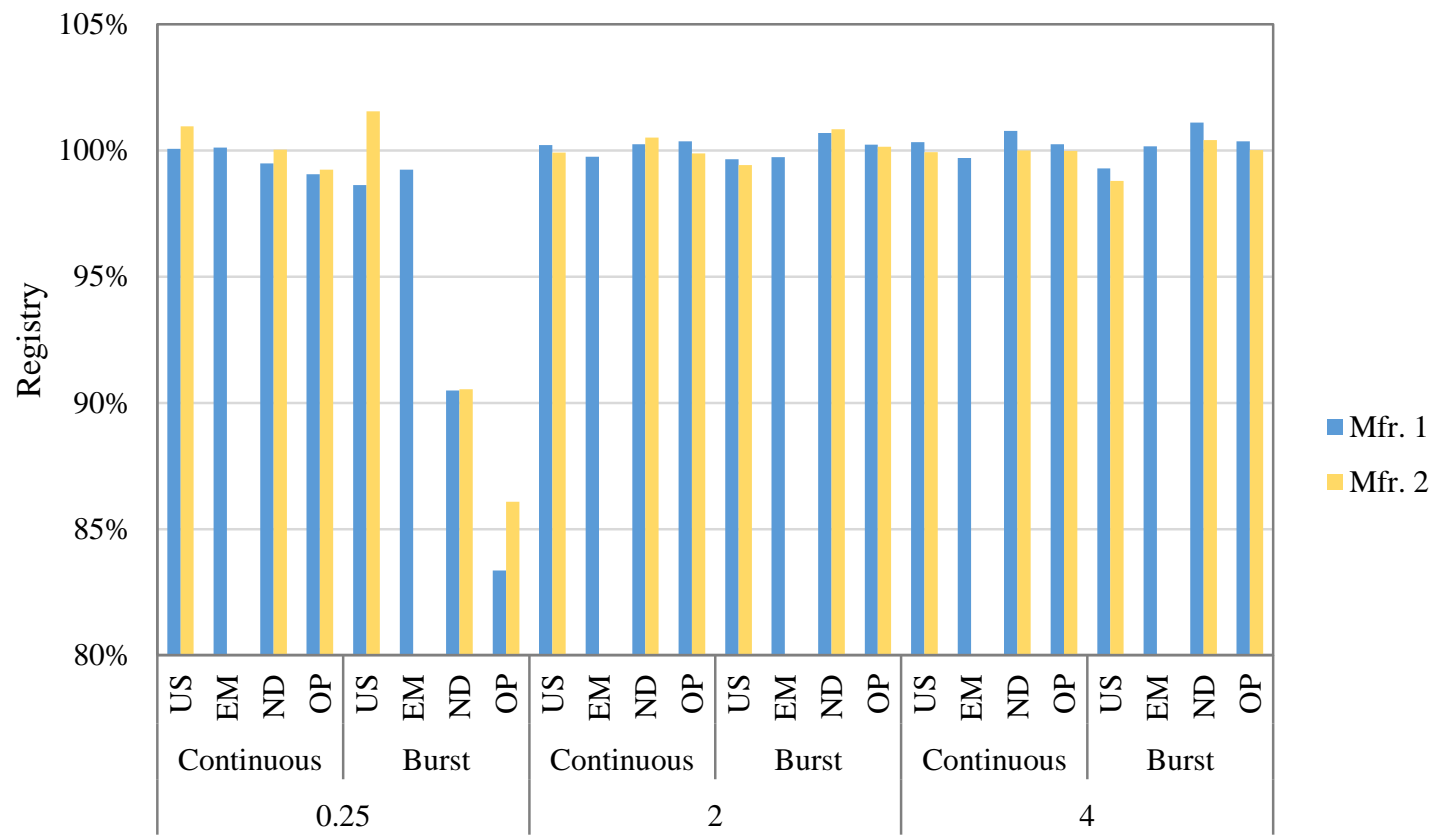

Flow (gpm)

Figure 53. Average accuracy of meters in continuous and burst (PEX tubing with time combination of $1 / 2$ second on, 3 seconds off) conditions.

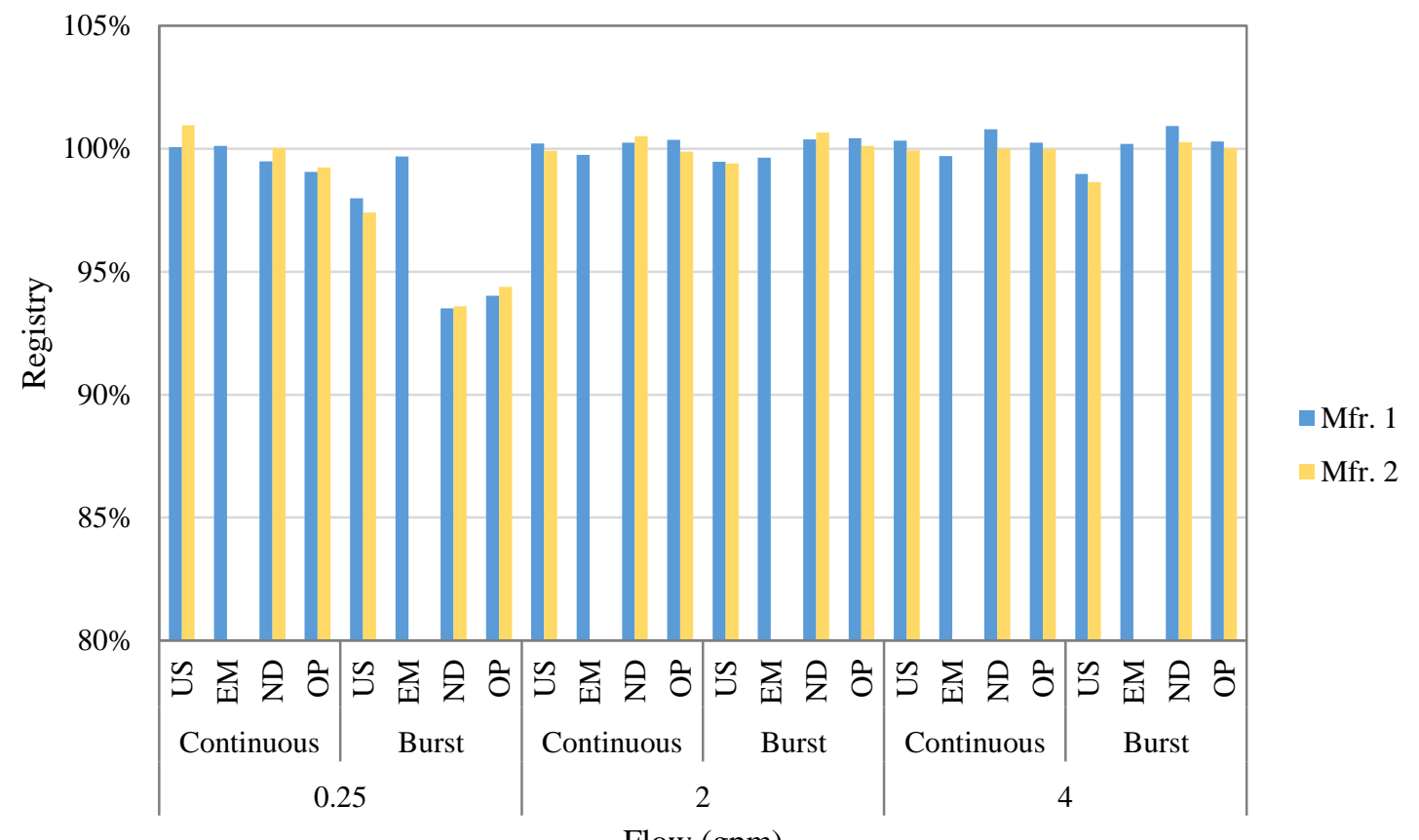

Flow (gpm)

Figure 54. Average accuracy of meters in continuous and burst (PEX tubing with time combination of 1 second on, 4 seconds off) conditions. 


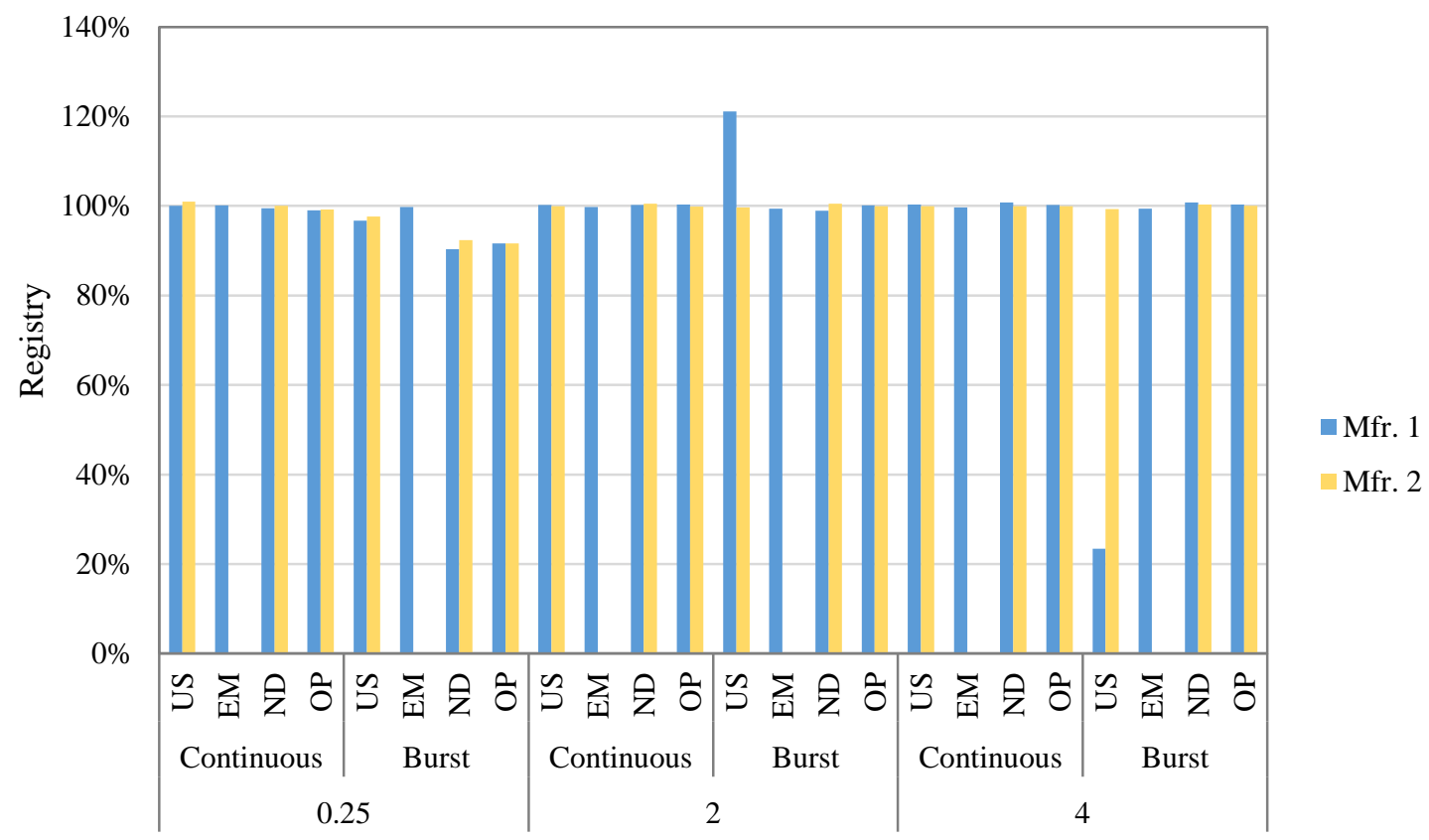

Flow (gpm)

Figure 55. Average accuracy of meters in continuous and burst (PEX tubing with time combination of 1 second on, 3 seconds off) conditions.

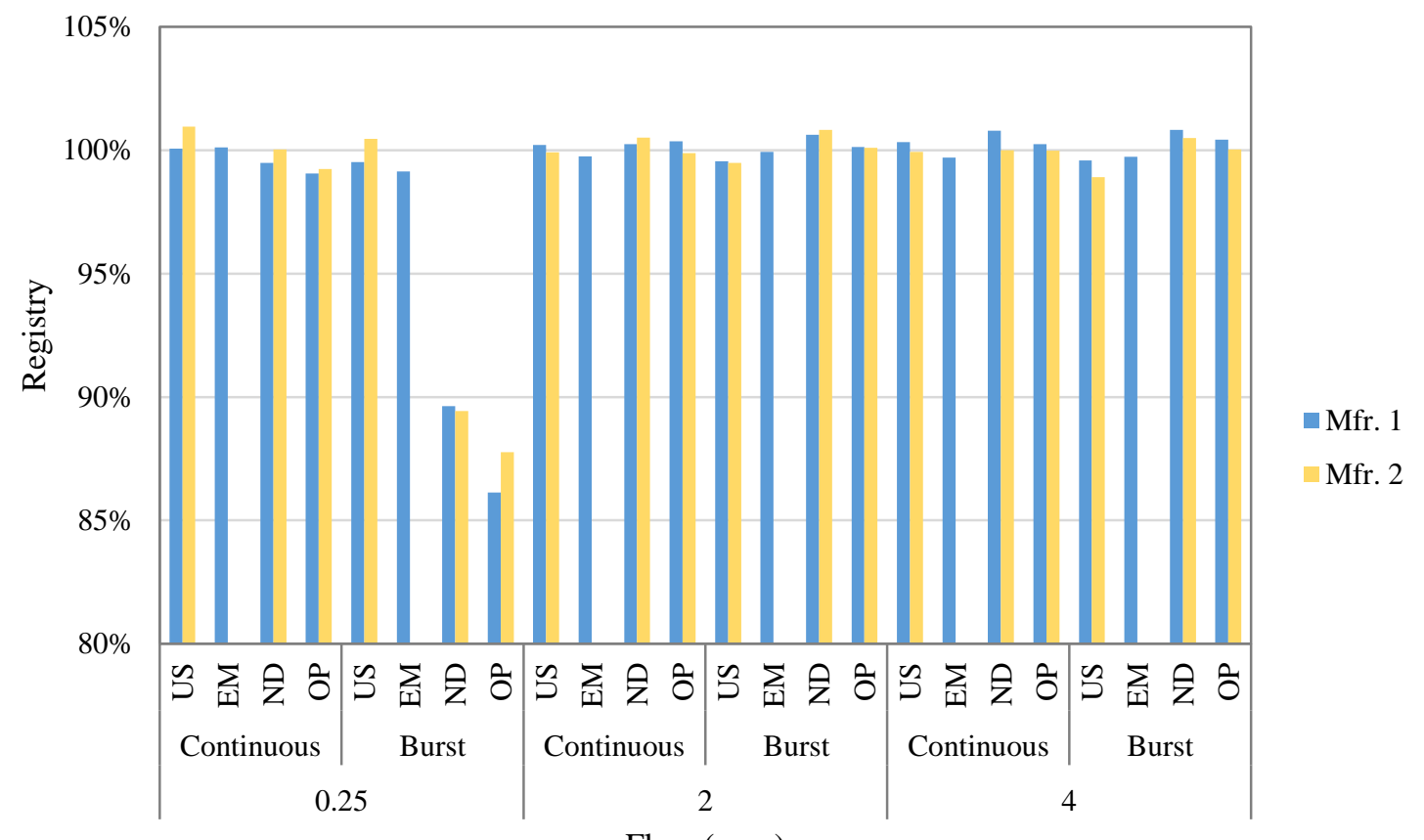

Flow (gpm)

Figure 56. Average accuracy of meters in continuous and burst (both thermal expansion tank and PEX tubing with time combination of $1 / 2$ second on, 3 seconds off) conditions. 


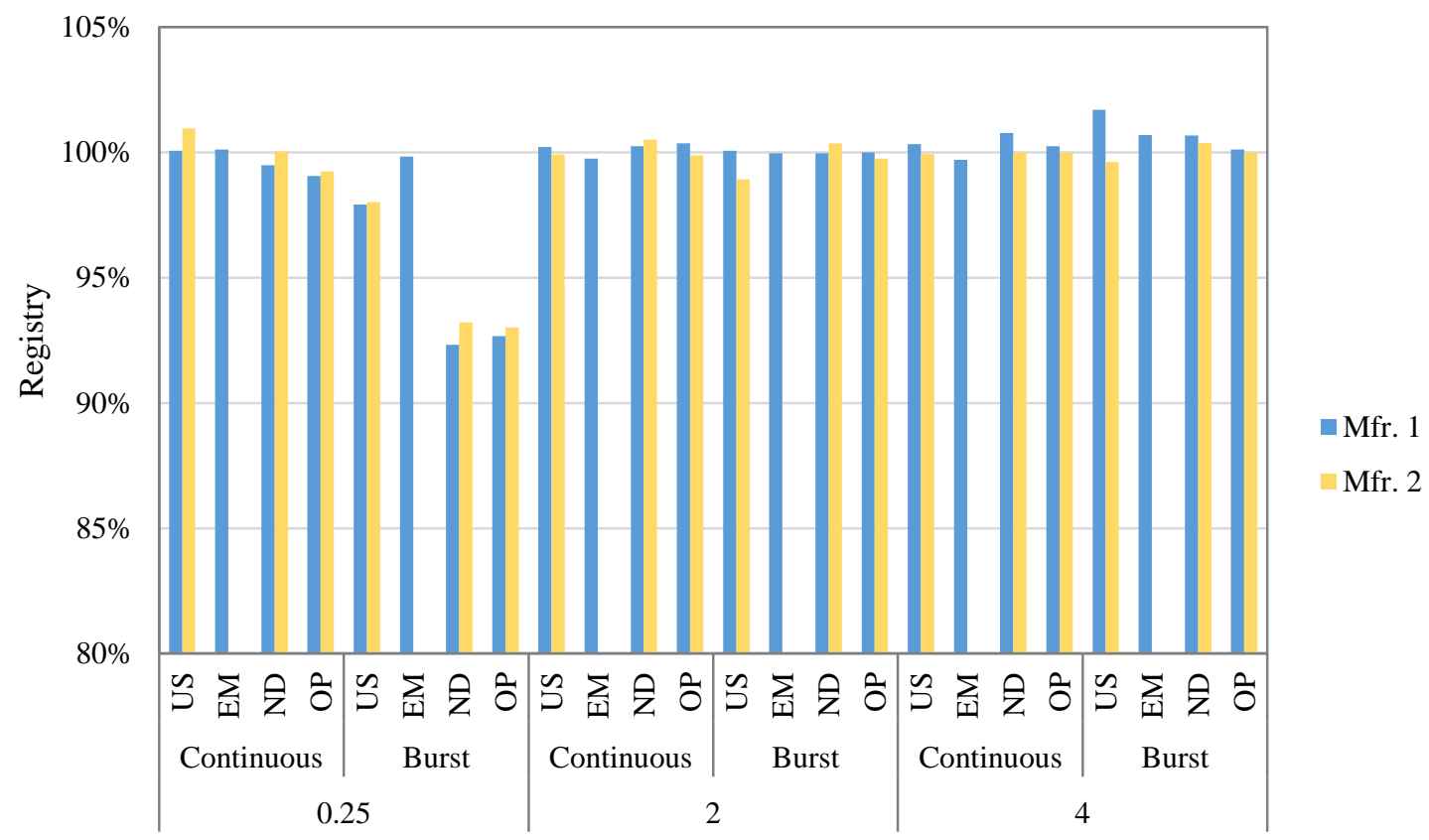

Flow (gpm)

Figure 57. Average accuracy of meters in continuous and burst (both thermal expansion tank and PEX tubing with time combination of 1 second on, 4 seconds off) conditions.

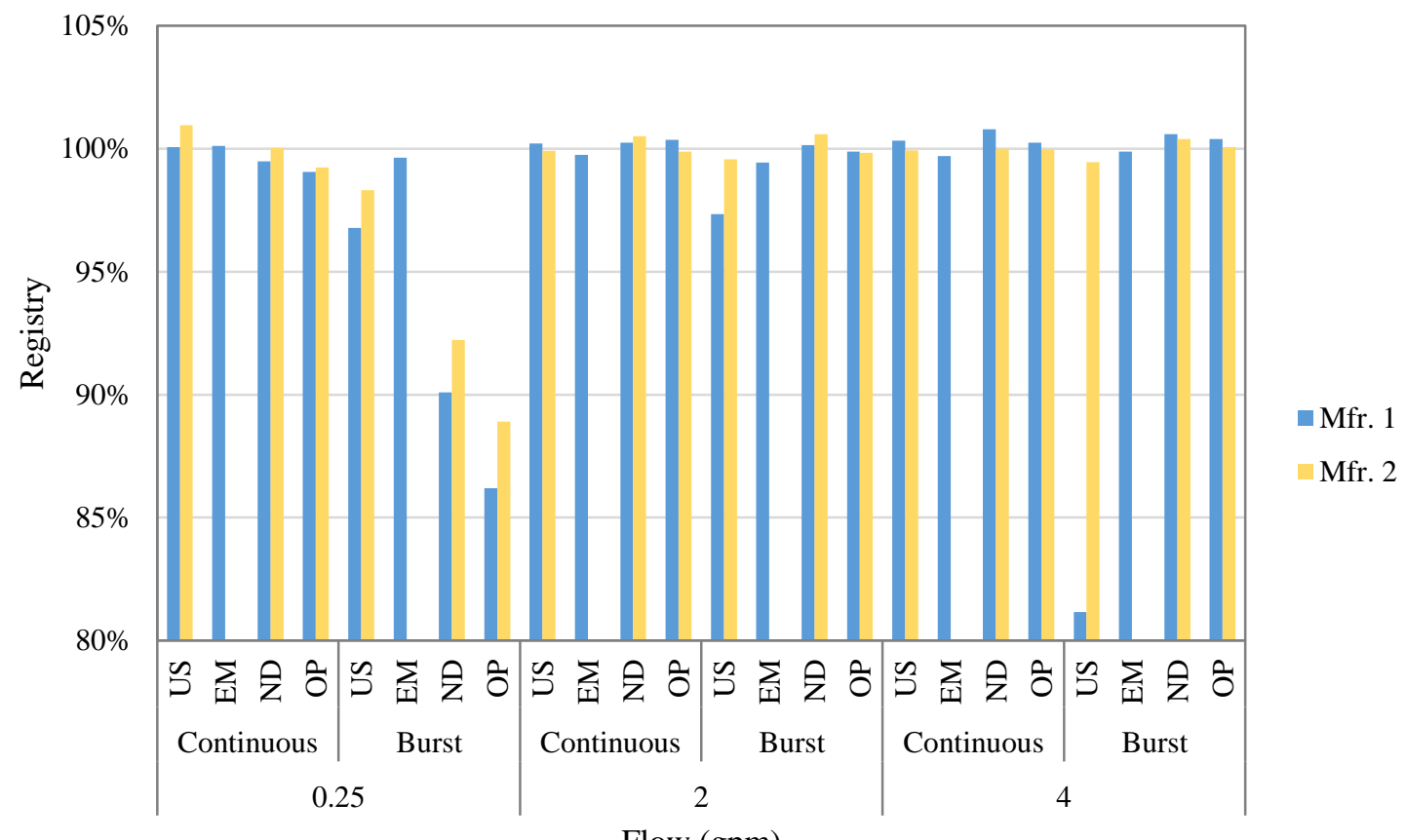

Flow (gpm)

Figure 58. Average accuracy of meters in continuous and burst (both thermal expansion tank and PEX tubing with time combination of 1 second on, 3 seconds off) conditions. 
APPENDIX B: Individual Meter Results for Burst Flows 
Table 8. Accuracies of ultrasonic Manufacturer 1 meters in the burst flow condition.

\begin{tabular}{|c|c|c|c|c|c|c|c|c|c|}
\hline $\begin{array}{l}\text { Test } \\
\text { No. }\end{array}$ & $\begin{array}{l}\text { Nominal } \\
\text { Flow } \\
\text { (gpm) }\end{array}$ & $\begin{array}{c}\text { Test } \\
\text { Setup }\end{array}$ & $\begin{array}{c}\text { Time } \\
\text { Comb. } \\
\text { (s on, } \\
\text { s off) }\end{array}$ & Meter 1 & Meter 2 & Meter 3 & Meter 4 & Meter 5 & Meter 6 \\
\hline 1 & 0.25 & Neither & 1,3 & $95.50 \%$ & $95.77 \%$ & $98.51 \%$ & $92.57 \%$ & $96.13 \%$ & $78.99 \%$ \\
\hline 2 & 0.25 & Tank & 1,3 & $100.12 \%$ & $100.82 \%$ & $100.02 \%$ & $81.68 \%$ & $80.39 \%$ & $98.24 \%$ \\
\hline 3 & 0.25 & PEX & 1,3 & $100.83 \%$ & $102.21 \%$ & $97.69 \%$ & $87.05 \%$ & $86.95 \%$ & $105.39 \%$ \\
\hline 4 & 0.25 & Both & 1,3 & $99.43 \%$ & $100.12 \%$ & $99.14 \%$ & $93.33 \%$ & $90.52 \%$ & $98.11 \%$ \\
\hline 5 & 0.25 & Neither & 1,4 & $96.73 \%$ & $96.63 \%$ & $96.83 \%$ & $97.74 \%$ & $97.07 \%$ & $97.07 \%$ \\
\hline 6 & 0.25 & Tank & 1,4 & $97.91 \%$ & $99.10 \%$ & $97.22 \%$ & $96.75 \%$ & $97.05 \%$ & $97.25 \%$ \\
\hline 7 & 0.25 & PEX & 1,4 & $98.15 \%$ & $99.44 \%$ & $98.05 \%$ & $97.04 \%$ & $97.44 \%$ & $97.74 \%$ \\
\hline 8 & 0.25 & Both & 1,4 & $98.20 \%$ & $98.79 \%$ & $98.10 \%$ & $97.54 \%$ & $97.24 \%$ & $97.63 \%$ \\
\hline 9 & 0.25 & Neither & $0.5,3$ & $97.29 \%$ & $99.58 \%$ & $98.68 \%$ & $100.72 \%$ & $100.56 \%$ & $100.64 \%$ \\
\hline 10 & 0.25 & Tank & $0.5,3$ & $98.61 \%$ & $99.40 \%$ & $98.11 \%$ & $100.44 \%$ & $100.06 \%$ & $100.54 \%$ \\
\hline 11 & 0.25 & PEX & $0.5,3$ & $96.62 \%$ & $97.59 \%$ & $96.97 \%$ & $100.62 \%$ & $100.04 \%$ & $99.94 \%$ \\
\hline 12 & 0.25 & Both & $0.5,3$ & $98.65 \%$ & $99.26 \%$ & $98.27 \%$ & $100.35 \%$ & $100.25 \%$ & $100.35 \%$ \\
\hline 13 & 2 & Neither & 1,3 & $130.74 \%$ & $24.32 \%$ & $47.52 \%$ & $155.34 \%$ & $155.05 \%$ & $65.71 \%$ \\
\hline 14 & 2 & Tank & 1,3 & $2.08 \%$ & $0.00 \%$ & $158.53 \%$ & $20.38 \%$ & $35.09 \%$ & $152.49 \%$ \\
\hline 15 & 2 & PEX & 1,3 & $151.66 \%$ & $156.36 \%$ & $162.16 \%$ & $73.46 \%$ & $169.40 \%$ & $13.82 \%$ \\
\hline 16 & 2 & Both & 1,3 & $180.68 \%$ & $177.50 \%$ & $3.38 \%$ & $26.82 \%$ & $123.88 \%$ & $71.72 \%$ \\
\hline 17 & 2 & Neither & 1,4 & $98.60 \%$ & $99.59 \%$ & $99.10 \%$ & $100.10 \%$ & $99.43 \%$ & $100.39 \%$ \\
\hline 18 & 2 & Tank & 1,4 & $99.37 \%$ & $98.79 \%$ & $100.83 \%$ & $100.49 \%$ & $99.60 \%$ & $100.20 \%$ \\
\hline 19 & 2 & PEX & 1,4 & $99.57 \%$ & $101.16 \%$ & $96.18 \%$ & $99.43 \%$ & $99.53 \%$ & $100.91 \%$ \\
\hline 20 & 2 & Both & 1,4 & $98.94 \%$ & $100.91 \%$ & $100.71 \%$ & $99.98 \%$ & $99.29 \%$ & $100.57 \%$ \\
\hline 21 & 2 & Neither & $0.5,3$ & $100.03 \%$ & $99.54 \%$ & $97.54 \%$ & $99.44 \%$ & $98.65 \%$ & $100.24 \%$ \\
\hline 22 & 2 & Tank & $0.5,3$ & $97.00 \%$ & $100.47 \%$ & $98.59 \%$ & $100.18 \%$ & $99.39 \%$ & $99.58 \%$ \\
\hline 23 & 2 & PEX & $0.5,3$ & $100.57 \%$ & $99.54 \%$ & $99.35 \%$ & $98.92 \%$ & $99.02 \%$ & $100.51 \%$ \\
\hline 24 & 2 & Both & $0.5,3$ & $98.68 \%$ & $99.77 \%$ & $99.37 \%$ & $99.42 \%$ & $99.92 \%$ & $100.12 \%$ \\
\hline 25 & 4 & Neither & 1,3 & $278.24 \%$ & $103.80 \%$ & $117.60 \%$ & $0.00 \%$ & $0.00 \%$ & $100.87 \%$ \\
\hline 26 & 4 & Tank & 1,3 & $37.06 \%$ & $211.03 \%$ & $0.00 \%$ & $15.74 \%$ & $14.55 \%$ & $39.31 \%$ \\
\hline 27 & 4 & PEX & 1,3 & $0.30 \%$ & $22.32 \%$ & $0.40 \%$ & $0.59 \%$ & $117.21 \%$ & $0.00 \%$ \\
\hline 28 & 4 & Both & 1,3 & $189.07 \%$ & $21.78 \%$ & $202.23 \%$ & $0.00 \%$ & $73.34 \%$ & $0.59 \%$ \\
\hline 29 & 4 & Neither & 1,4 & $98.03 \%$ & $95.98 \%$ & $97.93 \%$ & $101.55 \%$ & $100.08 \%$ & $102.44 \%$ \\
\hline 30 & 4 & Tank & 1,4 & $102.45 \%$ & $101.96 \%$ & $95.24 \%$ & $100.78 \%$ & $105.65 \%$ & $97.35 \%$ \\
\hline 31 & 4 & PEX & 1,4 & $98.50 \%$ & $97.40 \%$ & $101.98 \%$ & $99.77 \%$ & $99.86 \%$ & $96.28 \%$ \\
\hline 32 & 4 & Both & 1,4 & $101.90 \%$ & $111.46 \%$ & $96.83 \%$ & $98.07 \%$ & $101.56 \%$ & $100.30 \%$ \\
\hline 33 & 4 & Neither & $0.5,3$ & $98.44 \%$ & $101.43 \%$ & $99.63 \%$ & $100.41 \%$ & $98.73 \%$ & $102.10 \%$ \\
\hline 34 & 4 & Tank & $0.5,3$ & $99.61 \%$ & $101.10 \%$ & $98.72 \%$ & $117.89 \%$ & $105.52 \%$ & $105.32 \%$ \\
\hline 35 & 4 & PEX & $0.5,3$ & $98.82 \%$ & $98.23 \%$ & $99.71 \%$ & $99.68 \%$ & $101.25 \%$ & $98.00 \%$ \\
\hline 36 & 4 & Both & $0.5,3$ & $98.24 \%$ & $99.83 \%$ & $97.25 \%$ & $99.40 \%$ & $102.55 \%$ & $100.19 \%$ \\
\hline
\end{tabular}


Table 9. Accuracies of ultrasonic Manufacturer 2 meters in the burst flow condition.

\begin{tabular}{|c|c|c|c|c|c|c|c|c|c|}
\hline $\begin{array}{l}\text { Test } \\
\text { No. }\end{array}$ & $\begin{array}{l}\text { Nominal } \\
\text { Flow } \\
\text { (gpm) }\end{array}$ & $\begin{array}{c}\text { Test } \\
\text { Setup }\end{array}$ & $\begin{array}{l}\text { Time } \\
\text { Comb. } \\
\text { (s on, } \\
\text { s off) }\end{array}$ & Meter 1 & Meter 2 & Meter 3 & Meter 4 & Meter 5 & Meter 6 \\
\hline 1 & 0.25 & Neither & 1,3 & $100.02 \%$ & $99.84 \%$ & $97.36 \%$ & $95.65 \%$ & $97.68 \%$ & $97.68 \%$ \\
\hline 2 & 0.25 & Tank & 1,3 & $100.92 \%$ & $100.62 \%$ & $99.13 \%$ & $95.86 \%$ & $97.74 \%$ & $97.74 \%$ \\
\hline 3 & 0.25 & PEX & 1,3 & $99.54 \%$ & $98.34 \%$ & $97.88 \%$ & $96.12 \%$ & $97.22 \%$ & $97.02 \%$ \\
\hline 4 & 0.25 & Both & 1,3 & $100.42 \%$ & $99.83 \%$ & $97.85 \%$ & $97.45 \%$ & $97.17 \%$ & $97.17 \%$ \\
\hline 5 & 0.25 & Neither & 1,4 & $99.72 \%$ & $97.23 \%$ & $94.53 \%$ & $96.39 \%$ & $99.08 \%$ & $97.45 \%$ \\
\hline 6 & 0.25 & Tank & 1,4 & $99.50 \%$ & $98.21 \%$ & $95.04 \%$ & $96.35 \%$ & $98.14 \%$ & $97.15 \%$ \\
\hline 7 & 0.25 & PEX & 1,4 & $98.75 \%$ & $98.05 \%$ & $95.75 \%$ & $97.64 \%$ & $96.94 \%$ & $97.34 \%$ \\
\hline 8 & 0.25 & Both & 1,4 & $98.79 \%$ & $97.10 \%$ & $95.70 \%$ & $98.90 \%$ & $98.41 \%$ & $99.19 \%$ \\
\hline 9 & 0.25 & Neither & $0.5,3$ & $103.26 \%$ & $102.17 \%$ & $97.89 \%$ & $103.68 \%$ & $104.46 \%$ & $102.98 \%$ \\
\hline 10 & 0.25 & Tank & $0.5,3$ & $101.80 \%$ & $101.70 \%$ & $98.11 \%$ & $102.62 \%$ & $102.72 \%$ & $101.48 \%$ \\
\hline 11 & 0.25 & PEX & $0.5,3$ & $100.59 \%$ & $99.53 \%$ & $95.39 \%$ & $103.94 \%$ & $105.69 \%$ & $104.13 \%$ \\
\hline 12 & 0.25 & Both & $0.5,3$ & $99.65 \%$ & $99.34 \%$ & $96.65 \%$ & $102.24 \%$ & $102.24 \%$ & $102.64 \%$ \\
\hline 13 & 2 & Neither & 1,3 & $101.03 \%$ & $100.07 \%$ & $99.20 \%$ & $99.34 \%$ & $100.13 \%$ & $100.32 \%$ \\
\hline 14 & 2 & Tank & 1,3 & $100.68 \%$ & $100.42 \%$ & $97.20 \%$ & $99.60 \%$ & $99.21 \%$ & $99.90 \%$ \\
\hline 15 & 2 & PEX & 1,3 & $101.20 \%$ & $100.28 \%$ & $99.27 \%$ & $98.02 \%$ & $100.01 \%$ & $99.31 \%$ \\
\hline 16 & 2 & Both & 1,3 & $100.03 \%$ & $99.83 \%$ & $98.63 \%$ & $99.74 \%$ & $99.44 \%$ & $99.74 \%$ \\
\hline 17 & 2 & Neither & 1,4 & $99.59 \%$ & $99.79 \%$ & $99.29 \%$ & $99.62 \%$ & $99.62 \%$ & $100.39 \%$ \\
\hline 18 & 2 & Tank & 1,4 & $101.41 \%$ & $102.76 \%$ & $98.99 \%$ & $99.11 \%$ & $99.21 \%$ & $100.10 \%$ \\
\hline 19 & 2 & PEX & 1,4 & $101.26 \%$ & $98.57 \%$ & $99.37 \%$ & $99.23 \%$ & $99.73 \%$ & $98.24 \%$ \\
\hline 20 & 2 & Both & 1,4 & $98.94 \%$ & $98.34 \%$ & $98.15 \%$ & $99.38 \%$ & $99.19 \%$ & $99.48 \%$ \\
\hline 21 & 2 & Neither & $0.5,3$ & $97.64 \%$ & $99.84 \%$ & $99.54 \%$ & $99.74 \%$ & $99.44 \%$ & $100.14 \%$ \\
\hline 22 & 2 & Tank & $0.5,3$ & $99.08 \%$ & $99.97 \%$ & $98.89 \%$ & $99.29 \%$ & $99.29 \%$ & $99.98 \%$ \\
\hline 23 & 2 & PEX & $0.5,3$ & $99.73 \%$ & $100.48 \%$ & $98.79 \%$ & $98.92 \%$ & $99.02 \%$ & $99.52 \%$ \\
\hline 24 & 2 & Both & $0.5,3$ & $99.77 \%$ & $99.86 \%$ & $99.07 \%$ & $98.53 \%$ & $99.32 \%$ & $100.32 \%$ \\
\hline 25 & 4 & Neither & 1,3 & $100.61 \%$ & $101.61 \%$ & $97.96 \%$ & $101.36 \%$ & $99.03 \%$ & $98.74 \%$ \\
\hline 26 & 4 & Tank & 1,3 & $100.55 \%$ & $100.36 \%$ & $100.55 \%$ & $101.09 \%$ & $99.21 \%$ & $99.80 \%$ \\
\hline 27 & 4 & PEX & 1,3 & $99.24 \%$ & $99.44 \%$ & $98.95 \%$ & $99.40 \%$ & $99.60 \%$ & $99.40 \%$ \\
\hline 28 & 4 & Both & 1,3 & $101.27 \%$ & $98.99 \%$ & $99.58 \%$ & $99.38 \%$ & $98.31 \%$ & $99.19 \%$ \\
\hline 29 & 4 & Neither & 1,4 & $98.33 \%$ & $100.19 \%$ & $97.35 \%$ & $96.92 \%$ & $99.58 \%$ & $100.86 \%$ \\
\hline 30 & 4 & Tank & 1,4 & $102.45 \%$ & $99.78 \%$ & $101.76 \%$ & $96.77 \%$ & $103.36 \%$ & $96.77 \%$ \\
\hline 31 & 4 & PEX & 1,4 & $97.80 \%$ & $100.49 \%$ & $97.00 \%$ & $101.00 \%$ & $96.85 \%$ & $98.73 \%$ \\
\hline 32 & 4 & Both & 1,4 & $96.43 \%$ & $101.90 \%$ & $103.40 \%$ & $101.27 \%$ & $98.26 \%$ & $96.42 \%$ \\
\hline 33 & 4 & Neither & $0.5,3$ & $97.54 \%$ & $97.64 \%$ & $99.03 \%$ & $99.62 \%$ & $100.21 \%$ & $100.11 \%$ \\
\hline 34 & 4 & Tank & $0.5,3$ & $101.00 \%$ & $99.81 \%$ & $96.74 \%$ & $98.93 \%$ & $94.71 \%$ & $105.02 \%$ \\
\hline 35 & 4 & PEX & $0.5,3$ & $100.80 \%$ & $100.70 \%$ & $96.74 \%$ & $103.03 \%$ & $96.42 \%$ & $95.04 \%$ \\
\hline 36 & 4 & Both & $0.5,3$ & $98.83 \%$ & $99.13 \%$ & $98.34 \%$ & $99.50 \%$ & $100.09 \%$ & $97.53 \%$ \\
\hline
\end{tabular}


Table 10. Accuracies of electromagnetic Manufacturer 1 meters in the burst flow condition.

\begin{tabular}{|c|c|c|c|c|c|c|c|c|c|}
\hline $\begin{array}{l}\text { Test } \\
\text { No. }\end{array}$ & $\begin{array}{c}\text { Nominal } \\
\text { Flow } \\
\text { (gpm) }\end{array}$ & $\begin{array}{c}\text { Test } \\
\text { Setup }\end{array}$ & $\begin{array}{c}\text { Time } \\
\text { Comb. } \\
\text { (s on, } \\
\text { s off) }\end{array}$ & Meter 1 & Meter 2 & Meter 3 & Meter 4 & Meter 5 & Meter 6 \\
\hline 1 & 0.25 & Neither & 1,3 & $99.84 \%$ & $99.66 \%$ & $99.58 \%$ & $99.89 \%$ & $99.79 \%$ & $99.51 \%$ \\
\hline 2 & 0.25 & Tank & 1,3 & $99.72 \%$ & $99.82 \%$ & $100.22 \%$ & $99.82 \%$ & $99.72 \%$ & $99.72 \%$ \\
\hline 3 & 0.25 & PEX & 1,3 & $99.72 \%$ & $99.72 \%$ & $99.54 \%$ & $99.81 \%$ & $100.41 \%$ & $99.51 \%$ \\
\hline 4 & 0.25 & Both & 1,3 & $98.84 \%$ & $98.94 \%$ & $99.43 \%$ & $100.92 \%$ & $99.51 \%$ & $100.17 \%$ \\
\hline 5 & 0.25 & Neither & 1,4 & $100.02 \%$ & $101.12 \%$ & $100.12 \%$ & $100.33 \%$ & $100.14 \%$ & $100.72 \%$ \\
\hline 6 & 0.25 & Tank & 1,4 & $100.09 \%$ & $99.89 \%$ & $99.50 \%$ & $100.14 \%$ & $99.84 \%$ & $99.44 \%$ \\
\hline 7 & 0.25 & PEX & 1,4 & $99.25 \%$ & $99.94 \%$ & $100.24 \%$ & $99.93 \%$ & $99.73 \%$ & $98.94 \%$ \\
\hline 8 & 0.25 & Both & 1,4 & $98.99 \%$ & $99.79 \%$ & $100.09 \%$ & $100.56 \%$ & $100.07 \%$ & $99.48 \%$ \\
\hline 9 & 0.25 & Neither & $0.5,3$ & $99.48 \%$ & $99.68 \%$ & $99.88 \%$ & $99.70 \%$ & $98.93 \%$ & $100.02 \%$ \\
\hline 10 & 0.25 & Tank & $0.5,3$ & $99.20 \%$ & $99.01 \%$ & $99.60 \%$ & $99.21 \%$ & $99.40 \%$ & $100.25 \%$ \\
\hline 11 & 0.25 & PEX & $0.5,3$ & $98.74 \%$ & $99.35 \%$ & $99.09 \%$ & $99.16 \%$ & $99.26 \%$ & $99.84 \%$ \\
\hline 12 & 0.25 & Both & $0.5,3$ & $98.96 \%$ & $98.57 \%$ & $99.65 \%$ & $99.35 \%$ & $99.55 \%$ & $98.75 \%$ \\
\hline 13 & 2 & Neither & 1,3 & $99.03 \%$ & $100.07 \%$ & $100.16 \%$ & $100.13 \%$ & $99.34 \%$ & $99.05 \%$ \\
\hline 14 & 2 & Tank & 1,3 & $99.72 \%$ & $97.55 \%$ & $100.24 \%$ & $99.80 \%$ & $98.91 \%$ & $99.01 \%$ \\
\hline 15 & 2 & PEX & 1,3 & $99.54 \%$ & $99.91 \%$ & $99.91 \%$ & $100.01 \%$ & $98.42 \%$ & $98.72 \%$ \\
\hline 16 & 2 & Both & 1,3 & $99.53 \%$ & $99.83 \%$ & $100.12 \%$ & $99.44 \%$ & $98.64 \%$ & $99.04 \%$ \\
\hline 17 & 2 & Neither & 1,4 & $100.19 \%$ & $99.59 \%$ & $100.29 \%$ & $99.82 \%$ & $100.20 \%$ & $100.30 \%$ \\
\hline 18 & 2 & Tank & 1,4 & $101.31 \%$ & $101.12 \%$ & $101.02 \%$ & $99.90 \%$ & $100.10 \%$ & $99.51 \%$ \\
\hline 19 & 2 & PEX & 1,4 & $98.67 \%$ & $101.46 \%$ & $98.27 \%$ & $99.83 \%$ & $99.83 \%$ & $99.73 \%$ \\
\hline 20 & 2 & Both & 1,4 & $100.52 \%$ & $99.13 \%$ & $100.42 \%$ & $99.88 \%$ & $100.37 \%$ & $99.48 \%$ \\
\hline 21 & 2 & Neither & $0.5,3$ & $100.73 \%$ & $100.23 \%$ & $100.43 \%$ & $99.84 \%$ & $100.24 \%$ & $99.74 \%$ \\
\hline 22 & 2 & Tank & $0.5,3$ & $100.86 \%$ & $100.86 \%$ & $100.57 \%$ & $99.78 \%$ & $100.08 \%$ & $100.08 \%$ \\
\hline 23 & 2 & PEX & $0.5,3$ & $99.82 \%$ & $100.38 \%$ & $99.07 \%$ & $99.62 \%$ & $99.82 \%$ & $99.72 \%$ \\
\hline 24 & 2 & Both & $0.5,3$ & $100.06 \%$ & $99.37 \%$ & $100.36 \%$ & $99.82 \%$ & $100.32 \%$ & $99.62 \%$ \\
\hline 25 & 4 & Neither & 1,3 & $98.41 \%$ & $99.51 \%$ & $99.51 \%$ & $98.45 \%$ & $100.39 \%$ & $100.29 \%$ \\
\hline 26 & 4 & Tank & 1,3 & $100.16 \%$ & $98.98 \%$ & $99.67 \%$ & $98.81 \%$ & $99.40 \%$ & $99.40 \%$ \\
\hline 27 & 4 & PEX & 1,3 & $98.26 \%$ & $99.15 \%$ & $99.84 \%$ & $99.30 \%$ & $100.09 \%$ & $99.89 \%$ \\
\hline 28 & 4 & Both & 1,3 & $99.68 \%$ & $99.68 \%$ & $99.88 \%$ & $99.97 \%$ & $100.16 \%$ & $99.87 \%$ \\
\hline 29 & 4 & Neither & 1,4 & $100.09 \%$ & $100.48 \%$ & $100.38 \%$ & $99.78 \%$ & $99.88 \%$ & $99.48 \%$ \\
\hline 30 & 4 & Tank & 1,4 & $100.77 \%$ & $100.18 \%$ & $100.28 \%$ & $100.31 \%$ & $100.31 \%$ & $100.31 \%$ \\
\hline 31 & 4 & PEX & 1,4 & $102.38 \%$ & $97.60 \%$ & $101.09 \%$ & $99.96 \%$ & $100.24 \%$ & $99.86 \%$ \\
\hline 32 & 4 & Both & 1,4 & $101.11 \%$ & $101.41 \%$ & $101.11 \%$ & $99.91 \%$ & $100.30 \%$ & $100.30 \%$ \\
\hline 33 & 4 & Neither & $0.5,3$ & $99.93 \%$ & $101.23 \%$ & $100.53 \%$ & $99.92 \%$ & $100.31 \%$ & $100.11 \%$ \\
\hline 34 & 4 & Tank & $0.5,3$ & $99.51 \%$ & $98.32 \%$ & $99.12 \%$ & $100.51 \%$ & $100.31 \%$ & $100.60 \%$ \\
\hline 35 & 4 & PEX & $0.5,3$ & $100.90 \%$ & $98.82 \%$ & $101.00 \%$ & $100.07 \%$ & $99.97 \%$ & $100.17 \%$ \\
\hline 36 & 4 & Both & $0.5,3$ & $98.74 \%$ & $99.53 \%$ & $99.13 \%$ & $100.39 \%$ & $99.99 \%$ & $100.58 \%$ \\
\hline
\end{tabular}


Table 11. Accuracies of nutating disc Manufacturer 1 meters in the burst flow condition.

\begin{tabular}{|c|c|c|c|c|c|c|c|c|c|}
\hline $\begin{array}{l}\text { Test } \\
\text { No. }\end{array}$ & $\begin{array}{l}\text { Nominal } \\
\text { Flow } \\
(\text { gpm) }\end{array}$ & $\begin{array}{c}\text { Test } \\
\text { Setup }\end{array}$ & $\begin{array}{c}\text { Time } \\
\text { Comb. } \\
\text { (s on, } \\
\text { s off) }\end{array}$ & Meter 1 & Meter 2 & Meter 3 & Meter 4 & Meter 5 & Meter 6 \\
\hline 1 & 0.25 & Neither & 1,3 & $90.10 \%$ & $90.72 \%$ & $91.43 \%$ & $90.16 \%$ & $92.86 \%$ & $92.57 \%$ \\
\hline 2 & 0.25 & Tank & 1,3 & $87.45 \%$ & $86.75 \%$ & $87.65 \%$ & $90.11 \%$ & $92.69 \%$ & $92.19 \%$ \\
\hline 3 & 0.25 & PEX & 1,3 & $87.56 \%$ & $87.10 \%$ & $87.19 \%$ & $92.23 \%$ & $94.03 \%$ & $93.83 \%$ \\
\hline 4 & 0.25 & Both & 1,3 & $86.09 \%$ & $85.79 \%$ & $86.29 \%$ & $93.14 \%$ & $94.64 \%$ & $94.64 \%$ \\
\hline 5 & 0.25 & Neither & 1,4 & $88.84 \%$ & $89.14 \%$ & $89.24 \%$ & $87.74 \%$ & $90.72 \%$ & $89.38 \%$ \\
\hline 6 & 0.25 & Tank & 1,4 & $91.17 \%$ & $91.27 \%$ & $91.57 \%$ & $87.26 \%$ & $90.26 \%$ & $89.56 \%$ \\
\hline 7 & 0.25 & PEX & 1,4 & $95.95 \%$ & $95.95 \%$ & $96.15 \%$ & $89.85 \%$ & $91.65 \%$ & $91.45 \%$ \\
\hline 8 & 0.25 & Both & 1,4 & $95.70 \%$ & $95.70 \%$ & $95.90 \%$ & $86.52 \%$ & $90.91 \%$ & $89.16 \%$ \\
\hline 9 & 0.25 & Neither & $0.5,3$ & $96.59 \%$ & $96.49 \%$ & $96.59 \%$ & $81.71 \%$ & $88.64 \%$ & $86.31 \%$ \\
\hline 10 & 0.25 & Tank & $0.5,3$ & $94.41 \%$ & $94.11 \%$ & $94.01 \%$ & $78.65 \%$ & $86.23 \%$ & $84.43 \%$ \\
\hline 11 & 0.25 & PEX & $0.5,3$ & $96.01 \%$ & $95.48 \%$ & $95.74 \%$ & $81.22 \%$ & $88.34 \%$ & $86.19 \%$ \\
\hline 12 & 0.25 & Both & $0.5,3$ & $96.65 \%$ & $96.19 \%$ & $96.42 \%$ & $78.40 \%$ & $85.98 \%$ & $84.09 \%$ \\
\hline 13 & 2 & Neither & 1,3 & $99.29 \%$ & $99.47 \%$ & $99.81 \%$ & $100.03 \%$ & $100.52 \%$ & $100.23 \%$ \\
\hline 14 & 2 & Tank & 1,3 & $100.07 \%$ & $100.16 \%$ & $100.24 \%$ & $99.80 \%$ & $100.30 \%$ & $100.10 \%$ \\
\hline 15 & 2 & PEX & 1,3 & $92.45 \%$ & $99.54 \%$ & $100.00 \%$ & $100.41 \%$ & $100.70 \%$ & $100.41 \%$ \\
\hline 16 & 2 & Both & 1,3 & $100.12 \%$ & $100.22 \%$ & $100.32 \%$ & $99.84 \%$ & $100.33 \%$ & $100.03 \%$ \\
\hline 17 & 2 & Neither & 1 , & $100.19 \%$ & $100.29 \%$ & $100.49 \%$ & $99.72 \%$ & $100.39 \%$ & $100.01 \%$ \\
\hline 18 & 2 & Tank & 1,4 & $101.21 \%$ & $101.21 \%$ & $101.41 \%$ & $99.51 \%$ & $100.20 \%$ & $100.00 \%$ \\
\hline 19 & 2 & PEX & 1,4 & $100.27 \%$ & $100.27 \%$ & $100.56 \%$ & $100.22 \%$ & $100.52 \%$ & $100.42 \%$ \\
\hline 20 & 2 & Both & 1,4 & $99.83 \%$ & $99.92 \%$ & $100.12 \%$ & $99.78 \%$ & $100.17 \%$ & $99.98 \%$ \\
\hline 21 & 2 & Neither & $0.5,3$ & $100.23 \%$ & $100.23 \%$ & $100.43 \%$ & & $100.34 \%$ & $100.04 \%$ \\
\hline 22 & 2 & Tank & $0.5,3$ & $100.27 \%$ & $100.47 \%$ & $100.57 \%$ & $99.29 \%$ & $100.08 \%$ & $99.68 \%$ \\
\hline 23 & 2 & PEX & $0.5,3$ & $100.48 \%$ & $100.57 \%$ & $100.85 \%$ & $100.81 \%$ & $100.81 \%$ & $100.61 \%$ \\
\hline 24 & 2 & Both & $0.5,3$ & $100.46 \%$ & $100.56 \%$ & $100.76 \%$ & $100.52 \%$ & $100.81 \%$ & $100.61 \%$ \\
\hline 25 & 4 & Neither & 1,3 & $97.96 \%$ & $100.51 \%$ & $100.88 \%$ & $99.71 \%$ & $99.52 \%$ & $100.29 \%$ \\
\hline 26 & 4 & Tank & 1,3 & $99.96 \%$ & $100.45 \%$ & $100.85 \%$ & $98.81 \%$ & $98.61 \%$ & $99.90 \%$ \\
\hline 27 & 4 & PEX & 1,3 & $100.63 \%$ & $100.33 \%$ & $100.73 \%$ & $101.16 \%$ & $101.06 \%$ & $100.67 \%$ \\
\hline 28 & 4 & Both & 1,3 & $99.68 \%$ & $100.57 \%$ & $100.87 \%$ & $101.04 \%$ & $100.85 \%$ & $100.55 \%$ \\
\hline 29 & 4 & Neither & 1,4 & $99.89 \%$ & $100.38 \%$ & $100.77 \%$ & $100.86 \%$ & $100.67 \%$ & $100.67 \%$ \\
\hline 30 & 4 & Tank & 1,4 & $100.48 \%$ & $100.97 \%$ & $101.26 \%$ & $101.07 \%$ & $100.88 \%$ & $100.97 \%$ \\
\hline 31 & 4 & PEX & 1,4 & $101.39 \%$ & $100.29 \%$ & $100.69 \%$ & $101.28 \%$ & $101.19 \%$ & $100.71 \%$ \\
\hline 32 & 4 & Both & 1,4 & $100.21 \%$ & $100.31 \%$ & $100.51 \%$ & $101.37 \%$ & $101.08 \%$ & $100.59 \%$ \\
\hline 33 & 4 & Neither & $0.5,3$ & $100.13 \%$ & $100.33 \%$ & $100.63 \%$ & $100.31 \%$ & $100.61 \%$ & $100.41 \%$ \\
\hline 34 & 4 & Tank & $0.5,3$ & $99.32 \%$ & $99.61 \%$ & $99.81 \%$ & $101.29 \%$ & $101.39 \%$ & $101.19 \%$ \\
\hline 35 & 4 & PEX & $0.5,3$ & $101.59 \%$ & $100.30 \%$ & $100.60 \%$ & $101.84 \%$ & $101.75 \%$ & $100.46 \%$ \\
\hline 36 & 4 & Both & $0.5,3$ & $100.13 \%$ & $100.52 \%$ & $100.72 \%$ & $101.47 \%$ & $101.47 \%$ & $100.58 \%$ \\
\hline
\end{tabular}


Table 12. Accuracies of nutating disc Manufacturer 2 meters in the burst flow condition.

\begin{tabular}{|c|c|c|c|c|c|c|c|c|c|}
\hline $\begin{array}{l}\text { Test } \\
\text { No. }\end{array}$ & $\begin{array}{l}\text { Nominal } \\
\text { Flow } \\
\text { (gpm) }\end{array}$ & $\begin{array}{c}\text { Test } \\
\text { Setup }\end{array}$ & $\begin{array}{c}\text { Time } \\
\text { Comb. } \\
\text { (s on, } \\
\text { s off) }\end{array}$ & Meter 1 & Meter 2 & Meter 3 & Meter 4 & Meter 5 & Meter 6 \\
\hline 1 & 0.25 & Neither & 1,3 & $94.97 \%$ & $96.03 \%$ & $95.06 \%$ & $94.79 \%$ & $89.97 \%$ & $89.78 \%$ \\
\hline 2 & 0.25 & Tank & 1,3 & $92.34 \%$ & $94.73 \%$ & $91.54 \%$ & $93.87 \%$ & $89.02 \%$ & $89.91 \%$ \\
\hline 3 & 0.25 & PEX & 1,3 & $91.43 \%$ & $94.56 \%$ & $91.98 \%$ & $94.73 \%$ & $90.44 \%$ & $91.24 \%$ \\
\hline 4 & 0.25 & Both & 1,3 & $91.43 \%$ & $94.29 \%$ & $90.54 \%$ & $94.92 \%$ & $90.89 \%$ & $91.27 \%$ \\
\hline 5 & 0.25 & Neither & 1,4 & $93.04 \%$ & $93.93 \%$ & $93.54 \%$ & $91.59 \%$ & $83.71 \%$ & $88.70 \%$ \\
\hline 6 & 0.25 & Tank & 1,4 & $94.94 \%$ & $94.54 \%$ & $94.94 \%$ & $89.96 \%$ & $84.07 \%$ & $88.86 \%$ \\
\hline 7 & 0.25 & PEX & 1,4 & $97.45 \%$ & $97.75 \%$ & $97.85 \%$ & $92.45 \%$ & $86.46 \%$ & $89.55 \%$ \\
\hline 8 & 0.25 & Both & 1,4 & $97.40 \%$ & $97.00 \%$ & $97.20 \%$ & $92.27 \%$ & $86.91 \%$ & $88.47 \%$ \\
\hline 9 & 0.25 & Neither & $0.5,3$ & $98.09 \%$ & $98.39 \%$ & $98.19 \%$ & $85.22 \%$ & $78.44 \%$ & $83.19 \%$ \\
\hline 10 & 0.25 & Tank & $0.5,3$ & $95.91 \%$ & $96.31 \%$ & $95.81 \%$ & $80.54 \%$ & $78.93 \%$ & $76.75 \%$ \\
\hline 11 & 0.25 & PEX & $0.5,3$ & $97.77 \%$ & $98.30 \%$ & $97.94 \%$ & $84.34 \%$ & $82.39 \%$ & $82.49 \%$ \\
\hline 12 & 0.25 & Both & $0.5,3$ & $98.34 \%$ & $98.65 \%$ & $98.11 \%$ & $83.79 \%$ & $81.69 \%$ & $76.01 \%$ \\
\hline 13 & 2 & Neither & 1,3 & $100.42 \%$ & $100.59 \%$ & $100.59 \%$ & $100.42 \%$ & $100.62 \%$ & $100.72 \%$ \\
\hline 14 & 2 & Tank & 1,3 & $100.33 \%$ & $100.85 \%$ & $100.76 \%$ & $100.40 \%$ & $100.60 \%$ & $100.70 \%$ \\
\hline 15 & 2 & PEX & 1,3 & $100.46 \%$ & $100.56 \%$ & $100.65 \%$ & $100.31 \%$ & $100.60 \%$ & $100.70 \%$ \\
\hline 16 & 2 & Both & 1,3 & $100.42 \%$ & $100.92 \%$ & $100.72 \%$ & $100.43 \%$ & $100.53 \%$ & $100.53 \%$ \\
\hline 17 & 2 & Neither & 1,4 & & $100.88 \%$ & 100.6 & $100.39 \%$ & $100.49 \%$ & $100.49 \%$ \\
\hline 18 & 2 & Tank & 1,4 & $101.70 \%$ & $101.89 \%$ & 101.9 & $100.49 \%$ & $100.39 \%$ & $100.29 \%$ \\
\hline 19 & 2 & PEX & 1,4 & $100.56 \%$ & $100.96 \%$ & $100.76 \%$ & $100.52 \%$ & $100.52 \%$ & $100.62 \%$ \\
\hline 20 & 2 & Both & 1,4 & $100.32 \%$ & $100.71 \%$ & $100.62 \%$ & $100.17 \%$ & $100.17 \%$ & $100.17 \%$ \\
\hline 21 & 2 & Neither & $0.5,3$ & $100.43 \%$ & $100.93 \%$ & $100.73 \%$ & $100.44 \%$ & $100.64 \%$ & $100.24 \%$ \\
\hline 22 & 2 & Tank & $0.5,3$ & $100.67 \%$ & $100.96 \%$ & $100.86 \%$ & $100.18 \%$ & $100.47 \%$ & $100.08 \%$ \\
\hline 23 & 0 & PEX & $0.5,3$ & $100.76 \%$ & $101.14 \%$ & $100.95 \%$ & $100.71 \%$ & $100.91 \%$ & $100.51 \%$ \\
\hline 24 & 2 & Both & $0.5,3$ & $100.76 \%$ & $101.15 \%$ & $101.05 \%$ & $100.71 \%$ & $100.81 \%$ & $100.42 \%$ \\
\hline 25 & 4 & Neither & 1,3 & $100.24 \%$ & $100.24 \%$ & $100.33 \%$ & $100.20 \%$ & $100.10 \%$ & $100.39 \%$ \\
\hline 26 & 4 & Tank & 1,3 & $100.16 \%$ & $100.26 \%$ & $100.26 \%$ & $99.60 \%$ & $99.60 \%$ & $99.80 \%$ \\
\hline 27 & 4 & PEX & 1,3 & $100.33 \%$ & $100.33 \%$ & $100.33 \%$ & $100.18 \%$ & $100.18 \%$ & $100.77 \%$ \\
\hline 28 & 4 & Both & 1,3 & $100.37 \%$ & $100.47 \%$ & $100.47 \%$ & $100.16 \%$ & $100.16 \%$ & $100.65 \%$ \\
\hline 29 & 4 & Neither & 1,4 & $100.19 \%$ & $100.19 \%$ & $100.29 \%$ & $100.08 \%$ & $100.08 \%$ & $100.47 \%$ \\
\hline 30 & 4 & Tank & 1,4 & $100.97 \%$ & $101.07 \%$ & $101.07 \%$ & $100.50 \%$ & $100.50 \%$ & $100.88 \%$ \\
\hline 31 & 4 & PEX & 1,4 & $100.19 \%$ & $100.19 \%$ & $100.29 \%$ & $100.15 \%$ & $100.15 \%$ & $100.62 \%$ \\
\hline 32 & 4 & Both & 1,4 & $100.41 \%$ & $100.51 \%$ & $100.51 \%$ & $100.11 \%$ & $100.20 \%$ & $100.50 \%$ \\
\hline 33 & 4 & Neither & $0.5,3$ & $100.23 \%$ & $100.33 \%$ & $100.43 \%$ & $100.41 \%$ & $100.51 \%$ & $100.91 \%$ \\
\hline 34 & 4 & Tank & $0.5,3$ & $99.41 \%$ & $99.51 \%$ & $99.51 \%$ & $100.80 \%$ & $100.70 \%$ & $101.00 \%$ \\
\hline 35 & 4 & PEX & $0.5,3$ & $100.30 \%$ & $100.40 \%$ & $100.50 \%$ & $100.27 \%$ & $100.37 \%$ & $100.56 \%$ \\
\hline 36 & 4 & Both & $0.5,3$ & $100.52 \%$ & $100.52 \%$ & $100.62 \%$ & $100.29 \%$ & $100.29 \%$ & $100.68 \%$ \\
\hline
\end{tabular}


Table 13. Accuracies of oscillating piston Manufacturer 1 meters in the burst flow condition.

\begin{tabular}{|c|c|c|c|c|c|c|c|c|c|}
\hline $\begin{array}{l}\text { Test } \\
\text { No. }\end{array}$ & $\begin{array}{c}\text { Nominal } \\
\text { Flow } \\
\text { (gpm) }\end{array}$ & $\begin{array}{c}\text { Test } \\
\text { Setup }\end{array}$ & $\begin{array}{c}\text { Time } \\
\text { Comb. } \\
\text { (s on, } \\
\text { s off) }\end{array}$ & Meter 1 & Meter 2 & Meter 3 & Meter 4 & Meter 5 & Meter 6 \\
\hline 1 & 0.25 & Neither & 1,3 & $87.79 \%$ & $87.53 \%$ & $88.77 \%$ & $94.40 \%$ & $92.67 \%$ & $91.99 \%$ \\
\hline 2 & 0.25 & Tank & 1,3 & $79.06 \%$ & $80.36 \%$ & $82.25 \%$ & $93.97 \%$ & $92.09 \%$ & $91.60 \%$ \\
\hline 3 & 0.25 & PEX & 1,3 & $89.12 \%$ & $89.58 \%$ & $89.58 \%$ & $94.63 \%$ & $93.43 \%$ & $93.33 \%$ \\
\hline 4 & 0.25 & Both & 1,3 & $77.49 \%$ & $77.69 \%$ & $80.06 \%$ & $94.64 \%$ & $93.52 \%$ & $93.80 \%$ \\
\hline 5 & 0.25 & Neither & 1,4 & $91.74 \%$ & $89.74 \%$ & $93.34 \%$ & $94.57 \%$ & $92.07 \%$ & $90.63 \%$ \\
\hline 6 & 0.25 & Tank & 1,4 & $91.87 \%$ & $90.78 \%$ & $93.75 \%$ & $92.75 \%$ & $90.46 \%$ & $89.86 \%$ \\
\hline 7 & 0.25 & PEX & 1,4 & $95.75 \%$ & $94.55 \%$ & $96.45 \%$ & $93.64 \%$ & $91.95 \%$ & $91.75 \%$ \\
\hline 8 & 0.25 & Both & 1,4 & $95.20 \%$ & $93.90 \%$ & $96.70 \%$ & $90.42 \%$ & $90.13 \%$ & $89.64 \%$ \\
\hline 9 & 0.25 & Neither & $0.5,3$ & $96.09 \%$ & $95.80 \%$ & $96.99 \%$ & $78.44 \%$ & $79.22 \%$ & $77.19 \%$ \\
\hline 10 & 0.25 & Tank & $0.5,3$ & $93.51 \%$ & $93.51 \%$ & $94.71 \%$ & $71.26 \%$ & $68.70 \%$ & $68.51 \%$ \\
\hline 11 & 0.25 & PEX & $0.5,3$ & $95.74 \%$ & $95.21 \%$ & $96.89 \%$ & $72.64 \%$ & $70.20 \%$ & $69.42 \%$ \\
\hline 12 & 0.25 & Both & $0.5,3$ & $96.19 \%$ & $95.89 \%$ & $96.96 \%$ & $77.70 \%$ & $76.11 \%$ & $73.91 \%$ \\
\hline 13 & 2 & Neither & 1,3 & $99.29 \%$ & $99.03 \%$ & $99.90 \%$ & $99.05 \%$ & $99.05 \%$ & $97.87 \%$ \\
\hline 14 & 2 & Tank & 1,3 & $99.81 \%$ & $99.37 \%$ & $100.76 \%$ & $98.41 \%$ & $98.31 \%$ & $98.01 \%$ \\
\hline 15 & 2 & PEX & 1,3 & $99.54 \%$ & $99.36 \%$ & $100.37 \%$ & $100.50 \%$ & $100.70 \%$ & $100.11 \%$ \\
\hline 16 & 2 & Both & 1,3 & $99.83 \%$ & $99.43 \%$ & $101.02 \%$ & $99.74 \%$ & $99.74 \%$ & $99.54 \%$ \\
\hline 17 & 2 & Neither & 1,4 & $99.89 \%$ & $99.39 \%$ & $100.98 \%$ & $97.80 \%$ & $97.70 \%$ & $97.42 \%$ \\
\hline 18 & 2 & Tank & 1,4 & $100.63 \%$ & $100.05 \%$ & $101.79 \%$ & $98.91 \%$ & $98.91 \%$ & $98.62 \%$ \\
\hline 19 & 2 & PEX & 1,4 & $100.07 \%$ & $99.57 \%$ & $101.56 \%$ & $100.52 \%$ & $100.62 \%$ & $100.22 \%$ \\
\hline 20 & 2 & Both & 1,4 & $99.53 \%$ & $99.13 \%$ & $100.71 \%$ & $100.37 \%$ & $100.27 \%$ & $99.98 \%$ \\
\hline 21 & 2 & Neither & $0.5,3$ & $99.94 \%$ & $99.54 \%$ & $100.83 \%$ & $98.05 \%$ & $97.95 \%$ & $97.15 \%$ \\
\hline 22 & 2 & Tank & $0.5,3$ & $99.88 \%$ & $99.48 \%$ & $101.06 \%$ & $96.43 \%$ & $96.52 \%$ & $93.96 \%$ \\
\hline 23 & 2 & PEX & $0.5,3$ & $100.10 \%$ & $99.54 \%$ & $101.14 \%$ & $100.31 \%$ & $100.31 \%$ & $99.92 \%$ \\
\hline 24 & 2 & Both & $0.5,3$ & $100.06 \%$ & $99.57 \%$ & $100.95 \%$ & $100.22 \%$ & $100.12 \%$ & $99.82 \%$ \\
\hline 25 & 4 & Neither & 1,3 & $99.97 \%$ & $99.88 \%$ & $100.70 \%$ & $100.49 \%$ & $100.10 \%$ & $100.29 \%$ \\
\hline 26 & 4 & Tank & 1,3 & $99.96 \%$ & $100.06 \%$ & $100.85 \%$ & $99.80 \%$ & $99.50 \%$ & $99.80 \%$ \\
\hline 27 & 4 & PEX & 1,3 & $100.13 \%$ & $100.03 \%$ & $100.82 \%$ & $100.48 \%$ & $100.18 \%$ & $100.38 \%$ \\
\hline 28 & 4 & Both & 1,3 & $100.18 \%$ & $100.18 \%$ & $100.87 \%$ & $100.46 \%$ & $100.16 \%$ & $100.46 \%$ \\
\hline 29 & 4 & Neither & 1,4 & $99.99 \%$ & $100.09 \%$ & $100.77 \%$ & $100.47 \%$ & $100.08 \%$ & $100.37 \%$ \\
\hline 30 & 4 & Tank & 1,4 & $100.48 \%$ & $100.18 \%$ & $101.26 \%$ & $100.69 \%$ & $100.31 \%$ & $100.59 \%$ \\
\hline 31 & 4 & PEX & 1,4 & $99.99 \%$ & $99.99 \%$ & $100.79 \%$ & $100.43 \%$ & $100.15 \%$ & $100.43 \%$ \\
\hline 32 & 4 & Both & 1,4 & $99.71 \%$ & $99.12 \%$ & $100.61 \%$ & $100.50 \%$ & $100.30 \%$ & $100.40 \%$ \\
\hline 33 & 4 & Neither & $0.5,3$ & $100.13 \%$ & $100.03 \%$ & $100.83 \%$ & $100.11 \%$ & $100.11 \%$ & $99.82 \%$ \\
\hline 34 & 4 & Tank & $0.5,3$ & $99.22 \%$ & $99.22 \%$ & $100.01 \%$ & $100.70 \%$ & $100.51 \%$ & $100.51 \%$ \\
\hline 35 & 4 & PEX & $0.5,3$ & $100.01 \%$ & $99.91 \%$ & $100.90 \%$ & $100.56 \%$ & $100.27 \%$ & $100.46 \%$ \\
\hline 36 & 4 & Both & $0.5,3$ & $100.22 \%$ & $100.03 \%$ & $101.02 \%$ & $100.58 \%$ & $100.19 \%$ & $100.48 \%$ \\
\hline
\end{tabular}


Table 14. Accuracies of oscillating piston Manufacturer 2 meters in the burst flow condition.

\begin{tabular}{|c|c|c|c|c|c|c|c|c|c|}
\hline $\begin{array}{l}\text { Test } \\
\text { No. }\end{array}$ & $\begin{array}{c}\text { Nominal } \\
\text { Flow } \\
\text { (gpm) }\end{array}$ & $\begin{array}{c}\text { Test } \\
\text { Setup }\end{array}$ & $\begin{array}{c}\text { Time } \\
\text { Comb. } \\
\text { (s on, } \\
\text { s off) }\end{array}$ & Meter 1 & Meter 2 & Meter 3 & Meter 4 & Meter 5 & Meter 6 \\
\hline 1 & 0.25 & Neither & 1,3 & $90.54 \%$ & $90.72 \%$ & $89.30 \%$ & $93.15 \%$ & $94.50 \%$ & $92.28 \%$ \\
\hline 2 & 0.25 & Tank & 1,3 & $85.95 \%$ & $84.65 \%$ & $85.15 \%$ & $92.88 \%$ & $93.97 \%$ & $92.09 \%$ \\
\hline 3 & 0.25 & PEX & 1,3 & $89.58 \%$ & $89.58 \%$ & $89.58 \%$ & $93.73 \%$ & $94.73 \%$ & $92.83 \%$ \\
\hline 4 & 0.25 & Both & 1,3 & $84.90 \%$ & $83.62 \%$ & $82.33 \%$ & $94.17 \%$ & $95.02 \%$ & $93.42 \%$ \\
\hline 5 & 0.25 & Neither & 1,4 & $89.34 \%$ & $93.54 \%$ & $90.84 \%$ & $92.16 \%$ & $94.47 \%$ & $92.07 \%$ \\
\hline 6 & 0.25 & Tank & 1,4 & $90.58 \%$ & $94.05 \%$ & $92.36 \%$ & $91.35 \%$ & $93.05 \%$ & $91.06 \%$ \\
\hline 7 & 0.25 & PEX & 1,4 & $95.25 \%$ & $97.35 \%$ & $96.15 \%$ & $92.35 \%$ & $93.64 \%$ & $91.55 \%$ \\
\hline 8 & 0.25 & Both & 1,4 & $94.90 \%$ & $96.80 \%$ & $95.30 \%$ & $90.13 \%$ & $90.81 \%$ & $90.13 \%$ \\
\hline 9 & 0.25 & Neither & $0.5,3$ & $96.99 \%$ & $97.79 \%$ & $96.99 \%$ & $79.61 \%$ & $82.72 \%$ & $79.84 \%$ \\
\hline 10 & 0.25 & Tank & $0.5,3$ & $94.21 \%$ & $95.51 \%$ & $94.11 \%$ & $71.73 \%$ & $76.09 \%$ & $72.01 \%$ \\
\hline 11 & 0.25 & PEX & $0.5,3$ & $95.92 \%$ & $97.41 \%$ & $96.36 \%$ & $74.98 \%$ & $77.61 \%$ & $74.20 \%$ \\
\hline 12 & 0.25 & Both & $0.5,3$ & $96.42 \%$ & $97.57 \%$ & $96.50 \%$ & $78.00 \%$ & $80.40 \%$ & $77.70 \%$ \\
\hline 13 & 2 & Neither & 1,3 & $99.29 \%$ & $99.81 \%$ & $99.47 \%$ & $99.64 \%$ & $97.68 \%$ & $97.77 \%$ \\
\hline 14 & 2 & Tank & 1,3 & $99.81 \%$ & $100.59 \%$ & $100.33 \%$ & $98.11 \%$ & $98.01 \%$ & $98.11 \%$ \\
\hline 15 & 2 & PEX & 1,3 & $99.63 \%$ & $100.28 \%$ & $99.91 \%$ & $100.31 \%$ & $99.61 \%$ & $100.01 \%$ \\
\hline 16 & 2 & Both & 1,3 & $99.73 \%$ & $100.62 \%$ & $100.22 \%$ & $99.64 \%$ & $99.34 \%$ & $99.44 \%$ \\
\hline 17 & 2 & Neither & 1,4 & $99.79 \%$ & $100.69 \%$ & $100.29 \%$ & $97.61 \%$ & $97.51 \%$ & $97.51 \%$ \\
\hline 18 & 2 & Tank & 1,4 & $100.44 \%$ & $101.70 \%$ & $101.12 \%$ & $98.91 \%$ & $98.42 \%$ & $98.52 \%$ \\
\hline 19 & 2 & PEX & 1,4 & $99.97 \%$ & $100.76 \%$ & $100.27 \%$ & $100.22 \%$ & $99.53 \%$ & $99.93 \%$ \\
\hline 20 & 2 & Both & 1,4 & $99.43 \%$ & $100.42 \%$ & $99.92 \%$ & $99.98 \%$ & $99.29 \%$ & $99.48 \%$ \\
\hline 21 & 2 & Neither & $0.5,3$ & $99.74 \%$ & $100.73 \%$ & $100.23 \%$ & $98.85 \%$ & $96.55 \%$ & $95.86 \%$ \\
\hline 22 & 2 & Tank & $0.5,3$ & $99.58 \%$ & $100.86 \%$ & $100.07 \%$ & $98.20 \%$ & $94.16 \%$ & $93.76 \%$ \\
\hline 23 & 2 & PEX & $0.5,3$ & $99.73 \%$ & $100.95 \%$ & $100.20 \%$ & $100.61 \%$ & $99.32 \%$ & $100.01 \%$ \\
\hline 24 & 2 & Both & $0.5,3$ & $99.67 \%$ & $100.85 \%$ & $100.26 \%$ & $100.61 \%$ & $99.42 \%$ & $99.72 \%$ \\
\hline 25 & 4 & Neither & 1,3 & $99.51 \%$ & $99.97 \%$ & $99.51 \%$ & $100.29 \%$ & $100.39 \%$ & $100.00 \%$ \\
\hline 26 & 4 & Tank & 1,3 & $99.57 \%$ & $99.96 \%$ & $99.67 \%$ & $99.60 \%$ & $99.70 \%$ & $99.50 \%$ \\
\hline 27 & 4 & PEX & 1,3 & $99.74 \%$ & $100.13 \%$ & $99.74 \%$ & $100.28 \%$ & $100.38 \%$ & $100.09 \%$ \\
\hline 28 & 4 & Both & 1,3 & $99.78 \%$ & $100.18 \%$ & $99.68 \%$ & $100.26 \%$ & $100.46 \%$ & $99.97 \%$ \\
\hline 29 & 4 & Neither & 1,4 & $99.70 \%$ & $99.99 \%$ & $99.60 \%$ & $100.17 \%$ & $100.37 \%$ & $100.08 \%$ \\
\hline 30 & 4 & Tank & 1,4 & $99.98 \%$ & $100.57 \%$ & $100.08 \%$ & $100.50 \%$ & $100.59 \%$ & $100.40 \%$ \\
\hline 31 & 4 & PEX & 1,4 & $99.69 \%$ & $100.09 \%$ & $99.69 \%$ & $100.24 \%$ & $100.43 \%$ & $100.05 \%$ \\
\hline 32 & 4 & Both & 1,4 & $99.32 \%$ & $100.11 \%$ & $99.71 \%$ & $100.20 \%$ & $100.40 \%$ & $100.11 \%$ \\
\hline 33 & 4 & Neither & $0.5,3$ & $99.63 \%$ & $100.13 \%$ & $99.53 \%$ & $99.92 \%$ & $99.32 \%$ & $99.52 \%$ \\
\hline 34 & 4 & Tank & $0.5,3$ & $98.92 \%$ & $99.22 \%$ & $98.82 \%$ & $100.70 \%$ & $100.21 \%$ & $100.21 \%$ \\
\hline 35 & 4 & PEX & $0.5,3$ & $99.51 \%$ & $100.11 \%$ & $99.61 \%$ & $100.37 \%$ & $100.37 \%$ & $100.07 \%$ \\
\hline 36 & 4 & Both & $0.5,3$ & $99.53 \%$ & $100.22 \%$ & $99.63 \%$ & $100.29 \%$ & $100.39 \%$ & $100.09 \%$ \\
\hline
\end{tabular}


APPENDIX C: Individual Meter Results for Continuous Flows 
Table 15. Accuracies of ultrasonic Manufacturer 1 meters in the continuous flow condition.

\begin{tabular}{ccccccc}
\hline $\begin{array}{c}\text { Flow } \\
\text { (gpm) }\end{array}$ & Meter 1 & Meter 2 & Meter 3 & Meter 4 & Meter 5 & Meter 6 \\
\hline 0.0625 & $99.74 \%$ & $100.72 \%$ & $99.44 \%$ & $100.13 \%$ & $100.23 \%$ & $100.03 \%$ \\
0.125 & $99.33 \%$ & $100.12 \%$ & $99.23 \%$ & $100.02 \%$ & $99.92 \%$ & $99.92 \%$ \\
0.25 & $99.72 \%$ & $100.42 \%$ & $99.62 \%$ & $100.52 \%$ & $100.02 \%$ & $100.02 \%$ \\
0.5 & $99.76 \%$ & $100.36 \%$ & $100.16 \%$ & $100.66 \%$ & $100.26 \%$ & $100.06 \%$ \\
2 & $100.12 \%$ & $100.91 \%$ & $99.03 \%$ & $100.52 \%$ & $100.12 \%$ & $100.52 \%$ \\
4 & $100.17 \%$ & $100.56 \%$ & $99.59 \%$ & $100.73 \%$ & $100.63 \%$ & $100.24 \%$ \\
6 & $100.35 \%$ & $100.22 \%$ & $99.80 \%$ & $100.81 \%$ & $100.37 \%$ & $100.54 \%$ \\
8 & $99.90 \%$ & $99.92 \%$ & $100.08 \%$ & $100.43 \%$ & $98.96 \%$ & $99.25 \%$ \\
15 & $100.83 \%$ & $100.47 \%$ & $100.58 \%$ & $101.18 \%$ & $99.94 \%$ & $100.59 \%$ \\
20 & $99.31 \%$ & $100.65 \%$ & $100.26 \%$ & $99.80 \%$ & $100.85 \%$ & $99.14 \%$
\end{tabular}

Table 16. Accuracies of ultrasonic Manufacturer 2 meters in the continuous flow condition.

\begin{tabular}{ccccccc}
\hline $\begin{array}{c}\text { Flow } \\
\text { (gpm) }\end{array}$ & Meter 1 & Meter 2 & Meter 3 & Meter 4 & Meter 5 & Meter 6 \\
\hline 0.0625 & $100.72 \%$ & $100.32 \%$ & $98.55 \%$ & $101.60 \%$ & $103.08 \%$ & $101.70 \%$ \\
0.125 & $100.10 \%$ & $99.61 \%$ & $99.91 \%$ & $100.10 \%$ & $101.88 \%$ & $101.49 \%$ \\
0.25 & $100.51 \%$ & $101.14 \%$ & $99.73 \%$ & $100.51 \%$ & $102.47 \%$ & $101.38 \%$ \\
0.5 & $100.30 \%$ & $100.60 \%$ & $100.11 \%$ & $100.60 \%$ & $101.39 \%$ & $101.98 \%$ \\
2 & $100.03 \%$ & $100.32 \%$ & $99.55 \%$ & $99.17 \%$ & $100.03 \%$ & $100.41 \%$ \\
4 & $100.08 \%$ & $100.37 \%$ & $99.68 \%$ & $99.74 \%$ & $99.74 \%$ & $99.94 \%$ \\
6 & $99.94 \%$ & $100.15 \%$ & $99.57 \%$ & $100.22 \%$ & $99.77 \%$ & $100.17 \%$ \\
8 & $99.80 \%$ & $100.09 \%$ & $99.31 \%$ & $99.72 \%$ & $99.72 \%$ & $100.29 \%$ \\
15 & $99.51 \%$ & $99.47 \%$ & $98.80 \%$ & $99.05 \%$ & $99.11 \%$ & $99.86 \%$ \\
20 & $99.61 \%$ & $99.84 \%$ & $98.97 \%$ & $99.40 \%$ & $99.07 \%$ & $99.48 \%$
\end{tabular}


Table 17. Accuracies of electromagnetic Manufacturer 1 meters in the continuous flow condition.

\begin{tabular}{ccccccc}
\hline $\begin{array}{c}\text { Flow } \\
\text { (gpm) }\end{array}$ & Meter 1 & Meter 2 & Meter 3 & Meter 4 & Meter 5 & Meter 6 \\
\hline 0.0625 & $99.16 \%$ & $99.75 \%$ & $100.05 \%$ & $99.46 \%$ & $100.44 \%$ & $99.85 \%$ \\
0.125 & $99.05 \%$ & $99.45 \%$ & $99.84 \%$ & $99.55 \%$ & $99.84 \%$ & $99.94 \%$ \\
0.25 & $100.03 \%$ & $99.64 \%$ & $99.93 \%$ & $100.22 \%$ & $100.61 \%$ & $100.22 \%$ \\
0.5 & $99.70 \%$ & $100.10 \%$ & $100.00 \%$ & $100.00 \%$ & $100.10 \%$ & $100.10 \%$ \\
2 & $99.80 \%$ & $99.50 \%$ & $99.90 \%$ & $99.70 \%$ & $99.90 \%$ & $99.70 \%$ \\
4 & $99.68 \%$ & $99.59 \%$ & $99.78 \%$ & $99.55 \%$ & $99.94 \%$ & $99.65 \%$ \\
6 & $99.76 \%$ & $99.56 \%$ & $99.91 \%$ & $99.84 \%$ & $100.05 \%$ & $99.76 \%$ \\
8 & $100.32 \%$ & $100.21 \%$ & $100.61 \%$ & $100.36 \%$ & $100.62 \%$ & $99.65 \%$ \\
15 & $99.48 \%$ & $99.37 \%$ & $99.80 \%$ & $99.47 \%$ & $99.75 \%$ & $99.57 \%$ \\
20 & $99.83 \%$ & $99.57 \%$ & $99.82 \%$ & $99.56 \%$ & $99.86 \%$ & $99.54 \%$
\end{tabular}


Table 18. Accuracies of nutating disc Manufacturer 1 meters in the continuous flow condition.

\begin{tabular}{ccccccc}
\hline $\begin{array}{c}\text { Flow } \\
\text { (gpm) }\end{array}$ & Meter 1 & Meter 2 & Meter 3 & Meter 4 & Meter 5 & Meter 6 \\
\hline 0.0625 & $89.30 \%$ & $88.61 \%$ & $89.20 \%$ & $90.77 \%$ & $93.73 \%$ & $93.63 \%$ \\
0.125 & $96.25 \%$ & $95.36 \%$ & $95.75 \%$ & $96.94 \%$ & $98.13 \%$ & $98.13 \%$ \\
0.25 & $99.34 \%$ & $98.71 \%$ & $99.02 \%$ & $99.57 \%$ & $100.20 \%$ & $100.04 \%$ \\
0.5 & $100.89 \%$ & $100.60 \%$ & $100.80 \%$ & $100.89 \%$ & $101.19 \%$ & $101.09 \%$ \\
2 & $100.03 \%$ & $100.22 \%$ & $100.13 \%$ & $100.13 \%$ & $100.51 \%$ & $100.41 \%$ \\
4 & $100.27 \%$ & $100.17 \%$ & $100.96 \%$ & $101.32 \%$ & $100.73 \%$ & $101.22 \%$ \\
6 & $100.98 \%$ & $100.77 \%$ & $100.67 \%$ & $101.10 \%$ & $100.09 \%$ & $101.03 \%$ \\
8 & $100.71 \%$ & $100.39 \%$ & $100.49 \%$ & $100.58 \%$ & $99.99 \%$ & $100.57 \%$ \\
15 & $99.51 \%$ & $99.49 \%$ & $99.66 \%$ & $99.62 \%$ & $99.65 \%$ & $99.53 \%$ \\
20 & $99.62 \%$ & $99.59 \%$ & $99.76 \%$ & $99.68 \%$ & $99.69 \%$ & $99.53 \%$
\end{tabular}

Table 19. Accuracies of nutating disc Manufacturer 2 meters in the continuous flow condition.

\begin{tabular}{ccccccc}
\hline $\begin{array}{c}\text { Flow } \\
\text { (gpm) }\end{array}$ & Meter 1 & Meter 2 & Meter 3 & Meter 4 & Meter 5 & Meter 6 \\
\hline 0.0625 & $96.28 \%$ & $95.89 \%$ & $96.09 \%$ & $95.11 \%$ & $95.30 \%$ & $94.13 \%$ \\
0.125 & $99.19 \%$ & $98.79 \%$ & $99.09 \%$ & $98.49 \%$ & $98.79 \%$ & $98.20 \%$ \\
0.25 & $100.41 \%$ & $99.93 \%$ & $100.03 \%$ & $99.84 \%$ & $100.22 \%$ & $99.74 \%$ \\
0.5 & $100.92 \%$ & $100.62 \%$ & $100.62 \%$ & $100.72 \%$ & $100.92 \%$ & $100.82 \%$ \\
2 & $100.60 \%$ & $100.41 \%$ & $100.51 \%$ & $100.41 \%$ & $100.31 \%$ & $100.80 \%$ \\
4 & $99.98 \%$ & $99.98 \%$ & $99.98 \%$ & $99.94 \%$ & $99.94 \%$ & $100.14 \%$ \\
6 & $99.88 \%$ & $99.89 \%$ & $99.95 \%$ & $99.92 \%$ & $99.95 \%$ & $100.09 \%$ \\
8 & $99.60 \%$ & $99.63 \%$ & $99.76 \%$ & $99.76 \%$ & $99.56 \%$ & $99.69 \%$ \\
15 & $99.48 \%$ & $99.50 \%$ & $99.56 \%$ & $99.49 \%$ & $99.45 \%$ & $99.47 \%$ \\
20 & $99.48 \%$ & $99.45 \%$ & $99.54 \%$ & $99.50 \%$ & $99.55 \%$ & $99.57 \%$
\end{tabular}


Table 20. Accuracies of oscillating piston Manufacturer 1 meters in the continuous flow condition.

\begin{tabular}{ccccccc}
\hline $\begin{array}{c}\text { Flow } \\
\text { (gpm) }\end{array}$ & Meter 1 & Meter 2 & Meter 3 & Meter 4 & Meter 5 & Meter 6 \\
\hline 0.0625 & $2.18 \%$ & $80.85 \%$ & $54.96 \%$ & $48.02 \%$ & $81.66 \%$ & $78.00 \%$ \\
0.125 & $92.94 \%$ & $95.21 \%$ & $94.62 \%$ & $96.10 \%$ & $95.46 \%$ & $94.86 \%$ \\
0.25 & $98.74 \%$ & $99.12 \%$ & $99.51 \%$ & $99.51 \%$ & $98.76 \%$ & $98.66 \%$ \\
0.5 & $100.22 \%$ & $99.72 \%$ & $100.71 \%$ & $100.52 \%$ & $100.20 \%$ & $99.90 \%$ \\
2 & $100.04 \%$ & $99.75 \%$ & $100.63 \%$ & $100.53 \%$ & $100.69 \%$ & $100.49 \%$ \\
4 & $99.88 \%$ & $100.17 \%$ & $100.66 \%$ & $100.43 \%$ & $99.94 \%$ & $100.33 \%$ \\
6 & $99.38 \%$ & $100.28 \%$ & $100.63 \%$ & $100.59 \%$ & $100.40 \%$ & $100.50 \%$ \\
8 & $99.45 \%$ & $100.30 \%$ & $100.50 \%$ & $100.35 \%$ & $101.10 \%$ & $101.18 \%$ \\
15 & $99.22 \%$ & $100.09 \%$ & $100.20 \%$ & $100.09 \%$ & $100.10 \%$ & $100.16 \%$ \\
20 & $99.66 \%$ & $100.58 \%$ & $100.69 \%$ & $100.58 \%$ & $100.06 \%$ & $100.11 \%$
\end{tabular}

Table 21. Accuracies of oscillating piston Manufacturer 2 meters in the continuous flow condition.

\begin{tabular}{ccccccc}
\hline $\begin{array}{c}\text { Flow } \\
\text { (gpm) }\end{array}$ & Meter 1 & Meter 2 & Meter 3 & Meter 4 & Meter 5 & Meter 6 \\
\hline 0.0625 & $50.40 \%$ & $56.45 \%$ & $84.03 \%$ & $83.83 \%$ & $68.75 \%$ & $28.27 \%$ \\
0.125 & $95.01 \%$ & $95.31 \%$ & $95.11 \%$ & $95.41 \%$ & $95.90 \%$ & $95.21 \%$ \\
0.25 & $99.03 \%$ & $99.51 \%$ & $98.93 \%$ & $99.22 \%$ & $99.41 \%$ & $99.31 \%$ \\
0.5 & $100.02 \%$ & $100.52 \%$ & $100.32 \%$ & $100.42 \%$ & $100.22 \%$ & $100.32 \%$ \\
2 & $99.85 \%$ & $99.95 \%$ & $99.75 \%$ & $99.95 \%$ & $100.04 \%$ & $99.75 \%$ \\
4 & $99.68 \%$ & $100.08 \%$ & $99.59 \%$ & $100.14 \%$ & $100.43 \%$ & $99.94 \%$ \\
6 & $100.10 \%$ & $100.10 \%$ & $99.92 \%$ & $100.32 \%$ & $100.60 \%$ & $100.22 \%$ \\
8 & $100.23 \%$ & $100.14 \%$ & $99.98 \%$ & $100.14 \%$ & $100.54 \%$ & $100.17 \%$ \\
15 & $100.11 \%$ & $99.93 \%$ & $99.85 \%$ & $99.94 \%$ & $100.25 \%$ & $99.75 \%$ \\
20 & $100.02 \%$ & $99.87 \%$ & $99.82 \%$ & $99.91 \%$ & $100.19 \%$ & $99.68 \%$
\end{tabular}

